Illinois State University

ISU ReD: Research and eData

Theses and Dissertations

$4-1-2021$

\title{
The Correlation Between Ankle Proprioception And Lower Extremity Muscle Reactions In Response To Simulated Lateral Ankle Sprains
}

Erin M. Carroll

Illinois State University, erinmcarroll21@gmail.com

Follow this and additional works at: https://ir.library.illinoisstate.edu/etd

Part of the Biomechanics Commons

\section{Recommended Citation}

Carroll, Erin M., "The Correlation Between Ankle Proprioception And Lower Extremity Muscle Reactions In Response To Simulated Lateral Ankle Sprains" (2021). Theses and Dissertations. 1358.

https://ir.library.illinoisstate.edu/etd/1358

This Thesis is brought to you for free and open access by ISU ReD: Research and eData. It has been accepted for inclusion in Theses and Dissertations by an authorized administrator of ISU ReD: Research and eData. For more information, please contact ISUReD@ilstu.edu. 
THE CORRELATION BETWEEN ANKLE PROPRIOCEPTION AND LOWER EXTREMITY

MUSCLE REACTIONS IN RESPONSE TO SIMULATED LATERAL ANKLE SPRAINS

\section{ERIN CARROLL}

\section{Pages}

Context: Lateral ankle sprains are one of the most commonly occurring sport-related injuries. The somatosensory system is primarily responsible for monitoring the position of the joints in space during movement. This system functions by way of neurological structures that provide proprioceptive and neuromuscular input to the brain. Motor control of the lower extremity relies on proprioceptive input to the central nervous system (CNS) and local neuromuscular control of each joint to produce coordinated, global muscular responses to external events. Previous research has investigated links between proprioception and neuromuscular control in relationship to ankle inversion separately, but none have searched for a link between proprioception and the body's neuromuscular response to ankle inversion.

Objective: The purpose of this study was to investigate a potential relationship between proprioception and lower extremity muscle reaction time in response to an inversion perturbation in healthy individuals. Design: This study was a descriptive, cross-sectional study to assess for a correlation between proprioception and muscle activation in healthy individuals Participants: Participants were healthy, college-aged volunteers recruited by word of mouth at a Midwest university. Inclusion criteria for this study required that the individual had not had lower extremity surgery one year prior to participation, had not been diagnosed with chronic ankle 
instability by a healthcare professional, and had not had an ankle injury that required medical attention 6 months prior to participation. Intervention: The active joint position sense (AJPS) and passive joint position sense (PJPS) of the subject was recorded and muscle reactions during unexpected inversion perturbations were observed with electromyography. Main Outcome Measure: Pearson's correlations were run between each muscle's average reaction time and both the active and passive joint position sense measures individually. Results: Statistically significant positive relationships were found between the peroneus longus (PL) reaction times and PJPS at $-30^{\circ}$ (exact error- $.49, \mathrm{p}=.03$ ) and AJPS at $5^{\circ}$ (absolute error- $.53, \mathrm{p}=.04$ ), and biceps femoris $(\mathrm{BF})$ reaction times and PJPS at $-30^{\circ}$ (exact error- $.75, \mathrm{p}=.001$, absolute error- .62 , $\mathrm{p}=.01$ ). Statistically significant negative relationships were found between the contralateral gluteus medius (CGMed) reaction times and PJPS at $5^{\circ}$ (exact error- $-.74, \mathrm{p}=.001$, absolute error- $-.78, \mathrm{p}=.01$ ) and gluteus maximus (GM) reaction times and AJPS at $5^{\circ}$ (exact error- -..63, p=.01, absolute error$-.54, \mathrm{p}=.04)$. Conclusions: Reaction time results for the PL were in line with past literature that has looked at the activation of the PL during other inversion tasks and muscle spindle activation. Results of the BF and GM were found to back up evidence found regarding kinematic changes within the affected limb, potentially pointing to an unloading response of the affected limb. The significant finding of the CGMed could potentially have significant meaning, but due to the very small percentage of times the muscle reacted the significant value found was most likely due to chance.

KEYWORDS: healthy, joint position sense, electromyography, reaction time, inversion perturbation, perturbation walkway 
THE CORRELATION BETWEEN ANKLE PROPRIOCEPTION AND LOWER EXTREMITY MUSCLE REACTIONS IN RESPONSE TO SIMULATED LATERAL ANKLE SPRAINS

ERIN CARROLL

A Thesis Submitted in Partial

Fulfillment of the Requirements

for the Degree of

MASTER OF SCIENCE

School of Kinesiology and Recreation

ILLINOIS STATE UNIVERSITY

2021 
Copyright 2021 Erin Carroll 
THE CORRELATION BETWEEN ANKLE PROPRIOCEPTION AND LOWER EXTREMITY MUSCLE REACTIONS IN RESPONSE TO SIMULATED LATERAL ANKLE SPRAINS

ERIN CARROLL

COMMITTEE MEMBERS:

Justin Stanek, Chair

Adam Jagodinsky 


\section{ACKNOWLEDGMENTS}

Who knew I would be involved in research throughout my two years as a graduate student at ISU, let alone write a thesis? I would first like to thank Dr. Stanek and Dr. J for their help, support, and guidance throughout this process. I would like to thank Dr. Nikki Hoffman for always being there to listen to my problems during random office stop-ins or hallway chats. Special thanks to the research teams I have had the pleasure of being a part of over my years on this project, especially Abby Salvadore for her continuous help and countless laughs in the biomechanics lab. Lastly, I would like to thank my mom and dad, the rest of my family back home, and my friends far and near for their continual love and support. I would not have made it this far without you all.

E.C. 


\section{CONTENTS}

Page

ACKNOWLEDGMENTS

TABLES

FIGURES

CHAPTER I: INTRODUCTION 1

CHAPTER II: REVIEW OF THE RELATED LITERATURE

$\begin{array}{ll}\text { Structural Anatomy } & 4\end{array}$

$\begin{array}{ll}\text { Functional Ankle Anatomy } & 13\end{array}$

$\begin{array}{ll}\text { Joint Stability } & 13\end{array}$

Assessing Ankle Proprioception and Neuromuscular Control 15

Local Ankle Muscle Activation During Gait $\quad 17$

Role of Lower Extremity Motor Control $\quad 19$

$\begin{array}{ll}\text { Conclusion } & 21\end{array}$

CHAPTER III: METHODS 22

$\begin{array}{ll}\text { Study Design } & 22\end{array}$

$\begin{array}{ll}\text { Participants } & 22\end{array}$

$\begin{array}{ll}\text { Instrumentation } & 22\end{array}$

$\begin{array}{ll}\text { Procedure } & 24\end{array}$

$\begin{array}{ll}\text { Biodex Dynamometer } & 24\end{array}$

$\begin{array}{ll}\text { EMG and MVIC } & 25\end{array}$

Inversion Perturbation Platform Walkway $\quad 27$

$\begin{array}{ll}\text { Data Processing } & 29\end{array}$ 
CHAPTER IV: RESULTS

CHAPTER V: DISCUSSION

Reaction Time

Joint Position Sense

Correlational Results

Limitations

Conclusions

REFERENCES

APPENDIX: VISUAL 3D PIPELINES 


\section{TABLES}

Table

Page

1. Total Number of V3D Indicated Muscle Reactions

2. Mean and SD of Reaction Times

3. Mean and SD of Chosen Angles Without Error

4. Correlation and P-Value of Exact JPS Error and Muscle Reaction Time

5. Correlation and P-Value of Absolute JPS Error and Muscle Reaction Time 


\section{FIGURES}

Figure $\quad$ Page

1. Biodex Multi-Joint System Setup and Dynamic Ankle Attachment 23

2. Inversion Perturbation Platform 24

3. Inversion Perturbation Platform Walkway Setup 24

4. EMG Setup- Frontal Plane 27

5. EMG Setup- Sagittal Plane 27

6. Optical Marker Calibration Setup- Frontal Plane 28

7. Optical Marker Calibration Setup- Sagittal Plane 28 


\section{CHAPTER I: INTRODUCTION}

Lateral, or inversion ankle sprains continue to be one of the most common sport-related injuries athletic trainers treat each year. ${ }^{1}$ About 28,000 ankle sprains are estimated to happen each year in the United States; ${ }^{1}$ about $84 \%$ of them involve ligament damage mostly affecting the lateral ankle ligaments specifically.,3 The effects of lateral ankle sprains are typically longstanding and may become chronic injuries; anywhere from 55-72\% of people who sustain sprains have residual symptoms for six to 18 weeks after the initial injury ${ }^{1}$ and are more prone to reoccurring sprains. This could be due to the ligament injury, hypermobility, decreased strength, and/or insufficient proprioception caused by the injury. ${ }^{1,4,5}$ The mechanism of injury of lateral ankle sprains typically consists of a combination of excessive inversion and internal rotation of the rearfoot, along with external rotation of the proximal limb. ${ }^{1}$ Because ankle sprains happen spontaneously and bodily responses to expected and unexpected injury mechanisms differ ${ }^{6}$, it is difficult for research to explain what puts some individuals at risk for ankle sprains over others and how the body reacts to the unexpected events.

Although lateral ankle sprains occur so often, the ankle joint is well equipped to protect it from injury; the anatomical arrangement of the distal tibia, fibula, and talus creates the ankle mortise and provides rigid stability to the medial and lateral ankle against excessive transverse and frontal plane rotation while weightbearing. ${ }^{1}$ In addition to this, neurological structures found within static structures, such as ligaments and joint capsule, and dynamic structures, such as muscles and tendons that cross the ankle joint ${ }^{7}$ exist to provide joint stability. These neurological tissues provide proprioception and neuromuscular control to the ankle. ${ }^{8}$

Proprioception and neuromuscular control are two aspects of the somatosensory system. ${ }^{8}$ Neuromuscular control cannot occur without proprioceptive information about the joint and its 
associated structures. ${ }^{8}$ Proprioception can be quantified by joint position sense, while neuromuscular control can be quantified by muscle activation and reaction to an event. ${ }^{8}$ Motor control integrates the local proprioceptive input and neuromuscular responses of the ankle joint into the overall response of the entire lower extremity that reacts to something such as an instantaneous change in ankle joint positioning.

The current literature has focused mainly on different aspects predisposing individuals to lateral ankle sprains or differences between healthy and unhealthy ankles in subjects in a lab. Some studies have attempted to pinpoint intrinsic risk factors, including potential deficiencies in proprioception or neuromuscular control, in retrospective studies. ${ }^{9-11}$ Other research has studied proprioception separately to look for potential differences in measurements such as joint position sense between uninjured and chronically sprained ankles. ${ }^{12}$ Neuromuscular control has been studied individually in controlled laboratory settings as muscle activity and reactivity to perturbed standing, walking, and landing in both uninjured and chronically injured ankles. ${ }^{13,14,14-}$ ${ }^{17}$ A gap in the literature exists between whether a relationship between ankle proprioception, local neuromuscular control of the ankle, and the response of the entire lower extremity in response to ankle perturbation. The existing evidence has provided inconsistent evidence regarding whether proprioception or neuromuscular control affects the body's more proximal lower extremity response. Due to a lack of evidence, a relationship between the two has not been explored.

The purpose of this study is to investigate the correlation between ankle proprioception and neuromuscular control of the entire lower extremity to determine if there is a relationship between JPS and muscular reactivity to unexpected ankle inversion. It is hypothesized that more 
positive relationships between reaction time and AJPS with unexpected ankle inversion perturbation will be found than positive relationships between PJPS and reaction times. 


\section{CHAPTER II: REVIEW OF THE RELATED LITERATURE}

\section{Structural Anatomy}

The ankle is a joint that withstands and distributes the forces created by the entire body. To do its job, the ankle joint must have static and dynamic stabilizers that work in unison to keep the joint functional and stable. The main bones that lay the foundation of the static stability of ankle joint are the tibia, fibula, talus, and calcaneus. The tibia and fibula together distribute the forces of the body throughout the rest of the $\operatorname{limb}^{18}$ and create the concave roof of the ankle mortise. The ankle mortise is a dome created by the distal tibia, fibula, and talus and provides a main component of static stability to the medial and lateral ankle due to the bony anatomy. When the ankle is fully weightbearing, the bony structure provides the primary mode of stabilization against excessive transverse and frontal plane rotation. ${ }^{1}$ Second to the bony structure, the ligaments of the ankle provide a large portion of the static stabilization of the joint. ${ }^{1}$ The interosseus membrane that runs from the lateral tibial shaft to the medial tibial shaft binds the tibia and fibula together ${ }^{18}$ and allows for little motion between the superior and distal tibiofibular articulations.

The tibia is the primary weightbearing done of the entire lower extremity. ${ }^{18}$ The distal portion is concave and produces the top of the ankle mortise ${ }^{18}$, while the medial malleolus creates a shallow medial side to the mortise. ${ }^{18}$ Along with bearing a great portion of the weight of the lower extremity, the tibia has important landmarks that provide attachment sites for many ligamentous and tendinous structures; the medial malleolus provides the attachment for the 4 branches of the deltoid ligaments. ${ }^{18}$ More proximally, the tibial tuberosity serves as the attachment sight for the patellar tendon. The pes anserine tuberosity is the insertion for three 
major hip muscles (the semitendinosis, gracilis, and sartorius) that cross and function at the knee by way of the tibia.

The fibula sits on the lateral portion of the lower leg and bares anywhere from $0-12 \%$ of the forces from the total body weight through the lower leg ${ }^{19}$ in comparison to the tibia. The lateral malleolus provides lateral boney stability to the ankle mortise. ${ }^{18}$ The fibula provides attachment sites for numerous muscles and ligaments and increases the forces created by muscle contraction by acting as a pully for muscles in the posterior compartment. ${ }^{18}$ The fibular head and shaft serve as an origination sites for muscles such as the peroneus longus, brevis, and tertious. The lateral malleolus is the origin of the anterior talofibular, calcaneofibular, and posterior talofibular ligaments that provide static stabilization to the lateral ankle.

The talus creates the floor of the ankle mortise. It is the bone that sits between the lower leg and the foot. ${ }^{18}$ The anterior portion of the talus is wider that the posterior portion, which limits the amount of dorsiflexion but increases the amount of plantarflexion of the tibiotalar joint. The slimmer posterior portion of the talus that allows for a greater amount of plantarflexion also creates some instability within the joint while the foot is in plantarflexion. As the ankle goes farther into plantarflexion, the slimmer portion of the talus moves more superiorly and creates more space within the ankle mortise. The greater amount of space creates more instability the farther the ankle moves into plantarflexion, which puts the ankle at greater risk of sustaining an injury. The talus also articulates with the calcaneus to create the subtalar joint. ${ }^{18}$ The calcaneus, or the heel, is the insertion of the lateral calcaneofibular and medial tibiocalcaneal ligaments of the ankle. The calcaneal tuberosity is the insertion of the Achilles tendon and creates a lever for the tendon to produce more powerful movement from contraction of the gastrocnemius, soleus, and plantaris. 
The navicular and cuboid are two bones found anterior to the talus. The navicular sits anteriomedially to the talus and serves as the insertion of the medial longitudinal arch of the foot, the tibialis posterior, and the calcaneonavicular ligament. ${ }^{18}$ The cuboid sits on the anteriolateral side of the foot. It is part of the lateral longitudinal arch and articulates with the proximal bases of the fourth and fifth metatarsals. ${ }^{18}$

The bones of the ankle described above lead into the arrangement of the joints that exist in the ankle. The rearfoot of the ankle is the articulation of the distal 1/3 of the tibia and fibula and calcaleus. ${ }^{7}$ In this portion, the talocrural, subtalar, and distal tibiofibular joints all work in union to create motion at the rearfoot. ${ }^{1}$ The motions produced at the joints are created in all three planes of motion; dorsiflexion and plantarflexion occur in the sagittal plane, inversion and eversion occur in the sagittal plane, and internal and external rotation occur in the transverse plane. ${ }^{1}$ This multiplanar axis of the rearfoot is also known as an oblique axis and can produce more than one motion simultaneously. ${ }^{1}$ For example, the mixed planar motions of the rearfoot can be described as pronation and supination. ${ }^{1}$

The talocrural (or tibiotalar joint) is a biarticular, synovial hinge joint. This joint is most associated with the bony ankle mortise. The shape of the mortise plays a role in how forces are transferred from the lower leg as internal and external rotation into the foot as supination and pronation. ${ }^{1}$ This joint primarily has one degree of freedom ${ }^{18}$ within the sagittal plane ${ }^{1}$ and mainly produces dorsiflexion and plantarflexion ${ }^{7}$; only small degrees of motion in the frontal and transverse planes happen at this joint. ${ }^{1}$ The entire joint is covered by a fibrous covering called the joint capsule that is thicker posteriorly and thins out over the anterior portion of the ankle. ${ }^{18}$ All of the ankle ligaments are created by thickened portions of the joint capsule except for the calcaneofibular ligament, which is found outside of the joint capsule, or extracapsularly. ${ }^{18}$ 
The subtalar (or talocalcaneal) joint is made up of the talus and calcaneus. ${ }^{18}$ It is a uniaxial, gliding synovial joint ${ }^{18}$ that transfers moments of force between the lower leg and the foot. It glides on an oblique axis that allows for most of the supination and pronation of the foot and ankle. ${ }^{7}$ The anterior portion of the subtalar joint creates a piece of the talocalcaneonavicular joint located on the medial side of the ankle. ${ }^{1}$ This subjoint is created by the head of the talus, anterior superior facets of the calcaneus, sustentaculum tali, and navicular. ${ }^{1}$ It is close to a balland-socket joint, where the talar head is the ball and the anterior calcaneus and proximal portion of the navicular create the socket. ${ }^{1}$ This joint, along with the rest of the subtalar joint, are supported statically by ligaments and dynamically by muscles to stop excessive supination and pronation of the foot and ankle. ${ }^{7}$ The structure and mobility of the subtalar joint plays a vital role in the occurrence of lateral ankle sprains.

When the talocrural and subtalar joint functions are combined, the three planes of motion can be achieved. ${ }^{18}$ The motion from both joints are typically combined to describe supination and pronation of the foot and ankle at the oblique axis. ${ }^{18}$ Pronation is a combination of dorsiflexion, abduction, and eversion, and supination is a combination of plantarflexion, adduction, and inversion. When the entire lower extremity kinetic chain is included, closed chain eversion on the ankle creates internal tibial rotation, knee flexion, and internal hip rotation. Closed chain ankle inversion causes external tibial rotation, knee extension, and external hip rotation. $^{18}$

The distal tibiofibular syndesmosis is the articulation between the concave tibial facet and convex facet on the fibula attached by a dense, fatty tissue. ${ }^{18}$ The ligaments of the syndesmosis are important providing stability to the ankle mortise because it stabilizes the positioning of the talus within the mortise. ${ }^{18}$ This syndesmosis must glide slightly forward in the anterior ankle for 
normal function of the entire ankle to occur. ${ }^{1}$ It also maintains the stability of the mortise by allowing inferior gliding of the fibula during weightbearing, which allows the syndesmosis to tighten while loaded. ${ }^{18}$

The talonavicular joint creates mobility in the arch of the foot. It rotates around all three axes of motion and allows for supination and pronation of the ankle to occur. ${ }^{20}$ It also contributes to a portion of plantarflexion and dorsiflexion created by the talocrural joint. ${ }^{21}$ The articulations of the navicular, medial cuneiform, and first metatarsal of the foot make up the "first ray" of the foot. ${ }^{7}$ These articulations create oblique axis rotation and allows for more supination and pronation to happen at the foot. ${ }^{7}$

As mentioned above, the ankle ligaments provide another component of static support to the ankle. There are three major ligaments in the lateral ankle: the anterior talofibular, calcaneofibular, and posterior talofibular ligaments. The anterior talofibular ligament (ATFL) is the most commonly injured ligament of the lateral ankle. ${ }^{1}$ Its origin is the anteriolateral surface of the lateral malleolus of the fibula, and its insertion is on the talus near the sinus tarsi. ${ }^{18}$ The ligament is tightest during plantarflexion, limits anterior movement of the talus on the calcaneus, and helps resist internal rotation and inversion of the talus within the mortise. ${ }^{18}$ It cannot withstand as much stress before injury to the collagen fibers occurs when compared to the other lateral ankle ligaments. Therefore, when the ankle is put into plantarflexion and inversion, this ankle is the first to withstand an injury.

The calcaneofibular ligament $(\mathrm{CFL})$ is an extracapsular ligament ${ }^{18}$ that originates on the outermost portion of the lateral malleolus of the fibula and the inserts into the calcaneus. It is the primary resistor of talocrural and subtalar inversion at the midpoint of talocrural range of motion. ${ }^{1,18}$ The CFL is tightest when the ankle is in dorsiflexion. ${ }^{1}$ The posterior talofibular 
ligament (PTFL). Its origin is the posterior portion of the lateral malleolus of the fibula, and its insertion inferior and posterior portions of the talus and calcaneus. ${ }^{18}$ It is the strongest of the lateral ligaments and limits posterior displacement of talus on the tibia. ${ }^{18}$ It also resists inversion and internal rotation of the talocrural joint when the ankle is loaded. ${ }^{1}$

The deltoid ligament is the primary medial ankle stabilizing ligament and has four separate branches that work as the main stabilizers of the talus. ${ }^{22}$ All four branches of the deltoid originate off different parts of the medial malleolus of the tibia. The first is the anteriotibiotalar (ATT) branch; it originates on the anteriomedial portion of the medial malleolus and inserts into the superior portion of the medial talus. ${ }^{18}$ The tibiocalcaneal (TC) portion originates from the top of the medial malleolus and inserts into the superior portion of the calcaneus. ${ }^{18}$ The posteriotibiotalar (PTT) branch originates posterior medial malleolus and inserts on the posterior talus. ${ }^{18}$ These three branches all help to resist eversion of the talus. ${ }^{18}$ The fourth branch of the deltoid, called the tibionavicular branch, is underneath and slightly posterior to the ATT. ${ }^{18}$ The origin is the medial malleolus and the insertion is the medial navicular surface. ${ }^{18}$ This ligament limits the lateral translation and rotation of the tibia on the foot. ${ }^{18}$ The ATT and TN become tightest with talocrural plantarflexion and the TC and PTT become tightest with dorsiflexion. ${ }^{18}$

The inferior anterior and inferior posterior tibiofibular ligaments, inferior transverse ligament, and the crural interosseus ligament all play a role in maintaining the tibiofibular syndesmosis. ${ }^{18}$ All of them combined play a secondary role in stabilizing the mortise by limiting the motion of the talus. ${ }^{18}$ The distal anterior and distal posterior tibiofibular ligaments are an extension of the interosseus membrane. ${ }^{18}$ The calcaneonavicular ligament, or spring ligament, originates on the calcaneus and inserts on the navicular and plays a role in holding up the medial 
longitudinal arch of the foot. It allows for the arch to contract and expand with the metatarsals to absorb and distribute the forces from the leg and ankle through the foot.

All the bones and ligaments of the ankle, including the joint capsule, provide static stabilization of the ankle, while the muscles provide dynamic stabilization. The stiffness of the muscles that act on and cross the ankle joint provide the stability and contribute to overall joint stiffness. The muscles that act on the ankle are divided into four compartments: the anterior, lateral, superficial posterior, and deep posterior compartments. The anterior compartment is comprised of the tibialis anterior, extensor digitorum longus, extensor hallucis longus, and peroneus tertious. The tibialis anterior is the primary dorsiflexor of the ankle and helps with supination. ${ }^{18}$ It can also produce subtalar inversion by adducting the calcaneus. ${ }^{23}$ Its origin is the lateral tibial condyle and superior half of the lateral tibial surface ${ }^{18}$; its insertion is the medial and plantar aspects of the first cuneiform and first metatarsal. ${ }^{18}$ The extensor digitorum longus assists the ankle in dorsiflexion and pronation due to its primary function of extending the toes. Its origin is the lateral tibial condyle, proximal three-fourths of the anterior fibula, and proximal interosseus membrane. ${ }^{18}$ The muscle runs between the medial and lateral malleoli, rests under the extensor retinaculum, and inserts into the distal phalanx of the second-fifth toes. ${ }^{18}$ The extensor hallucis longus has the same assisting actions at the ankle as the extensor digitorum longus, while its primary action is to extend the big toe. Its origin is the distal one-third of the fibula and portion of the interosseus membrane. ${ }^{18}$ and its insertion is the dorsal portion of the fifth metatarsal. ${ }^{18}$

The lateral compartment is composed of the peroneus longus and brevis. The peroneus longus originates on the fibular head, lateral tibial condyle, and superior two-thirds of the fibula. ${ }^{18}$ It inserts into the lateral and dorsal aspects of the lateral cuneiform and lateral portion of 
the first metatarsal. ${ }^{18}$ The peroneus brevis originates from the distal two-thirds of the fibula and inserts onto the styloid process of the base of the fifth metatarsal. ${ }^{18}$ Both the peroneus longus and brevis run posteriorly and inferiorly to the lateral malleolus and perform ankle eversion and plantarflexion.

The superficial posterior compartment is comprised of the gastrocnemius, plantaris, and soleus. All three muscles merge into the Achilles tendon insertion at the calcaneus and have similar actions at the ankle. The gastrocnemius has two different origination points due to it having two heads. The medial head attaches to the posterior aspect of the medial femoral condyle and the lateral head attaches to the posterior aspect of the lateral femoral condyle. The main action of the gastrocnemius is to plantarflex the ankle and assists with knee flexion. It also works to prevent excessive pronation of the subtalar joint. ${ }^{24}$ The soleus originates off of the soleal line on the posterior tibia and posterior fibular head ${ }^{18}$ and works to plantarflex the ankle. The gastrocnemius and soleus together create the triceps surae group. ${ }^{18}$ The plantaris originates off of the posteriolateral aspect of the femoral condyle ${ }^{18}$ and performs ankle plantarflexion and assists with knee flexion. The Achilles crosses slightly medial to the subtalar joint to create an inversion moment. $^{25}$

The deep posterior compartment consists of the tibialis posterior, flexor digitorum longus, and flexor hallucis longus. The tibialis posterior originates from the superior two-thirds of the fibula and interosseus membrane ${ }^{18}$ and inserts onto the navicular tuberosity. ${ }^{18}$ The tibialis posterior plantarflexes the ankle, inverts the subtalar joint, and adducts the forefoot. ${ }^{18}$ The flexor digitorum longus originates from the posteriomedial portion of the distal two-thirds of the tibia ${ }^{18}$ and inserts onto the plantar aspect of the distal phalanxes of the second-fifth metatarsals. This muscle runs through the tarsal tunnel posterior to the medial malleolus. Its main action is to flex 
the second-fifth toes and assists the ankle in plantarflexion and inversion. The flexor hallucis longus also runs through the tarsal tunnel with the flexor digitorum longus. It originates on the posterior distal $2 / 3$ of the fibula and interosseus membrane and inserts on the plantar surface of the proximal phalanx of the big toe. ${ }^{18}$ Its main action is to flex the big toe and assist with ankle plantarflexion and inversion.

Within each compartment of muscles, there is soft tissue that also contributes to the static and dynamic stability of the ankle. The anterior compartment has the extensor retinaculum, which is a zig-zagged band of soft tissue that lays over the anterior portion of the talocrural joint and covers the muscles and tendons that run on the dorsum of the foot. Its purpose is to prevent a bowstring effect of the tendons, or when the tendons "pop" out of their bony groove as they become taught during musclecontraction. ${ }^{18}$ The common peroneal nerve wraps around the fibular head, splits into the deep peroneal nerve more distally in the anterior compartment, and then parallels the interosseus membrane to run deep to the tibialis anterior. ${ }^{18}$ The deep peroneal nerve innovates the muscles of the anterior compartment. ${ }^{18}$ The anterior tibial artery supplies the anterior compartment with blood, runs from the interosseous membrane, and follows the deep peroneal nerve. ${ }^{18}$ It eventually branches off to create the dorsalis pedis artery and supplies the dorsum of the foot with blood. ${ }^{18}$

In the lateral compartment, the superior and inferior retinacula hold the peroneal tendons in the peroneal canal to prevent them from snapping over the lateral malleolus. The superficial peroneal nerve runs parallel with the peroneal muscles and innervates the peroneus longus and brevis. The posterior tibial artery branches off into the peroneal artery that runs lateral to the interosseus membrane and provides blood to the lateral ankle structures. ${ }^{18}$ The superficial posterior compartment houses the tibial nerve, which runs between the medial and lateral heads 
of the gastrocnemius and posteriorly to the medial malleolus. ${ }^{18}$ It innervates the muscles of the superficial and deep posterior compartments. The posterior tibial artery runs along with the tibial nerve and innervates the two posterior compartments.

\section{Functional Ankle Anatomy}

If all static and dynamic components of the ankle function correctly and in unison, the ankle does its job proficiently. It is mainly responsible for shock absorption and deceleration of the loading rate on the lower extremity to avoid injuring anatomical structures during locomotion. ${ }^{26}$ The tibia and fibula work as levers of motion ${ }^{7}$, allowing all of the muscles that originate from them and cross the ankle to contract and elongate. This creates the acceleration and deceleration forces that absorb the force from the motion of the body. The three factors that contribute to joint stability to allow this to happen in a normal ankle are: compatibility between articulating surfaces, stable static stabilizers, and musculotendinous complexes that provide dynamic and functional stabilization of the joints. ${ }^{1,8}$

\section{Joint Stability}

Stability within the ankle joint is provided by two components: the static and dynamic stabilizers. The static stabilizers only act against forces that act on them; they cannot create their own forces. Some structures that contribute to static stabilization are ligaments, joint capsule, cartilage, bony geometric structure, and skin. The dynamic stabilizers of the ankle create force to combat the intrinsic and extrinsic forces placed on the ankle joint. The structures mainly involved in dynamic stabilization are muscles and their associated tendons. The muscles and tendons act consciously and unconsciously to provide stability for the ankle during all types of functional activities that require joint stability and lower extremity balance. ${ }^{8}$ 
The ability of the muscles to dynamically stabilize the ankle comes from the work of the somatosensory system. The somatosensory system combines all incoming and outgoing sensory information and the central integration and processing structures that work simultaneously to maintain functional joint stability. ${ }^{8}$ The static and dynamic stabilizers primarily rely on different types of afferent nerve endings within the ankle structures to provide feedback and feedforward information $^{8}$ about the movement and positioning of the joint. Feedback and feedforward mechanisms receive information about the internal and external environment surrounding a joint to prepare for and respond to a rapidly changing environment. The local, muscular response of the ankle joint to a changing internal or external environment is part of the neuromuscular control division of the somatosensory system. Neuromuscular control is comprised of the unconscious activation of the local, dynamic constraints of the ankle through nerves such as muscle spindles and golgi tendon organs (GTOs) found within muscles and tendons. Because it relies mainly on feedback and feedforward, neuromuscular control prepares for and creates a local, muscular response to ankle joint motion and loading to maintain stability during expected and unexpected joint forces. ${ }^{8}$

Proprioception is the division of the sensorimotor system that provides conscious awareness and perception of joint stability using structures such as muscle spindles and GTOs in dynamic stabilizers and mechanoreceptors found in static ankle stabilizers. Proprioception works to maintain joint stability, postural control, and senses changes in resistance and force also through feedback and feedforward mechanisms. ${ }^{8}$ Because some of this input comes from static ankle stabilization structures, injury to them could contribute to decreased bodily awareness of the ankle. ${ }^{8}$ 


\section{Assessing Ankle Proprioception and Neuromuscular Control}

Stability of the ankle provided by the somatosensory system can be assessed in several ways; one popular measure has been by assessing active and passive joint position sense (JPS). ${ }^{9,27}$ Active JPS (AJPS) relies mainly on the muscle spindles of muscles and tendons that surround the ankle joint, while passive JPS (PJPS) is monitored mainly by mechanoreceptors found in static stabilizers, such as ligaments and joint capsule. ${ }^{12}$ These mechanoreceptors, specifically muscle spindles, respond reflexively to stretch during movement. Tissue stretch causes activation of the feedforward pathway and creates a muscular reaction; this pathway generally requires a stimulus (tissue stretch in this case), receptor potential, generator potential, and ultimately causes an action potential to be sent to create a bodily response to the stimulus. ${ }^{28}$ Therefore, the sensitivity of the muscle spindles may largely determine the ability of the brain to sense specific joint position and create a muscular response and react quickly enough to tissue stretch. $^{29}$

The degradation of the muscle spindles and mechanoreceptors impair the neuromuscular control and proprioception of the ankle; therefore, conscious and subconscious awareness of the ankle joint in space is decreased in individuals with CAI. To determine the role of the muscle spindles and mechanoreceptors in the ankle in AJPS and PJPS, studies have injected the static structures with anesthetic and evaluated the subjects' JPS. ${ }^{30-34}$ The results found by Konradson et al. show that AJPS is not affected by inactive mechanoreceptors in the dynamic structures ${ }^{30}$, but PJPS was decreased when compared to values taken without the injected anesthetic. ${ }^{31}$

A study conducted by De Carlo and Talbot injected subjects' ATFLs with lidocaine before and after balancing exercises on a multiaxial balance disc to measure proprioception of the subjects. ${ }^{33}$ They found that the injections did not have significant effects on the subject's 
balancing performance before and after. ${ }^{33}$ Another study using injected lidocaine into the ATFL was performed by Hertel et al. ${ }^{34}$ This study used PJPS before and after injection as a measure of proprioception in the subjects and found no significant differences in subjects' performance between the two conditions. ${ }^{34}$ This could be attributed to the dynamic stabilizers providing ankle stabilization in both weightbearing and non-weightbearing positions while the ATFL was numbed. This shows that neuromuscular control and proprioception work together to provide overall joint awareness throughout activity. In a healthy, functionally stable ankle, neuromuscular control and proprioception are integrated by the somatosensory system to provide most of the ankle's functional stability.

Both AJPS and PJPS are usually used as a comparative factor between variables or subject conditions. Several articles have used PJPS, AJPS, or both as intrinsic factors that can predict the occurrence of lateral ankle sprains. ${ }^{9,11,27,35,36}$ Willems et al. used both PJPS and AJPS in attempt to distinguish intrinsic risk factors predisposing males ${ }^{9}$ and females ${ }^{27}$ separately to lateral ankle sprains. JPS has also been used in attempt to examine subjects with and without CAI or functional instabilities to see if there is a difference between the proprioceptive abilities of CAI or functional instability subjects versus the contralateral ankle ${ }^{17,30}$ or a control group. ${ }^{4,30,37,38}$ Some studies used JPS as another variable to compare to other qualities such as muscle strength or joint laxity. ${ }^{4,53}$ As shown here, most JPS research has been used as a predictors or potential explanations for why or how lateral ankle sprain continuously happen in individuals.

Although differences exist between the structures that AJPS and PJPS test, both measures assess the combined effort of the proprioceptive and neuromuscular control structures of the ankle during assessment. A systematic review including JPS usage found that AJPS and PJPS 
measured by a Biodex Stability System were valid and reliable in assessing the somatosensation of the joint being evaluated. ${ }^{40}$

\section{Local Ankle Muscle Activation During Gait}

Because many factors that put individuals at risk for lateral ankle sprain exist, normal mechanics and muscle activation during gait is crucial. The muscles of the lower leg are extremely important in the gait cycle because they maintain forward motion while providing vertical support to the distal lower extremity. ${ }^{41}$ However, it hard to determine exactly which muscles cause acceleration and deceleration of joints because muscles may act on joints and segments they do not $\operatorname{cross}^{42}$ (such as the knee).

The plantarflexors are mainly responsible for stability throughout stance phase and the forward propulsion of toe-off in late stance phase. ${ }^{43,44}$ The gastrocnemius has the main job (with help from the soleus) of decelerating forward motion during early stance phase. ${ }^{45}$ It creates ankle plantarflexion and knee flexion to provide some ankle support during stance phase by continuing to resist the opposing ground reaction forces (GRF) and keep the leg erect. ${ }^{23}$ The soleus plantarflexes the ankle from heel-strike to the beginning of stance phase to begin to prepare the ankle to resist the GRF the leg experiences during full, single legged stance phase. ${ }^{23}$ It can also evert the subtalar joint at heel-strike to help the plantarflexors accelerate the body's center of mass forward. ${ }^{23}$ Between the gastrocnemius and soleus, the soleus has a longer deceleration period on the center of mass. ${ }^{23}$ The tibialis anterior creates most of the dorsiflexion force throughout stance phase ${ }^{23}$ to oppose the plantarflexors. It also has a large ability to invert the subtalar joint from heel-strike to the beginning of stance phase and propel the center of mass from stance phase into toe-off. ${ }^{23}$ 
The addition of unexpected inversion perturbation during gait has been shown to alter these muscle activation patterns of the ankle seen during functional activities such as gait and drop jump landings. Hopkins et al. used an inversion perturbation walkway to observe the muscular activation of the ankle during unexpected inversion. ${ }^{15}$ Surface EMG (SEMG) was used on the tibialis anterior $(\mathrm{TA})$, peroneus longus $(\mathrm{PL})$, and peroneus brevis $(\mathrm{PB})$ of the dominant leg to capture average and peak EMG activity, as well as reaction time of each muscle in response to the inversion drop. ${ }^{15}$ They found the time to maximal inversion while walking was approximately $114.9 \mathrm{~ms}$, and the PL reaction time to the inversion was approximately $56.9 \mathrm{~ms} .{ }^{15}$ The reaction time of the TA was found to be slightly slower at approximately $65 \mathrm{~ms}$, behind the PB reaction time of approximately $60.1 \mathrm{~ms}$ post-drop. ${ }^{15}$

In a study performed by Simpson et al., an inversion platform was used to compare TA and PL activation during drop jump landings with expected and unexpected inversion perturbation ${ }^{46}$ Their data showed that the PL reaction time (the point at which EMG muscle activity increased 5 standard deviations above the mean muscle activation pre-landing) of the healthy, control group for the unexpected inversion drop landing took about $46.36 \mathrm{~ms}$ versus the $37.87 \mathrm{~ms}$ reaction time for the expected inversion landings ${ }^{46}$ Another study focused on an unexpected, 10mm downward drop during gait performed by Nakazawa et al. recorded the reaction time of the coactivation of the soleus and TA. ${ }^{47}$ They found that the soleus reacted about $41.67 \mathrm{~ms}$ post-drop, and the TA reacted about $50.7 \mathrm{~ms}$ post-drop..$^{47}$ It was also observed that the lateral and medial heads of the gastrocnemius reacted about $41 \mathrm{~ms}$ post-drop. ${ }^{47}$ Although these studies ${ }^{46,47}$ do not look specifically at inversion perturbation while walking, they show how the main ankle dynamic stabilizers react to unexpected ankle perturbation in comparison to their activations during normal gait. 


\section{Role of Lower Extremity Motor Control}

Motor control is the term used to encompass all the mechanisms the CNS uses to produce purposeful and coordinated movements throughout the body in response to the environment to complete a task. ${ }^{48}$ It is crucial for accurate sensory information regarding the internal and external environment surrounding the body to be relayed to the CNS to create effective motor control. ${ }^{49-52}$ Several theories exist concerning how motor control functions throughout the body to coordinates such movement. One focuses specifically on how electrochemical signals from the brain react when proprioceptive feedback occurs and how motor neurons create changes in threshold muscle lengths or joint angles. ${ }^{48}$ This shows that proprioception at the local joint level is imperative for global muscular response to occur as changes happen. The local joint response is created by the neuromuscular control of the muscles surrounding a joint to provide dynamic joint stability ${ }^{53}$ and responds to changes in joint positioning with the information provided by proprioceptors. Therefore, functional joint stability arises not just from a local, joint response, but a full-body response coordinated by motor control. ${ }^{8}$

Motor control plays a role in predictable, everyday tasks as well as unexpected events such as lateral ankle sprains. Research has shown that during the latter part of swing phase in normal gait, the ankle is brought through at approximately $10^{\circ}$ of inversion. ${ }^{54}$ Indirect evidence has shown that if the amount of inversion is sensed to be too much by dynamic and static ankle structures, the local, lateral ankle musculature will activate to correct the positioning. ${ }^{55}$ The muscle most active when this occurs is the peroneus longus ${ }^{55}$, one of the primary ankle muscles that contributes to eversion. Because the local muscular reaction is enough during normal gait, no proximal bodily response is necessary to continue through subsequent gait cycles. 
When external forces act on the ankle joint and threaten joint stability, the entire body reacts in a consistent way ${ }^{54}$ locally at the ankle and globally throughout the entire lower extremity to respond.$^{56}$ Local responses have mainly been studied in lateral ankle sprains through the peroneal muscles. In research conducted by Konradson et al. and Nishikawa and Grabiner, muscular reflex reactions recorded by EMG were observed first in the peroneal muscles in response to inversion torque. ${ }^{56,57}$ In Konradson's research, median peroneal reflex activation occurred approximately $54 \mathrm{~ms}$ post-inversion perturbation during gait. ${ }^{56}$ This finding added support to previous findings stating that the peroneal reflex alone does not act fast enough to prevent the ankle joint from falling into inversion unexpectedly. ${ }^{17,56,58,59}$ Therefore, a local neuromuscular response is not enough to prevent or avoid ankle injury during sudden events.

In addition to the peroneal response, motor control of the entire lower extremity has been studied during inversion perturbations. Goniometric changes in the positioning of the knee and hip of the affected ankle were observed with inversion perturbation in Konradson et al.'s study. ${ }^{56}$ The median values of the proximal responses were $\sim 30^{\circ}$ of knee flexion and $\sim 25^{\circ}$ of hip flexion at a median time of $202 \mathrm{~ms}$ post-inversion perturbation. ${ }^{56} \mathrm{EMG}$ reaction time data of the rectus femoris or biceps femoris was not reported in these results due to their constant activation during the gait cycle ${ }^{56}$ Other research collected by Simpson et al. focused on kinematic changes of the ankle, knee, and hip during expected and unexpected inversion single-leg landings with respect to time. ${ }^{6}$ They found that knee flexion angle increased the most between $127-150 \mathrm{~ms}$ after unexpected, initial contact on the inversion board. ${ }^{6}$ They also observed significantly less hip flexion $67 \mathrm{~ms}$ pre-initial contact to $84 \mathrm{~ms}$ post-initial contact on the inversion board in the unexpected landing group. ${ }^{6}$ This shows that the positioning of the proximal lower extremity adjusts with sudden changes of the ankle. 
EMG data of the ipsilateral thigh and hip muscles collected by Stanek et al. showed statistically higher average and peak EMG activity of the rectus femoris, gluteus maximus and gluteus medius during perturbed gait as compared to normal gait. ${ }^{13}$ Another study done by Santos et al. found that in subjects activated the vastus medialis and biceps femoris and inhibited the tibialis anterior and soleus to unload the leg of the ankle that was subjected to inversion perturbation. ${ }^{60}$ These studies show that a global reaction of the lower extremity in response to the local proprioceptive input and neuromuscular control of the ankle structures could be at play in the response to unexpected ankle inversion perturbation.

\section{Conclusion}

This review of the literature discussed the structural components of the ankle joint, how the ankle is stabilized statically and dynamically, and how joint stability is maintained through proprioception and neuromuscular control, as well as the role of lower extremity motor control. During a lateral ankle sprain, unconscious muscle activation due to local joint neuromuscular control and proprioceptive occurs reflexively. Due to the local response being found to not occur quickly enough, it is also seen that motor control of the lower extremity also plays a role in avoiding injury and unloading the affected limb. An understanding of this literature will help in understanding whether the accuracy of AJPS and PJPS is related to the muscular response of the lower extremity in response to inversion perturbation in healthy individuals. 


\section{CHAPTER III: METHODS}

\section{Study Design}

This study was conducted as a descriptive, cross-sectional study to assess the correlation between the reactions of lower extremity muscles during simulated inversion ankle sprains and AJPS and PJPS measures in healthy individuals. Only the dominant ankle of each subject was dropped on the inversion platform. The variables in this study were the AJPS and PJPS measurements taken on the subject's dominant ankle and the reaction time of the lower extremity muscles being assessed during the inversion perturbation.

\section{Participants}

Based on a power analysis calculation with an alpha level set at .05 and power set to .8 , a sample size of at least 20 participants was recommended for this study. Participants were recruited by word of mouth. A total of 21 subjects ( 9 male, 12 female) completed the study. The age range of the participants ranged from $20-47$ years old (mean age 23 y/o \pm 6 , height $1.72 \mathrm{~m} \pm$ .095 , weight $72.81 \mathrm{~kg} \pm 15$ ). Inclusion criteria included that the subject was not diagnosed with chronic ankle instability (CAI) by a healthcare professional, had no lower extremity surgery within 1 year of participation, and had not had an ankle injury within the last 6 months of participation that required medical attention by a healthcare professional. A subject who answered "yes" to any of the 3 criteria stated above on the inclusion criteria survey was excluded. All subjects completed written, informed consent paperwork before participating in the study to follow the university's Institutional Review Board requirements.

\section{Instrumentation}

A Biodex Multi-Joint system (Biodex Medical Systems, NY) with the dynamic inversion/eversion ankle attachment was used to assess the subject's AJPS and PJPS. Wireless 
electromyography (EMG) equipment (BioNomadix series by BIOPAC Systems INC, MP150), and disposable gel-pad electrodes were used to collect electrical muscle activity during maximal voluntary isometric contraction (MVIC) testing and inversion perturbation platform walkway performance. Passive, optical reflective markers placed on the subject according to Vicon's lower extremity model were tracked using 6 infrared Vicon motion capture cameras and Vicon 2.10 software. Figure 1 depicts the Biodex Multi-Joint system used with the ankle attachment.

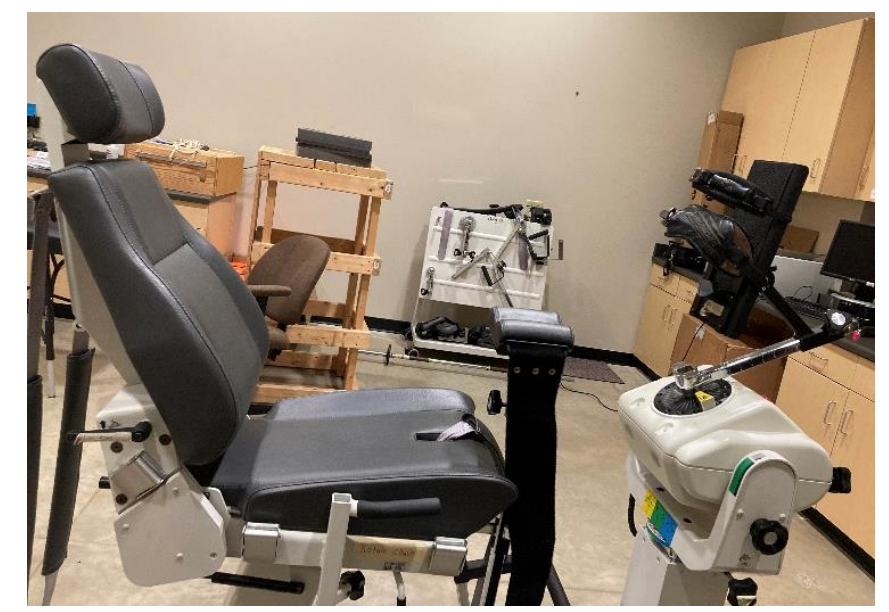

Figure 1: Biodex Mulit-Joint System Setup and Dynamic Ankle Attachment

The custom made inversion perturbation platform walkway used is $6.1 \mathrm{~m}$ long and $.76 \mathrm{~m}$ wide ${ }^{13}$ with railings along the entire length of and on both ends of the walkway. It is divided into 6 separate segments, with one that has a platform that can drop into $30^{\circ}$ of inversion on both the right and left sides with more than $.45 \mathrm{~kg}$ of force when unlocked. ${ }^{13}$ The platform is unlocked and locked manually by a lever located by the first segment ${ }^{13}$; when unlocked, the vertical support of the platform is removed and it sits on spring-ball plungers for minimal support until enough force is applied. ${ }^{13}$ The platform drop is detected by an electromagnetic switch that 
outputs a signal that marks the platform release with the EMG data for analysis. ${ }^{13}$ Pictures of inversion perturbation platform and compete walkway setup are below (Figures 2 and 3).

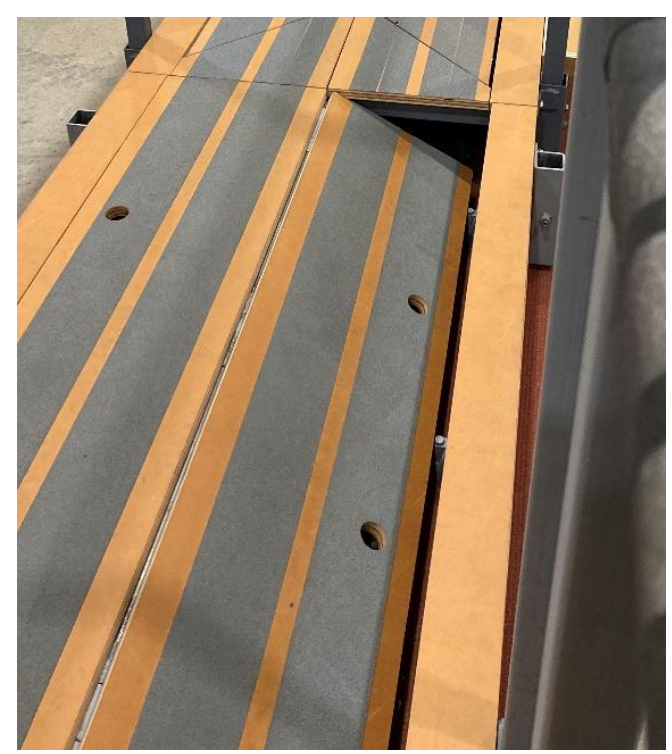

Figure 2: Inversion Perturbation Platform

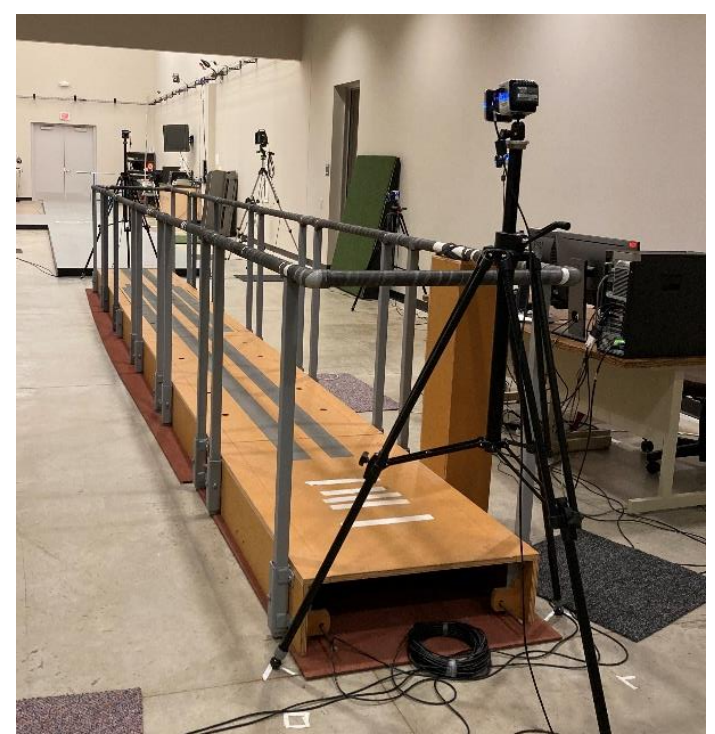

Figure 3: Inversion Perturbation Platform Walkway Setup

\section{Procedure}

\section{Biodex Dynamometer}

The dynamic ankle attachment was used to collect the AJPS and PJPS of all the subjects.

The subject sat upright with the same hip and knee of the dominant ankle flexed to approximately $90^{\circ}$ and the lower leg fully supported on the leg rest. The seat and lower leg rest placement are adjustable based on the height of the subject. The dorsum of foot of the subject's dominant ankle rested flat on the footplate of the ankle attachment with the heel fully supported on the ledge. The foot was secured to the footplate with straps across the distal portion of the metatarsals and tarsals.

The parameters used to measure AJPS and PJPS were set at target angles of $5^{\circ}$ of eversion and $15^{\circ}$ and $30^{\circ}$ of inversion $\left(-15^{\circ}\right.$ and $\left.-30^{\circ}\right)$ with a regulated speed of $5^{\circ} / \mathrm{sec}$. The 
researcher first entered the subject's basic information into the Biodex software and set the range of motion (ROM) limits of the subject by instructing the subject to perform maximal ankle inversion and eversion while fixed to the footplate. Once the ROM limits were set, the subject was given an emergency "comfort" stop button and a ROM stop button. The subject could press the "comfort" stop button if he/she became uncomfortable with the test or decided that he/she wanted to discontinue the test. The ROM stop button was used when the subject felt as though he/she had reached the target angle during the AJPS or PJPS test. The subject was blindfolded during both the AJPS and PJPS protocols.

The Biodex AJPS and PJPS protocols were identical, with the exception that the Biodex performed the movement throughout the subject's ROM for PJPS versus the subject moving his/her own ankle to recreate the target angle for AJPS. With the subject blindfolded, the subject was moved to the target angle by the researcher and held the position for 10 seconds. Once the time was completed, the subject was moved to neutral and the Biodex was released. For PJPS, the ankle attachment moved through the subject's entire set ROM while the subject tried to feel for the target angle. For AJPS, the Biodex was released and the subject was free to move the ankle into the target angle. Once the angle was felt, the subject would press the ROM stop button. The Biodex would record the subject's stopped position and perform the protocol for that angle 2 more times. Each of the 3 target angles was completed 3 times for AJPS and PJPS. Due to difference in collection times, PJPS was measured in 20 subjects, while AJPS was measured in 15 subjects.

\section{EMG and MVIC}

SEMG data was collected from 8 selected muscles of interest on both limbs. The subject's dominant leg was determined as the leg that the subject would use to kick a ball. The 
skin was prepared to minimize EMG signal noise. The areas where SEMG and ground electrodes were attached were shaved, abrased with sandpaper, and wiped with alcohol. 2 SEMG gel electrodes were placed with the gel centers approximately $2 \mathrm{~cm}$ apart in line with the muscle fibers of the target muscle. For every 2 muscles, 1 ground electrode was placed over a boney prominence.

The 8 muscles that were selected for EMG analysis were the tibialis anterior (TA), peroneus longus $(\mathrm{PL})$, soleus $(\mathrm{SOL})$, rectus femoris $(\mathrm{RF})$, biceps femoris $(\mathrm{BF})$, and gluteus maximus (GM) of the dominant leg and the gluteus medius (CGMed and IGMed) bilaterally. Due to different collection times, the RF, BF, and GM were collected in 15 subjects while the rest were collected in 20. Electrode placement was based on the specifications stated in Rainoldi et al. ${ }^{61}$ Once the SEMG electrodes were placed, maximal voluntary isometric contractions (MVIC) were recorded using manual muscle tests (MMT) to target each muscle marked individually. MMT positioning of the subjects and researcher was done according to Kendall et al. ${ }^{62}$ Figures 4 and 5 show the EMG and wireless EMG transmission equipment placement for all walking trials. 


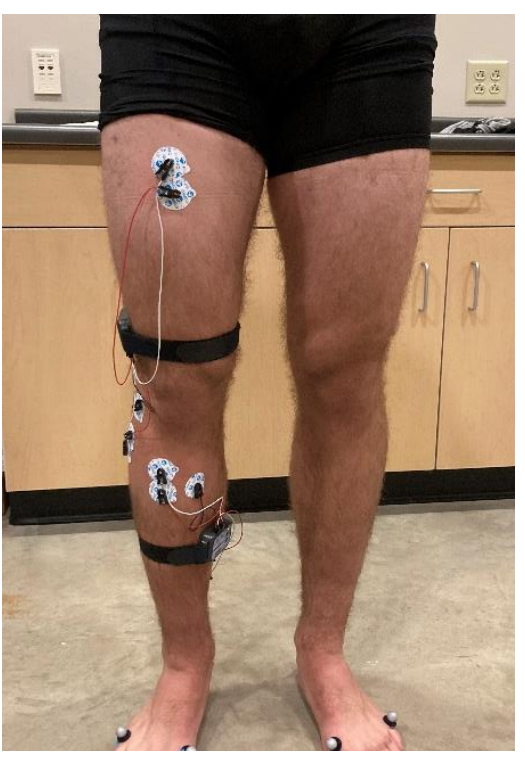

Figure 4: EMG Setup- Frontal Plane

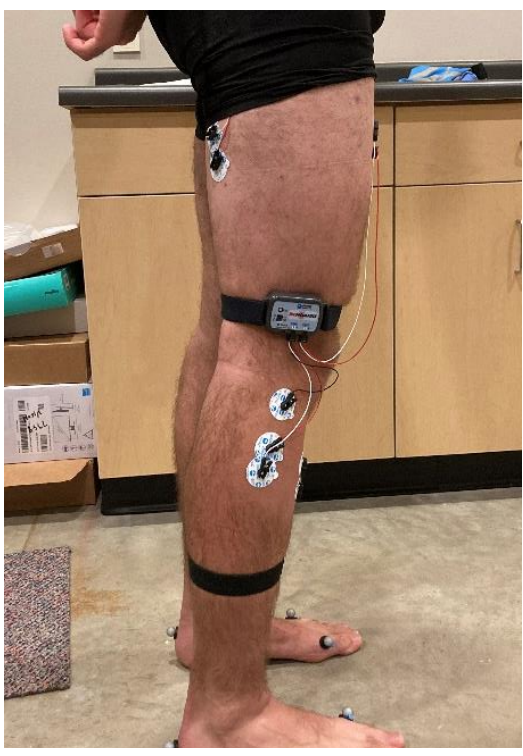

Figure 5: EMG Setup- Sagittal Plane

\section{Inversion Perturbation Platform Walkway}

Before beginning the walkway protocol, the subject's landmarks were marked with 33 passive, optical reflective markers on the lower extremity and pelvis according to the lower extremity model (Figures 6 and 7). After all the markers were attached, the subject was given blinder goggles to wear during every trial on the walkway to prevent him/her from looking at the walkway while performing each trial. A metronome set at $90 \mathrm{bpm}$ was played aloud for the subject to match his/her gait speed to during each trial to standardize the gait speed of every 


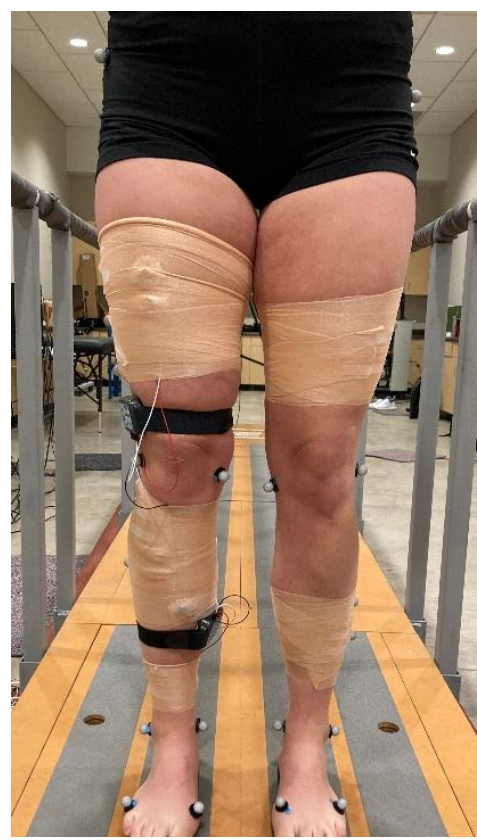

Figure 6: Optical Marker Calibration Setup- Frontal Plane

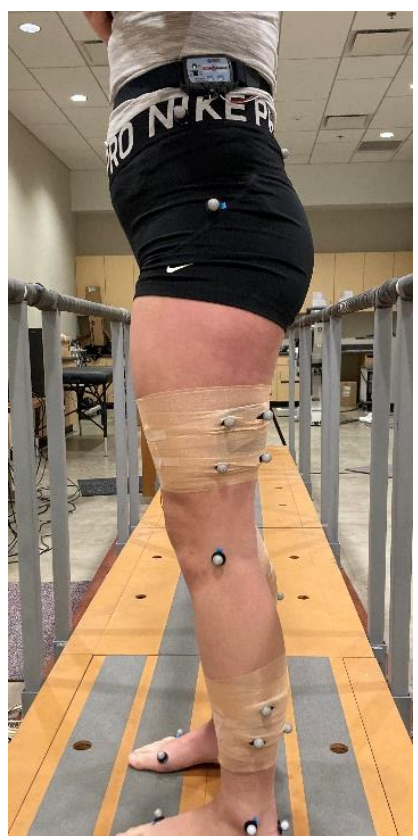

Figure 7 Optical Marker Calibration Setup- Sagittal Plane

subject. The subject's stride length was watched to determine the starting spot at the end of the walkway to ensure the inversion platform was hit with the dominant foot every time.

There was a total of 63 trials completed for each subject. For every "test" trial, 6 wash out trials followed. There were 3 non-drop trials, 3 inversion drop trials, and 3 inversion plantarflexion drop trials (done for other research purposes). The 6 wash out trials after each drop trial were done to normalize the subject's gait length, speed, and lessen apprehension while walking before the next drop trial occurred. The order of the 9 drop trials was randomized for each subject using randomizer.org to eliminate bias from the researchers choosing the order. The subject was not told when a drop trial would happen to ensure each trial created a spontaneous muscular response. 


\section{Data Processing}

Each subject's AJPS and PJPS was collected and analyzed according to absolute and exact error. Absolute error was defined as the absolute value of the difference in degrees between the target angle and the angle chosen by the participant during each trial. ${ }^{27}$ The exact error was defined as the difference between the target angle and the angle chosen by the participant. ${ }^{27}$ Using exact error will show whether the participant on average would chose an angle over or under the target angle. ${ }^{27}$ The JPS data was entered into Microsoft Excel and the absolute and exact errors were calculated by input equations.

EMG and drop platform signal data was exported to Visual 3D (V3D) software for processing. Pipelines were created in V3D to filter and analyze EMG data. First, the data was loaded, tagged, and filtered through a lowpass, Butterworth filter with a cutoff of $6 \mathrm{~Hz}$ and rectified using a root means squared set to 25 frames. Event were created for right and left heel strike and toe off for every gait cycle based on kinematic variables with respect to the pelvis. The heel strike of the step that the subject took onto the inversion drop platform as it dropped was tagged as the inversion drop event. The MVIC data was also processed in this pipeline but was not used in the analysis for this study. Then to calculate reaction time, the mean EMG activation 150ms pre-inversion drop was calculated and used in comparison to the EMG activity recorded 200ms post-drop. The reaction time was defined as when the EMG signal 200ms post-drop exceeded 2 standard deviation (SD) above the mean muscle activation 150ms prior to the drop. Event tags were created showing the initial activation point of each muscle that met reaction time criteria, and reaction time was calculated between the initial activation tag and the inversion drop event tag. The reaction times for each muscle that reacted within the 200ms post-drop window were calculated by V3D and manually inputted into Microsoft Excel for all the inversion drops 
of every subject. The average reaction time for each muscle that reacted for every subject was calculated, creating an average reaction time variable for all the muscles that reacted for each subject.

Once JPS errors and reaction times were calculated, all data was input into IBM SPSS for statistical analysis. Pearson's correlations between the mean reaction times of each lower extremity muscle for every subject were run between both AJPS and PJPS. Positive and negative relationships were identified and analyzed for each muscle and JPS condition. 


\section{CHAPTER IV: RESULTS}

Following data processing, one subject was eliminated due to biomechanical error, leaving a total sample of 20 participants. The reaction times of each muscle for every drop for all subjects were pooled into Microsoft Excel. Table 1 shows how many times each muscle reached the 2 SD threshold within the $200 \mathrm{~ms}$ post-drop window signaled by the Visual 3D pipeline. Every subject could have a maximum of three reactions (one per drop) and minimum of no reactions for each muscle within the post-drop window.

\begin{tabular}{|l|l|l|}
\hline Muscle & Total \# Reactions & \% Total Reactions \\
\hline TA & 56 & $93.3 \%$ \\
\hline PL & 56 & $93.3 \%$ \\
\hline SOL & 58 & $96.7 \%$ \\
\hline RF $^{*}$ & 40 & $88.9 \%$ \\
\hline BF $^{*}$ & 37 & $82.2 \%$ \\
\hline GM* & 35 & $77.8 \%$ \\
\hline CGMed & 16 & $26.7 \%$ \\
\hline IGMed & 43 & $71.7 \%$ \\
\hline
\end{tabular}

Table 1: Total Number of V3D Indicated Muscle Reactions

*indicates muscles that had different number of possible reaction times

All muscle reaction times and JPS means for each subject in Microsoft Excel were exported into IBM SPSS 26 for statistical analysis. Tables 2 and 3 show the means and SD of the reaction times of each muscle and scores of the JPS conditions.

\begin{tabular}{|l|l|l|}
\hline Muscle & Mean Rxn Time $(\mathbf{m s})$ & SD $( \pm, \mathbf{m s})$ \\
\hline TA & 58.5 & 24.9 \\
\hline PL & 72.3 & 38.2 \\
\hline SOL & 54.9 & 24.4 \\
\hline RF$^{*}$ & 58.8 & 31.6 \\
\hline BF $^{*}$ & 58.0 & 37.7 \\
\hline GM $^{*}$ & 44.6 & 32.1 \\
\hline CGMed & 149.3 & 57.9 \\
\hline IGMed & 55.1 & 20.2 \\
\hline
\end{tabular}

Table 2: Mean and SD of Reaction Times

*indicates muscles that had different number of subjects 


\begin{tabular}{|l|l|l|}
\hline Tested JPS Angle & \multicolumn{1}{|c|}{ Mean $\left(^{\circ}\right)$} & \multicolumn{1}{|c|}{ SD $\left( \pm,{ }^{\circ}\right)$} \\
\hline PJPS, $-15^{\circ}$ & -14.23 & 13.65 \\
\hline PJPS, $-30^{\circ}$ & -28.83 & 8.48 \\
\hline PJPS, $5^{\circ}$ & 7.33 & 2.41 \\
\hline AJPS $*-15^{\circ}$ & -19.37 & 6.24 \\
\hline AJPS*, $-30^{\circ}$ & -31.41 & 4.00 \\
\hline AJPS $* 5^{\circ}$ & 6.41 & 3.25 \\
\hline
\end{tabular}

Table 3: Mean and SD of Chosen Angles Without Error

*indicates conditions that had different number of subjects

Bivariate Pearson's correlations were run between the mean reaction times for the eight muscles and the mean scores of the exact and absolute error values of the AJPS and PJPS of each subject in IBM SPSS 26. A total of 96 correlations were run between the variables. Tables 4 and 5 show the correlational variables calculated for all muscles.

\begin{tabular}{|l|l|l|l|l|l|}
\hline & & \multicolumn{2}{|c|}{ Active JPS } & \multicolumn{2}{c|}{ Passive JPS } \\
\hline Exact Error & Muscle & Pearson & p-value & Pearson & p-value \\
\hline$-15^{\circ}$ & TA & .06 & .82 & -.41 & .075 \\
\hline & SOL & -.35 & .2 & -.35 & .13 \\
\hline & PL & -.37 & .17 & -.15 & .52 \\
\hline & RF & .03 & .91 & -.11 & .70 \\
\hline & BF & .001 & .996 & -.40 & .15 \\
\hline & CGMed & .36 & .48 & .52 & .13 \\
\hline & IGMed & -.07 & .82 & .21 & .46 \\
\hline & GM & .45 & .09 & -.06 & .82 \\
\hline$-30^{\circ}$ & TA & -.10 & .73 & -.25 & .30 \\
\hline & SOL & -.40 & .14 & -.03 & .92 \\
\hline & & & & &
\end{tabular}

(Table Continues) 


\begin{tabular}{|l|l|l|l|l|l|}
\hline & & \multicolumn{3}{l}{ Active JPS } & \multicolumn{2}{l|}{ Passive JPS } \\
\hline Exact Error & Muscle & Pearson & p-value & Pearson & p-value \\
\hline & PL & -.25 & .37 & $.49^{*}$ & .03 \\
\hline & RF & .02 & .94 & -.09 & .75 \\
\hline & BF & .17 & .54 & $.75^{* *}$ & .001 \\
\hline & CGMed & .02 & .98 & .10 & .78 \\
\hline & IGMed & -.11 & .69 & -.04 & .88 \\
\hline & GM & .41 & .13 & .10 & .74 \\
\hline & TA & .01 & .96 & -.11 & .63 \\
\hline & SOL & .33 & .23 & -.06 & .79 \\
\hline & PL & .12 & .67 & -.08 & .73 \\
\hline & RF & -.43 & .11 & -.41 & .13 \\
\hline & BF & .11 & .69 & .26 & .36 \\
\hline & CGMed & -.48 & .33 & $-.74^{*}$ & .01 \\
\hline & IGMed & -.25 & .38 & .12 & .66 \\
\hline & GM & $-.63^{\circ}$ & .01 & -.16 & .56 \\
\hline
\end{tabular}

Table 4: Correlation and P-Value of Exact JPS Error and Muscle Reaction Time

*statistical significance at $\mathrm{p} \leq .05, * *$ statistical significance at $\mathrm{p} \leq .01$ 


\begin{tabular}{|c|c|c|c|c|c|}
\hline & & Active JJ & & Passive & \\
\hline Absolute Error & Muscle & Pearson & p-value & Pearson & p-value \\
\hline$-15^{\circ}$ & TA & -.2 & .48 & -.27 & .25 \\
\hline & SOL & .16 & .57 & -.23 & .32 \\
\hline & PL & $\begin{array}{l}-.13 \\
\end{array}$ & .65 & $\begin{array}{l}-.17 \\
\end{array}$ & .47 \\
\hline & RF & -.03 & .90 & -.25 & .37 \\
\hline & $\mathrm{BF}$ & -.04 & .88 & -.19 & .49 \\
\hline & CGMed & .19 & .72 & .04 & .92 \\
\hline & IGMed & $\begin{array}{l}-.14 \\
\end{array}$ & .61 & .17 & .54 \\
\hline & GM & -.17 & .55 & -.25 & .37 \\
\hline$-30^{\circ}$ & TA & $\begin{array}{l}-.003 \\
\end{array}$ & .99 & $\begin{array}{l}-.24 \\
\end{array}$ & .31 \\
\hline & SOL & .16 & .57 & -.05 & .85 \\
\hline & PL & -.20 & .47 & .36 & .12 \\
\hline & $\mathrm{RF}$ & -.12 & .67 & $\begin{array}{l}-.30 \\
\end{array}$ & .27 \\
\hline & $\mathrm{BF}$ & -.24 & .39 & $.62 *$ & .01 \\
\hline & CGMed & .32 & .54 & $\begin{array}{l}-.04 \\
\end{array}$ & .91 \\
\hline & IGMed & .11 & .71 & .01 & .96 \\
\hline & GM & $\begin{array}{l}-29 \\
\end{array}$ & .29 & -.06 & .84 \\
\hline $5^{\circ}$ & TA & .01 & .99 & -.05 & .84 \\
\hline & SOL & .50 & .06 & -.06 & .82 \\
\hline & $\overline{\mathrm{PL}}$ & $.53^{*}$ & .04 & -.10 & .66 \\
\hline & RF & -.22 & .44 & -.39 & .16 \\
\hline & $\mathrm{BF}$ & .04 & .90 & .37 & .18 \\
\hline
\end{tabular}

(Table Continues) 


\begin{tabular}{|l|l|l|l|l|l|}
\hline & & \multicolumn{2}{|l|}{ Active JPS } & \multicolumn{2}{l|}{ Passive JPS } \\
\hline Absolute Error & Muscle & Pearson & p-value & Absolute & Muscle \\
& & & & Error & \\
\hline & & & & & .01 \\
\hline & CGMed & -.15 & .78 & $-.78^{* *}$ & .61 \\
\hline & IGMed & .18 & .52 & .14 & .63 \\
\hline
\end{tabular}

Table 5: Correlation and P-Value of Absolute JPS Error and Muscle Reaction Time ${ }^{*}$ statistical significance at $\mathrm{p} \leq .05, * *$ statistical significance at $\mathrm{p} \leq .01$

Statistically significant values were found within the PL, CGMed, BF, and GM groups. At $-30^{\circ}$ for PJPS exact error, a moderate, positive relationship for PL reaction time $(r=.49, n=20$, $\mathrm{p}=.03)$ and a moderately-high, positive relationship for $\mathrm{BF}$ reaction time $(\mathrm{r}=.75, \mathrm{n}=20, \mathrm{p}=.001)$ were found. A moderately-high, negative relationship between CGMed reaction time and PJPS exact error at $5^{\circ}(\mathrm{r}=-.74, \mathrm{n}=20, \mathrm{p}=.01)$ were found, meaning that the more accurate the subject's PJPS was, the slower the CGMed reacted to the unexpected inversion perturbation. A moderately high, negative relationship between GM and AJPS exact error at $5^{\circ}(\mathrm{r}=-.63, \mathrm{n}=15, \mathrm{p}=.01)$ were found. A moderately-high, positive relationship between BF reaction time and PJPS absolute error at $-30^{\circ}$ was found $(\mathrm{r}=.62, \mathrm{n}=20, \mathrm{p}=.01)$. A moderate, positive relationship between PL reaction time and AJPS absolute error at $5^{\circ}$ was found $(\mathrm{r}=.53, \mathrm{n}=20, \mathrm{p}=.04)$. A moderate, negative relationship between GM reaction time and AJPS absolute error at $5^{\circ}$ was found $(\mathrm{r}=$ $-.54, \mathrm{n}=15, \mathrm{p}=.04)$. A moderately-high, negative relationship between CGMed reaction time and PJPS absolute error at $5^{\circ}$ was found $(\mathrm{r}=-.78, \mathrm{n}=20, \mathrm{p}=.01)$.

The positive relationships between both PJPS at $-30^{\circ}$ and AJPS at $5^{\circ}$ and the PL reaction times mean that the more accurate the subject's ankle JPS was at those angles (whether it was 
active or passive), the quicker the PL reacted to the unexpected inversion perturbation. The positive relationships found between PJPS at $-30^{\circ}$ and $\mathrm{BF}$ reaction time show that the more accurate the subject's PJPS was at $-30^{\circ}$, the quicker the BF reacted to the inversion perturbation. The negative relationship between AJPS at $5^{\circ}$ and GM reaction time means that the more accurate the subject's AJPS was at $5^{\circ}$, the slower the GM would react to the inversion perturbation. Lastly, the negative relationship between PJPS at $5^{\circ}$ and CGMed reaction time means that the more accurate the subject's PJPS at $5^{\circ}$ was, the slower the CGMed reacted to the inversion perturbation. 


\section{CHAPTER V: DISCUSSION}

\section{Reaction Time}

Muscular reaction to unexpected, ankle joint movement has been found as an important factor in the avoidance of ankle sprains during functional activities. As the static ankle structures stretch while the ankle moves into inversion, they provide passive restraint against the movement. ${ }^{56}$ The information regarding joint position sense that the mechanoreceptors within the passive structures rely to the brain sparks a neurological, reflexive action by the dynamic structures supporting the ankle $\mathrm{e}^{63,64}$ as well as proximal muscles in the lower extremity kinetic chain surrounding the knee and hip. ${ }^{53}$ Combined reactions of the muscles creating local and global reactions to unexpected changes in ankle positioning must be coordinated and on time to protect the joint from excessive motion ${ }^{65}$ (inversion during a lateral ankle sprain). Therefore, the reaction time of muscles surrounding the knee and hip is equally as important in the avoidance of excessive inversion as ankle muscles such as the peroneus longus during dynamic joint stabilization. ${ }^{66}$

When lateral ankle sprains were accidentally studied during the Beijing Olympics, it was observed that the ankle reaches maximal inversion at approximately $80 \mathrm{~ms}$ after initial foot contact. ${ }^{67} \mathrm{~A}$ deviation from normal kinematics of the entire lower extremity was found to occur at approximately $60 \mathrm{~ms}$ after the injury mechanism occurred in a study observing accidental lateral ankle sprains in a biomechanics laboratory. ${ }^{68}$ Therefore, the lower extremity dynamic defense must happen in that pre-injury window and at least before $80 \mathrm{~ms}$ after initial foot contact. $^{68}$ This study found that the TA, PL, and SOL had mean reaction times of $58.5 \mathrm{~ms}$, $72.3 \mathrm{~ms}$, and $54.9 \mathrm{~ms}$ respectively, confirming that ankle muscle reactions to inversion are occurring within the pre-injury window. 
The knee and hip muscles that reacted before $80 \mathrm{~ms}$ post-drop were RF, BF, GM, and IGMed at average times of $58.8 \mathrm{~ms}, 58 \mathrm{~ms}, 44.6 \mathrm{~ms}$, and $55.1 \mathrm{~ms}$. In a study conducted by Konradson et al., goniometric increases knee and hip flexion $202 \mathrm{~ms}$ after drop were seen in response to sudden ankle inversion while standing on a supinating platform. ${ }^{56}$ The reaction times found in this study correspond to the timing. The average reaction time of the CGMed was 149.3ms after the inversion drop. This shows that the body's center of gravity may shift to the contralateral limb and require later, stabilizing action of the hip similar to activation tested in a Trendelenburg test. ${ }^{69}$

In the current literature, there are different ways reaction time has been defined based on EMG data. Knight and Weimar explain that there have been several ways different studies have defined reaction time activation in terms of the spikes in EMG feed. ${ }^{70}$ Reaction time has been determined by values of EMG signal $2^{13,15}, 5^{70,71}$, and $10^{72} \mathrm{SD}$ above the mean in different studies. Others have used things as simple as the first "peak" in the EMG feed after the stimulus is applied, such as an inversion drop. ${ }^{56}$ The lower the SD threshold, the more "sensitive" the measurement will be. ${ }^{70} 2 \mathrm{SD}$ was chosen in this study due to the reaction time window being defined as 200ms post-drop; a small time window such as the one chosen for this study required a more sensitive threshold to determine the reaction time. Therefore, the previous literature supports the use of the 2 SD threshold. ${ }^{13,15}$

\section{Joint Position Sense}

JPS was used in this study to assess static and dynamic ankle structures that monitor ankle joint positioning without visual cues. Statistically significant results were found between both AJPS and PJPS for four different muscles. PL and GM reaction times were found to be significant at $5^{\circ}$ during AJPS testing. PL, BF, and CGMed reaction times were found to be 
significant at $-30^{\circ}$ and $5^{\circ}$ during PJPS testing. The mix of statistically significant results could be attributed to little difference in the structures tested in AJPS and PJPS.

AJPS requires use of ankle muscles to alter the positioning of the ankle based on stretch monitored by the muscle spindles in the muscles and tendons of the ankle. ${ }^{8,28}$ PJPS potentially relies on the stretch of both active and passive stabilizers to provide information about the position of the ankle joint relative to the body, explaining why Hertel et al. found no significant differences in PJPS before and after lidocaine injections. ${ }^{34}$ Because all of these structures cross the ankle joint very closely and are all affected by movement, PJPS and AJPS both test static and dynamic structures simultaneously. This suggests that both types of structures work during active and passive movement of the ankle joint.

\section{Correlational Results}

Statistically significant results of this study were found for the correlations between PL and PJPS at $-30^{\circ}$ and AJPS at $5^{\circ}, \mathrm{BF}$ and PJPS at $-30^{\circ}$, CGMed and PJPS at $5^{\circ}$, and GM and AJPS at $5^{\circ}$. Positive relationships between reaction time and JPS were found with the PL and BF. Negative relationships were found with the CGMed and GM.

The positive relationship between PJPS at $-30^{\circ}$ and PL reaction time could be explained by the muscle spindles in the ankle joint. Muscle spindles respond to stretch and are a main component of the short latency response. ${ }^{29}$ The short latency response is the first step in the neuromuscular response that occurs with joint injury or changes in joint positioning. ${ }^{29}$ This accounts for reflexive muscle activation at a joint while joint position changes and tissues stretch. The positive relationship could be explained because as the large amount of tissue stretch at $-30^{\circ}$ is passively detected more accurately, the PL reaction time of those individuals may be shorter due to the sensitivity of the muscle spindles and modulation of the short latency 
response. ${ }^{29}$ This response causes the peroneal muscle group to activate in response to the inversion stimulus and attempt to pull the ankle out of inversion or slow the speed the ankle falls into inversion. This leads into the positive relationship between PL reaction time and AJPS at $5^{\circ}$ potentially occurring due to the peroneal reflex requires PL activation, just as AJPS into eversion requires PL activation mainly. Overall, these results are in line with prior research stating the peroneal reflex and muscle spindle activation occur during ankle inversion. ${ }^{14,15,29,46,56,58,66}$ The results also show that a subject's better awareness of JPS could be correlated to quicker reaction times of the PL in response to sudden inversion.

Significant correlations were also found more proximally in the lower extremity kinetic chain in this study. A positive relationship was found between reaction times of the BF and PJPS at $-30^{\circ}$ and a negative relationship between GM reaction times and AJPS at $5^{\circ}$. These findings can be explained in Konradson et al.'s research. ${ }^{56}$ They found that during standing inversion perturbations, goniometric changes of $30^{\circ}$ knee flexion and $25^{\circ}$ hip flexion $202 \mathrm{~ms}$ after drop occurred. ${ }^{56}$ The knee and hip flexion during the perturbation may have been an unloading response of the affected limb, observed by Santos and Lui in their study ${ }^{73}$ Santos and Lui found that with electrical stimulation of the ankle while in supination and neutral resulted in the affected extremity unloading the limb by flexing the knee and hip. ${ }^{73}$ This may explain the positive relationship seen involving the $\mathrm{BF}$ (knee flexor) and negative relationship involving the GM (hip extensor). The relationship involving PJPS at $-30^{\circ}$ and the BF may have to do with the stretch information relied from the muscle spindles of the ankle at $-30^{\circ}$ signaling the need to unload the affected limb proximally from potentially injurious stimuli. The negative relationship involving AJPS at $5^{\circ}$ and GM may also be explained because as the PL activates in response to the inversion perturbation (as it activates to actively recreate $5^{\circ}$ eversion), the GM may not react 
to the sudden inversion due to its antagonist flexing the hip as part of a proximal unloading response.

The last significant finding was a negative relationship between the reaction time of the CGMed and PJPS at $5^{\circ}$. This could also be explained by the unloading response observed by Santos and Lui. ${ }^{73}$ As flexion of the knee and hip occur to unload the affected limb, there could be a downward motion of the pelvis in response ${ }^{73}$ and cause something similar to a Trendelenburg

test to occur in the CGMed. ${ }^{69}$ This could be due to the unload only being used reflexively by the body to remove as much weight from the limb as possible without actively picking the limb up, potentially preparing the body to allow the ankle to give way to the harmful motion. If the leg is not lifted off of the ground and the pelvis lowers on the affected side, the CGMed would not fire to allow for the downward pelvic motion and explain the negative relationship between the CGMed and PJPS of the ankle.

Although the CGMed results were significant, these significant results were most likely due to chance to the number of reaction times recorded. Only 17 out of 60 potential reactions were recorded; this was only $26.7 \%$ out of the whole sample size in comparison to the other muscles that had reacted more than $70 \%$ of the time. The mean reaction time of the CGMed was also much longer than those of the other 7 muscles; it took 149ms for the CGMed to react in the $200 \mathrm{~ms}$ window, when the others reacted at an average of $57.5 \mathrm{~ms}$ (showed in table 2). Although the correlation was found to be significant, other factors lead to the belief that this result was most likely due to chance.

\section{Limitations}

This study had a few limitations. One was that the number of subjects throughout the study varied depending on the time the data was collected. 15 subjects completed data collection 
with all 8 lower extremity muscles and both AJPS and PJPS. This resulted in potential differences between the number of muscle reaction times that could have occurred during data collections for the muscles collected with only 15 subjects. Although the number of reaction times may not have changed, there is still the possibility that the deficit of subjects affected the number of reactions recorded due to the different number of total reactions possible. The difference in the number of subjects who completed AJPS may have affected the means recorded. This is not known for sure due to very similar percentages of reactions recorded from the total possible number seen in table 1.

Another potential limitation could be EMG noise error associated with soft tissue movement and placement on the muscle belly under the electrodes. Differences in the anatomy and composition of each subject could impact how accurately the EMG electrode is placed on each muscle belly to limit noise and how much other tissue movement would potentially occur with muscle contraction.

A third limitation could have occurred during the data processing done in Visual 3D. It was found that the electromagnetic signal released by the inversion perturbation platform was not activated during the inversion drops in three subjects. To compensate for this, a pipeline was created to calculate the number of frames between the last heel strike of each subject to the release of the inversion perturbation platform. The average was taken from all 17 subjects, and the average was used to estimate the location of where the inversion drop occurred after the last heel strike before the drop of the three subjects.

\section{Conclusions}

The results of this study overall disprove the hypothesis stating that more positive relationships would be found between reaction time and AJPS than reaction time and PJPS; 
statistically significant results were found involving both AJPS and PJPS, showing that there may be very little difference between the structures tested in the AJPS and PJPS measures. The positive relationship linking the PL reaction time to AJPS at $5^{\circ}$ and PJPS at $-30^{\circ}$ is in line with previous literature focused on the actions of the PL during ankle inversion landings and perturbations. The significant relationships involving the proximal lower extremity muscles (BF and GM specifically) are also in line with previous literature that studied goniometric and kinematic changes of the lower extremity in response to inversion perturbation. All of the results show that both a local, ankle response and global response from the knee and hip occur during unexpected ankle inversion to try and avoid potentially injurious forces distally. This information may help to explain the importance of ankle proprioception in relationship to muscle reactions during ankle inversion and provide clinicians insight into what the lower extremity does to avoid potential injury. 


\section{REFERENCES}

1. Hertel J. Functional Anatomy, Pathomechanics, and Pathophysiology of Lateral Ankle Instability. :12.

2. Doherty C, Delahunt E, Caulfield B, Hertel J, Ryan J, Bleakley C. The incidence and prevalence of ankle sprain injury: a systematic review and meta-analysis of prospective epidemiological studies. Sports Med. 2014;44(1):123-140.

3. Fong D, Hong Y, Chan L, Yung P, Chan K. A systematic review on ankle injury and ankle sprain in sports. Sports Med. 2007;37(1):73-94.

4. Willems T, Witvrouw E, Verstuyft J, Vaes P, De Clercq D. Proprioception and Muscle Strength in Subjects With a History of Ankle Sprains and Chronic Instability. J Athl Train. 2002;37(4):487-493.

5. Kaminski TW, Hartsell HD. Factors Contributing to Chronic Ankle Instability: A Strength Perspective. J Athl Train. 2002;37(4):394-405.

6. Simpson JD, Stewart EM, Mosby AM, Macias DM, Chander H, Knight AC. LowerExtremity Kinematics During Ankle Inversion Perturbations: A Novel Experimental Protocol That Simulates an Unexpected Lateral Ankle Sprain Mechanism. J Sport Rehabil. 2019;28(6):593-600. doi:10.1123/jsr.2018-0061

7. Morrison KE, Kaminski TW. Foot Characteristics in Association With Inversion Ankle Injury. :8. 
8. Riemann BL, Lephart SM. The Sensorimotor System, Part I: The Physiologic Basis of Functional Joint Stability. :9.

9. Willems TM, Witvrouw E, Delbaere K, Mahieu N, De Bourdeaudhuij L, De Clercq D. Intrinsic Risk Factors for Inversion Ankle Sprains in Male Subjects: A Prospective Study. Am J Sports Med. 2005;33(3):415-423. doi:10.1177/0363546504268137

10. Willems TM, Witvrouw E, Delbaere K, Philippaerts R, De Bourdeaudhuij I, De Clercq D. Intrinsic risk factors for inversion ankle sprains in females - a prospective study. Scand $J$ Med Sci Sports. 2005;15(5):336-345. doi:10.1111/j.1600-0838.2004.00428.x

11. Fousekis K, Tsepis E, Vagenas G. Intrinsic Risk Factors of Noncontact Ankle Sprains in Soccer: A Prospective Study on 100 Professional Players. Am J Sports Med. 2012;40(8):1842-1850. doi:10.1177/0363546512449602

12. Sousa ASP, Leite J, Costa B, Santos R. Bilateral Proprioceptive Evaluation in Individuals With Unilateral Chronic Ankle Instability. J Athl Train. 2017;52(4):360-367. doi:10.4085/1062-6050-52.2.08

13. Stanek J, McLoda T, Csiszer V, Hansen AJ. Hip- and Trunk-Muscle Activation Patterns During Perturbed Gait. J Sport Rehabil. 2011;20:287-295. doi:10.1123/jsr.20.3.287

14. Gutierrez GM, Knight CA, Swanik CB, et al. Examining Neuromuscular Control During Landings on a Supinating Platform in Persons With and Without Ankle Instability. Am J Sports Med. 2012;40(1):193-201. doi:10.1177/0363546511422323 
15. Hopkins J, McLoda T, Mccaw S. Muscle activation following sudden ankle inversion during standing and walking. Eur J Appl Physiol. 2007;99:371-378. doi:10.1007/s00421006-0356-9

16. Fitzpatrick RC, Taylor JL, McCloskey DI. Ankle stiffness of standing humans in response to imperceptible perturbation: reflex and task-dependent components. J Physiol. 1992;454(1):533-547. doi:10.1113/jphysiol.1992.sp019278

17. Delahunt E, Monaghan K, Caulfield B. Altered Neuromuscular Control and Ankle Joint Kinematics during Walking in Subjects with Functional Instability of the Ankle Joint. Am J Sports Med. 2006;34(12):1970-1976. doi:10.1177/0363546506290989

18. Starkey C, Brown S D. Examination of Orthopedic \& Athletic Injuries, 4th Edition - F.A. Davis Company. 4th ed. Jaypee Brothers Medical Publishers Ltd Accessed September 19, 2019. https://www.fadavis.com/product/athletic-training-examination-orthopedic-athleticinjuries-starkey-brown-4

19. Role of the fibula in weight-bearing. - Abstract - Europe PMC. Accessed October 1, 2019. https://europepmc.org/abstract/med/6705357

20. Hicks JH. THE MECHANICS OF THE FOOT. :13.

21. Lundberg A, Goldie I, Kalin B, Selvik G. Kinematics of the Ankle/Foot Complex: Plantarflexion and Dorsiflexion. Foot Ankle. 1989;9(4):194-200. doi:10.1177/107110078900900409 
22. Ankle Syndesmotic Injury : JAAOS - Journal of the American Academy of Orthopaedic Surgeons. Accessed September 21, 2019. https://journals.lww.com/jaaos/Abstract/2007/06000/Ankle_Syndesmotic_Injury.2.aspx

23. Wang R, Gutierrez-Farewik EM. The effect of subtalar inversion/eversion on the dynamic function of the tibialis anterior, soleus, and gastrocnemius during the stance phase of gait. Gait Posture. 2011;34(1):29-35. doi:10.1016/j.gaitpost.2011.03.003

24. Simon SR, Mann RA, Hagy JL, Larsen LJ. Role of the posterior calf muscles in normal gait. J Bone Joint Surg Am. 1978;60(4):465-472.

25. Czerniecki JM. Foot and ankle biomechanics in walking and running. A review. Am J Phys Med Rehabil. 1988;67(6):246-252.

26. Hargrave MD, Carcia CR, Gansneder BM, Shultz SJ. Subtalar Pronation Does Not Influence Impact Forces or Rate of Loading During a Single-Leg Landing. :6.

27. Willems TM, Witvrouw E, Delbaere K, Philippaerts R, Bourdeaudhuij ID, Clercq DD. Intrinsic risk factors for inversion ankle sprains in females - a prospective study. Scand J Med Sci Sports. 2005;15(5):336-345. doi:10.1111/j.1600-0838.2004.00428.x

28. Bewick GS, Banks RW. Mechanotransduction in the muscle spindle. Pflüg Arch - Eur J Physiol. 2015;467(1):175-190. doi:10.1007/s00424-014-1536-9

29. Hopkins JT, Brown TN, Christensen L, Palmieri-Smith RM. Deficits in peroneal latency and electromechanical delay in patients with functional ankle instability. J Orthop Res. 2009;27(12):1541-1546. doi:https://doi.org/10.1002/jor.20934 
30. Konradsen L. Factors Contributing to Chronic Ankle Instability: Kinesthesia and Joint Position Sense. J Athl Train. 2002;37(4):381-385.

31. Konradsen L, Ravn JB, S\#rensen AI. Proprioception at the Ankle: The Effecf of Anaesthetic Blockade of Ligament Receptors.

32. Riemann BL, Myers JB, Stone DA, Lephart SM. Effect of Lateral Ankle Ligament Anesthesia on Single-Leg Stance Stability: Med Sci Sports Exerc. 2004;36(3):388-396. doi:10.1249/01.MSS.0000117131.93989.9B

33. De Carlo MS, Talbot RW. Evaluation of Ankle Joint Proprioception Following Injection of the Anterior Talofibular Ligament. J Orthop Sports Phys Ther. 1986;8(2):70-76. doi:10.2519/jospt.1986.8.2.70

34. Hertel JN, Guskiewicz KM, Kahler DM, Perrin DH. Effect of Lateral Ankle Joint Anesthesia on Center of Balance, Postural Sway, and Joint Position Sense. J Sport Rehabil. 1996;5(2):111-119. doi:10.1123/jsr.5.2.111

35. de Noronha M, Refshauge KM, Herbert RD, Kilbreath SL, Hertel J. Do voluntary strength, proprioception, range of motion, or postural sway predict occurrence of lateral ankle sprain? * COMMENTARY. Br J Sports Med. 2006;40(10):824-828. doi:10.1136/bjsm.2006.029645

36. Kobayashi T, Yoshida M, Yoshida M, Gamada K. Intrinsic Predictive Factors of Noncontact Lateral Ankle Sprain in Collegiate Athletes: A Case-Control Study. Orthop J Sports Med. 2013;1(7):232596711351816. doi:10.1177/2325967113518163 
37. Brown C, Ross S, Mynark R, Guskiewicz K. Assessing Functional Ankle Instability with Joint Position Sense, Time to Stabilization, and Electromyography. J Sport Rehabil. 2004;13(2):122-134. doi:10.1123/jsr.13.2.122

38. Hertel J. Functional Instability Following Lateral Ankle Sprain. Sports Med. 2000;29(5):361-371. doi:10.2165/00007256-200029050-00005

39. Lentell G, Baas B, Lopez D, McGuire L, Sarrels M, Snyder P. The Contributions of Proprioceptive Deficits, Muscle Function, and Anatomic Laxity to Functional Instability of the Ankle. J Orthop Sports Phys Ther. 1995;21(4):206-215. doi:10.2519/jospt.1995.21.4.206

40. Bertrand-Charette M, Dambreville C, Bouyer LJ, Roy J-S. Systematic review of motor control and somatosensation assessment tests for the ankle. BMJ Open Sport Exerc Med. 2020;6(1):e000685. doi:10.1136/bmjsem-2019-000685

41. Liu MQ, Anderson FC, Pandy MG, Delp SL. Muscles that support the body also modulate forward progression during walking. J Biomech. 2006;39(14):2623-2630.

42. Zajac FE, Gordon ME. Determining Muscle's Force and Action in Multi-Articular Movement. Exerc Sport Sci Rev. 1989;17(1):187.

43. Kepple TM, Siegel KL, Stanhope SJ. Relative contributions of the lower extremity joint moments to forward progression and support during gait. Gait Posture. 1997;6(1):1-8. doi:10.1016/S0966-6362(96)01094-6 
44. Gottschall JS, Kram R. Energy cost and muscular activity required for propulsion during walking. J Appl Physiol. 2003;94(5):1766-1772. doi:10.1152/japplphysiol.00670.2002

45. Neptune RR, Zajac FE, Kautz SA. Muscle force redistributes segmental power for body progression during walking. Gait Posture. 2004;19(2):194-205. doi:10.1016/S09666362(03)00062-6

46. Simpson JD, Stewart EM, Turner AJ, et al. Neuromuscular control in individuals with chronic ankle instability: A comparison of unexpected and expected ankle inversion perturbations during a single leg drop-landing. Hum Mov Sci. 2019;64:133-141. doi:10.1016/j.humov.2019.01.013

47. Nakazawa K, Kawashima N, Akai M, Yano H. On the reflex coactivation of ankle flexor and extensor muscles induced by a sudden drop of support surface during walking in humans. J Appl Physiol. 2004;96(2):604-611. doi:10.1152/japplphysiol.00670.2003

48. Latash M, Levin M, Scholz J, Schöner G. Motor control theories and their applications. Medicina (Mex). 2010;46(6):382. doi:10.3390/medicina46060054

49. GHEZ C. The control of movement. Princ Neural Sci. Published online 1991:533-547.

50. Hasan Z, Stuart DG. Animal Solutions to Problems of Movement Control: The Role of Proprioceptors. Annu Rev Neurosci. 1988;11(1):199-223. doi:10.1146/annurev.ne.11.030188.001215

51. Leonard CT. The Neuroscience of Human Movement. Mosby; 1998. 
52. Matthews PBC. The 1989 James A. F. Stevenson Memorial Lecture. The knee jerk: still an enigma? Can J Physiol Pharmacol. Published online February 13, 2011. doi:10.1139/y90048

53. Riemann BL, Lephart SM. The Sensorimotor System, Part II: The Role of Proprioception in Motor Control and Functional Joint Stability. J Athl Train. 2002;37(1):80-84.

54. Konradsen L. Sensori-motor control of the uninjured and injured human ankle. Journal of Electromyography and Kinesiology. 2002;12(3):199-203. doi:https://doi.org/10.1016/S1050-6411(02)00021-4

55. Konradsen L, Hojsgaard C. Pre-heel-strike peroneal muscle activity during walking and running with and without an external ankle support. Scand J Med Sci Sports. 1993;3:99103.

56. Konradsen L, Voigt M, Hojsgaard C. Ankle Inversion Injuries: The Role of the Dynamic Defense Mechanism. Am J Sports Med. 1997;25(1):54-58. doi:10.1177/036354659702500110

57. Nishikawa T, Grabiner M. Ankle Braces Influence the Reflex Amplitude of Muscle in Response to Stretch.; 1996:397.

58. Isakov E, Mizrahi J, Solzi P. Response of the Peroneal Muscles to Sudden Inversion of the Ankle during Standing. Journal of Applied Biomechanics. 1986;2(2). Accessed January 7, 2021. https://journals.humankinetics.com/view/journals/jab/2/2/article-p100.xml 
59. Thonnard J-L, Plaghki L, Willems P, Benoit JC, De Nyer J. La pathogénie de l'entorse de la cheville: test d'une hypothèse. Acta Belg Medica Phys Organe Off Société R Belge Médecine Phys Réhabil. 1986;9(2):141.

60. Santos MJ, Liu H, Liu W. Unloading reactions in functional ankle instability. Gait Posture. 2008;27(4):589-594. doi:10.1016/j.gaitpost.2007.08.001

61. Rainoldi A, Melchiorri G, Caruso I. A Method for Positioning Electrodes during Surface EMG Recordings in Lower Limb Muscles. J Neurosci Methods. 2004;134:37-43. doi:10.1016/j.jneumeth.2003.10.014

62. Kendall FP, McCreary EK, Provance PG, Rodgers MM, Romani WA. Muscles: Testing and Testing and Function with Posture and Pain. Fifth, North American edition. LWW; 2005.

63. Lephart SM, Pincivero DM, Giraido JL, Fu FH. The Role of Proprioception in the Management and Rehabilitation of Athletic Injuries. Am J Sports Med. 1997;25(1):130-137. doi:10.1177/036354659702500126

64. Michelson J, Hutchins C. Mechanoreceptors in human ankle ligaments. J Bone Joint Surg Br. 1995;77-B(2):219-224. doi:10.1302/0301-620X.77B2.7706334

65. Berg CL, Hart JM, Palmieri-Smith R, Cross KM, Ingersoll CD. Cryotherapy Does Not Affect Peroneal Reaction Following Sudden Inversion. J Sport Rehabil. 2007;16(4):285294. doi:10.1123/jsr.16.4.285 
66. Palmieri-Smith RM, Ty Hopkins J, Brown TN. Peroneal Activation Deficits in Persons with Functional Ankle Instability. Am J Sports Med. 2009;37(5):982-988. doi:10.1177/0363546508330147

67. Mok K-M, Fong DT-P, Krosshaug T, et al. Kinematics Analysis of Ankle Inversion Ligamentous Sprain Injuries in Sports: 2 Cases During the 2008 Beijing Olympics. Am J Sports Med. 2011;39(7):1548-1552. doi:10.1177/0363546511399384

68. Fong DT-P, Hong Y, Shima Y, Krosshaug T, Yung PS-H, Chan K-M. Biomechanics of Supination Ankle Sprain: A Case Report of an Accidental Injury Event in the Laboratory. Am J Sports Med. 2009;37(4):822-827. doi:10.1177/0363546508328102

69. Hardcastle P, Nade S. The Significance of the Trendelenburg Test. The Journal of Bone and Joint Surgery British volume. 1985;67(5). https://pdfs.semanticscholar.org/0075/9323377fbcd9681f11863e2e1b8191a368e9.pdf

70. Knight AC, Weimar WH. Effects of Inversion Perturbation After Step-Down on the Latency of the Peroneus Longus and Peroneus Brevis. J Appl Biomech. 2011;27(4):283290. doi:10.1123/jab.27.4.283

71. Thain PK, Bleakley CM, Mitchell ACS. Muscle Reaction Time During a Simulated Lateral Ankle Sprain After Wet-Ice Application or Cold-Water Immersion. J Athl Train. 2015;50(7):697-703. doi:10.4085/1062-6050-50.4.05

72. Bhaskaran D, Wortley M, Chen Q, Milner CE, Fitzhugh EC, Zhang S. Effect of a combined inversion and plantarflexion surface on ankle kinematics and EMG activities in landing. $J$ Sport Health Sci. 2015;4(4):377-383. doi:10.1016/j.jshs.2014.10.005 
73. Santos MJ, Liu W. Unloading reaction to electrical stimulation at neutral and supinated ankle positions. Gait Posture. 2007;26(1):106-112. doi:10.1016/j.gaitpost.2006.08.004 


\section{APPENDIX: VISUAL 3D PIPELINES}

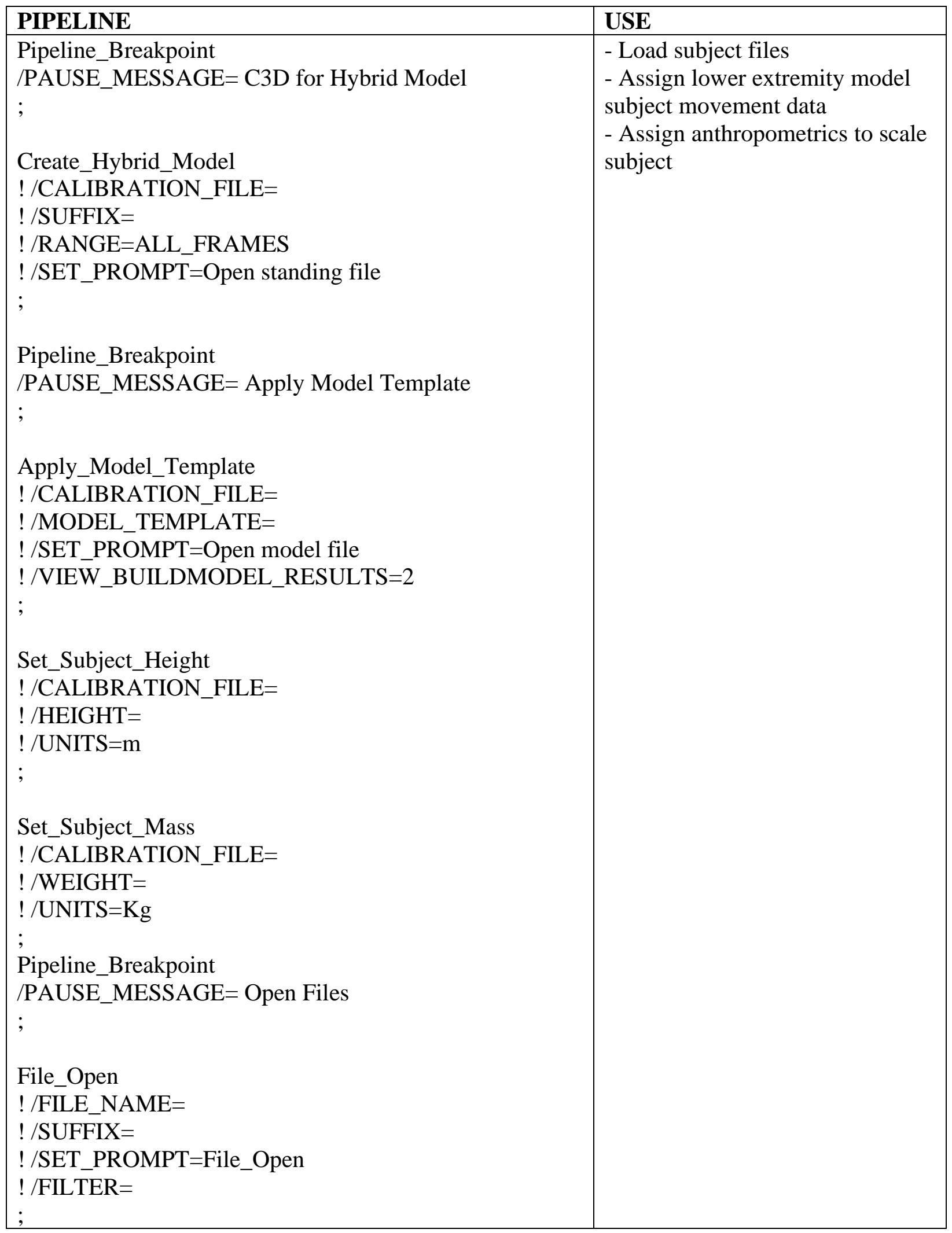




\begin{tabular}{|c|c|}
\hline $\begin{array}{l}\text { Assign_Model_File } \\
\text { !/CALIBRATION_FILE }= \\
\text { ! /MOTION_FILE_NAMES= } \\
\text { ! /REMOVE_EXISTING_ASSIGNMENTS=FALSE } \\
;\end{array}$ & \\
\hline 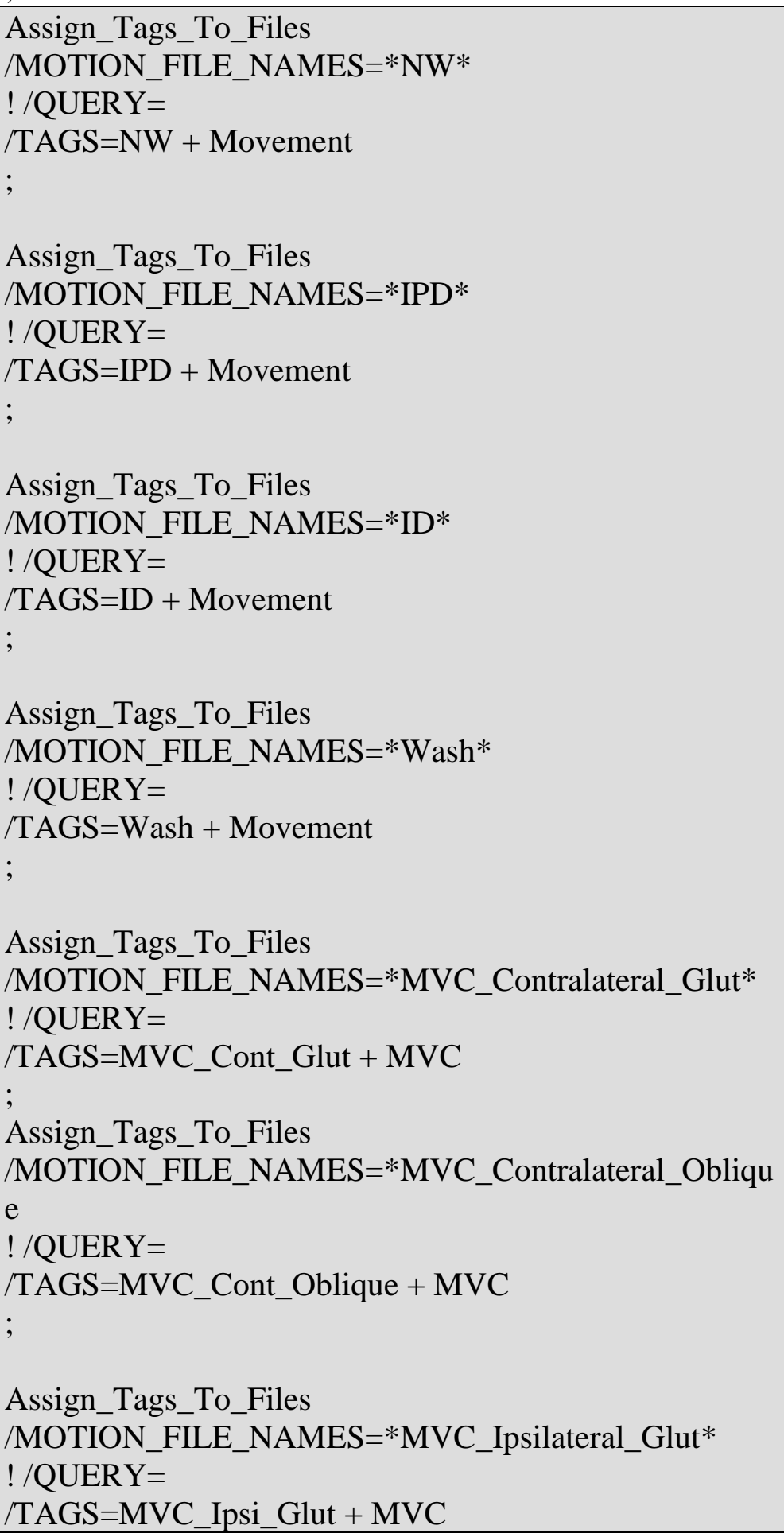 & $\begin{array}{l}\text { - Create tags and groups } \\
\text { movement and MVC files } \\
\text { - Rename and tag MVC files } \\
\text { from voltage channels } \\
\text { - Remove unused voltage } \\
\text { channels }\end{array}$ \\
\hline
\end{tabular}




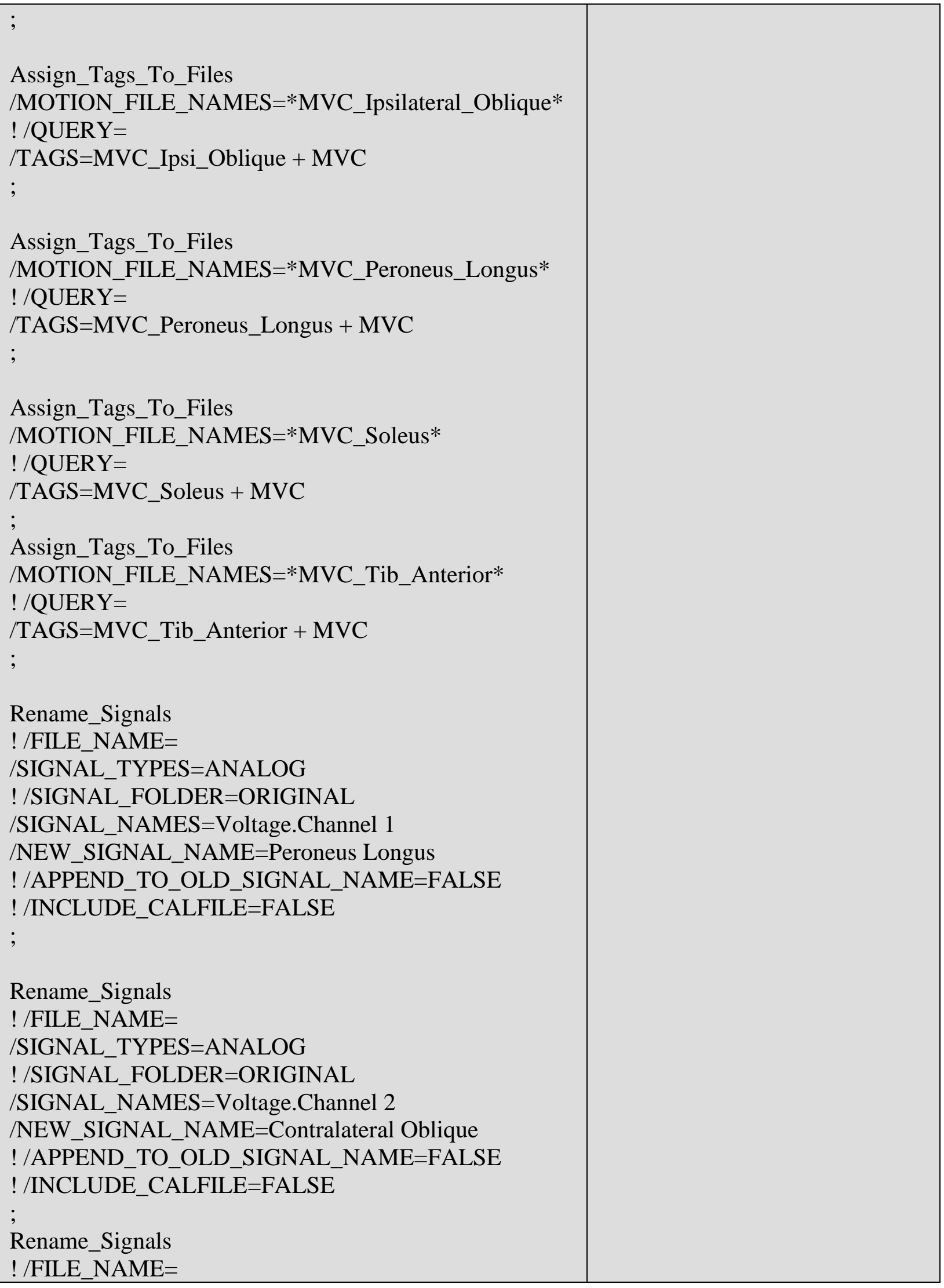




\begin{tabular}{|l|l|}
\hline /SIGNAL_TYPES=ANALOG & \\
!/SIGNAL_FOLDER=ORIGINAL \\
/SIGNAL_NAMES=Voltage.Channel 3 \\
/NEW_SIGNAL_NAME=Ipsilateral Gluteus Medius & \\
!/APPEND_TO_OLD_SIGNAL_NAME=FALSE & \\
!/INCLUDE_CALFILE=FALSE \\
$;$ \\
Rename_Signals \\
!/FILE_NAME= \\
/SIGNAL_TYPES=ANALOG \\
!/SIGNAL_FOLDER=ORIGINAL \\
/SIGNAL_NAMES=Voltage.Channel 4 \\
/NEW_SIGNAL_NAME=Soleus \\
!/APPEND_TO_OLD_SIGNAL_NAME=FALSE \\
!/INCLUDE_CALFILE=FALSE \\
; \\
Rename_Signals \\
!/FILE_NAME= \\
/SIGNAL_TYPES=ANALOG \\
!/SIGNAL_FOLDER=ORIGINAL \\
/SIGNAL_NAMES=Voltage.Channel 5 \\
/NEW_SIGNAL_NAME=Empty Channel \\
!/APPEND_TO_OLD_SIGNAL_NAME=FALSE \\
!/INCLUDE_CALFILE=FALSE \\
; \\
Rename_Signals \\
!/FILE_NAME= \\
/SIGNAL_TYPES=ANALOG \\
!/SIGNAL_FOLDER=ORIGINAL \\
/SIGNAL_NAMES=Voltage.Channel 6 \\
/NEW_SIGNAL_NAME=Contralateral Gluteus Medius \\
!/APPEND_TO_OLD_SIGNAL_NAME=FALSE \\
!/INCLUDE_CALFILE=FALSE \\
; \\
Rename_Signals \\
!/FILE_NAME= \\
/SIGNAL_TYPES=ANALOG \\
!/SIGNAL_FOLDER=ORIGINAL \\
/SIGNAL_NAMES=Voltage.Channel 7 \\
/NEW_SIGNAL_NAME=Ipsilateral Oblique \\
!/APPEND_TO_OLD_SIGNAL_NAME=FALSE \\
!/INCLUDE_CALFILE=FALSE \\
; \\
\hline
\end{tabular}




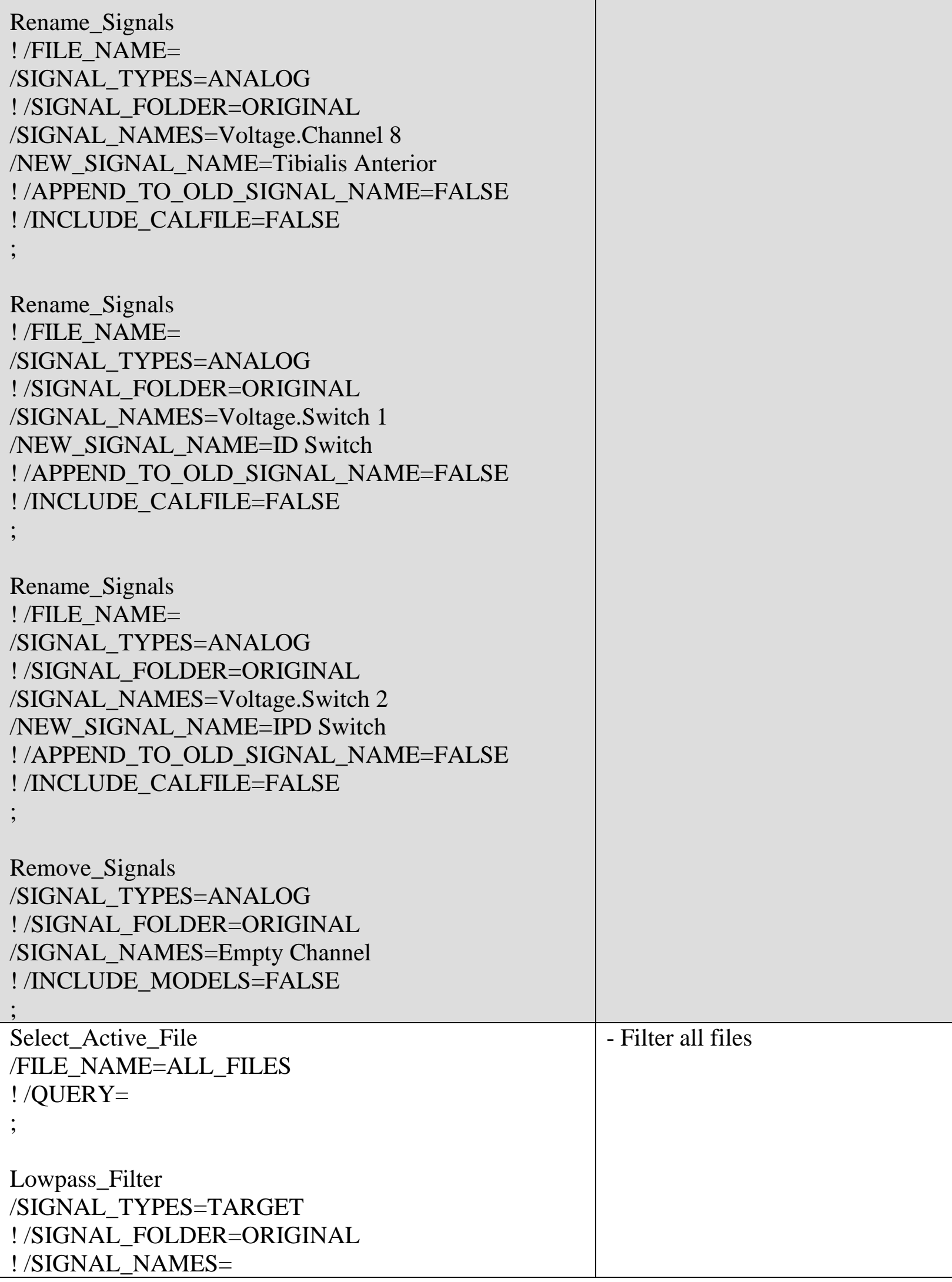




\begin{tabular}{|c|c|}
\hline $\begin{array}{l}\text { ! /RESULT_FOLDER=PROCESSED } \\
\text { ! /RESULT_SUFFIX= } \\
\text { ! /FILTER_CLASS=BUTTERWORTH } \\
\text { ! /FREQUENCY_CUTOFF=6.0 } \\
\text { ! /NUM_REFLECTED=6 } \\
\text { ! /NUM_EXTRAPOLATED=0 } \\
\text { ! /TOTAL_BUFFER_SIZE=6 } \\
\text { ! /NUM_BIDIRECTIONAL_PASSES=1 } \\
\text {; } \\
\text { Lowpass_Filter } \\
\text { /SIGNAL_TYPES=ANALOG+ANALOG+ANALOG+A } \\
\text { NALOG+ANALOG+ANALOG+ANALOG } \\
\text { /SIGNAL_FOLDER=ORIGINAL+ORIGINAL+ORIGIN } \\
\text { AL+ORIGINAL+ORIGINAL+ORIGINAL+ORIGINAL } \\
\text { /SIGNAL_NAMES=Contralateral Gluteus } \\
\text { Medius+Contralateral Oblique+Ipsilateral Gluteus } \\
\text { Medius+Ipsilateral Oblique+Peroneus } \\
\text { Longus+Soleus+Tibialis Anterior } \\
\text { ! /RESULT_FOLDER=PROCESSED } \\
\text { ! /RESULT_SUFFIX= } \\
\text { ! /FILTER_CLASS=BUTTERWORTH } \\
\text { /FREQUENCY_CUTOFF=300 } \\
\text { ! /NUM_REFLECTED=6 } \\
\text { ! /NUM_EXTRAPOLATED=0 } \\
\text { ! /TOTAL_BUFFER_SIZE=6 } \\
\text { ! /NUM_BIDIRECTIONAL_PASSES=1 } \\
\text {; } \\
\text { Select_Active_File } \\
\text { /FILE_NAME=Movement } \\
\text { ! /QUERY= } \\
\text {; } \\
\text { Compute_Model_Based_Data } \\
\text { /RESULT_NAME=RHEEL_WRT_PELVIS } \\
\text { /FUNCTION=SEG_PROXIMAL_JOINT } \\
\text { /SEGMENT=RFT } \\
\text { /REFERENCE_SEGMENT=RPV } \\
\text { /RESOLUTION_COORDINATE_SYSTEM=RPV } \\
\text { ! /USE_CARDAN_SEQUENCE=FALSE } \\
\text { ! /NORMALIZATION=FALSE } \\
\text { ! /NORMALIZATION_METHOD= } \\
\text { ! /NORMALIZATION_METRIC= } \\
\text { ! /NEGATEX=FALSE } \\
\text { ! /NEGATEY=FALSE }\end{array}$ & $\begin{array}{l}\text { - Gait events (LHS, LTO, RHS, } \\
\text { and RTO) created with respect to } \\
\text { pelvis }\end{array}$ \\
\hline
\end{tabular}




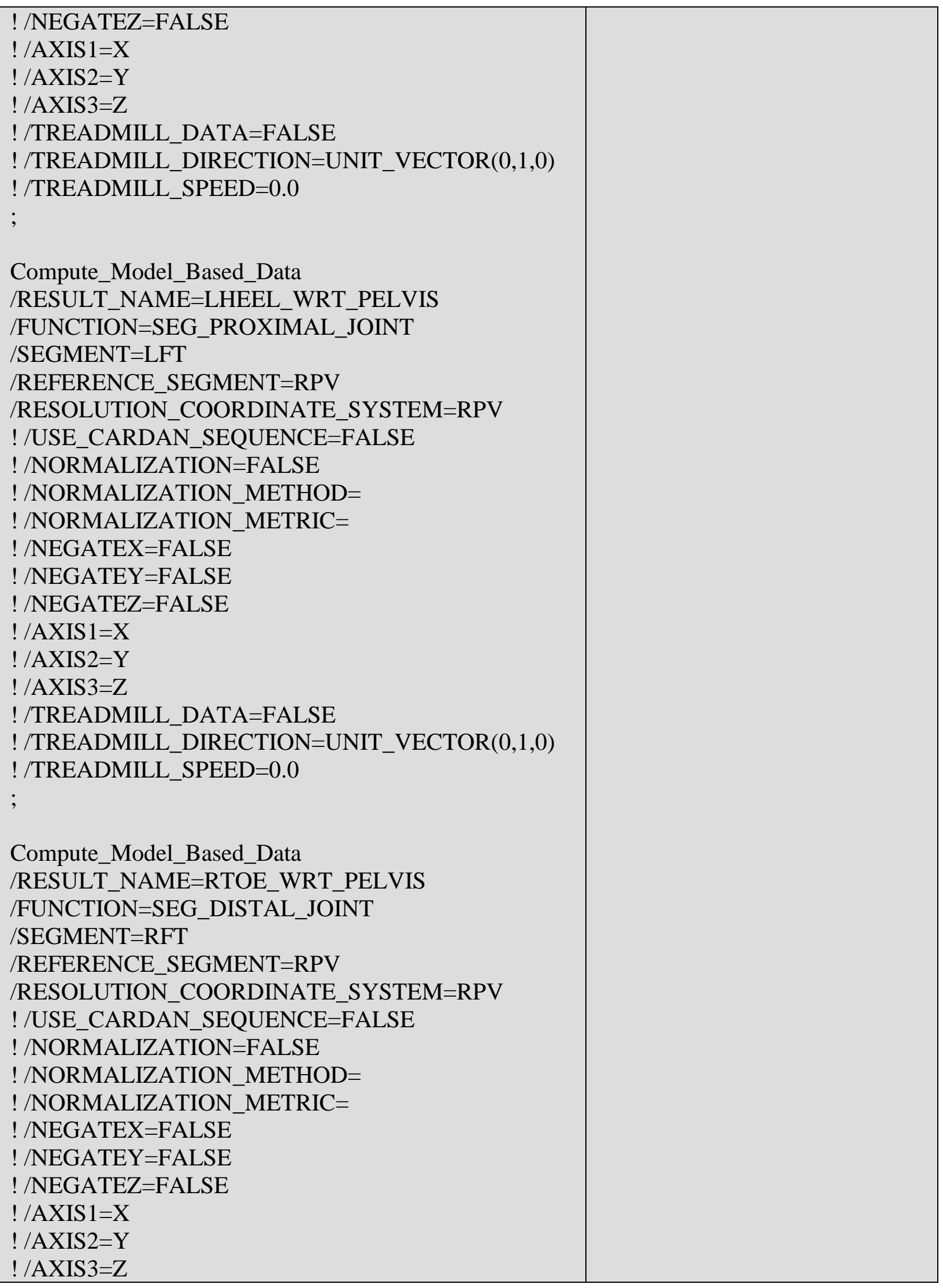




\begin{tabular}{|l|l|}
\hline !/TREADMILL_DATA=FALSE & \\
!/TREADMILL_DIRECTION=UNIT_VECTOR(0,1,0) & \\
!/TREADMILL_SPEED=0.0 & \\
$;$ & \\
Compute_Model_Based_Data & \\
/RESULT_NAME=LTOE_WRT_PELVIS & \\
/FUNCTION=SEG_DISTAL_JOINT & \\
/SEGMENT=LFT & \\
/REFERENCE_SEGMENT=RPV & \\
/RESOLUTION_COORDINATE_SYSTEM=RPV & \\
!/USE_CARDAN_SEQUENCE=FALSE & \\
!/NORMALIZATION=FALSE & \\
!/NORMALIZATION_METHOD= & \\
!/NORMALIZATION_METRIC= & \\
!/NEGATEX=FALSE & \\
!/NEGATEY=FALSE & \\
!/NEGATEZ=FALSE & \\
!/AXIS1=X & \\
!/AXIS2=Y & \\
!/AXIS3=Z & \\
!/TREADMILL_DATA=FALSE & \\
!/TREADMILL_DIRECTION=UNIT_VECTOR(0,1,0) & \\
!/TREADMILL_SPEED=0.0 & \\
; & \\
First_Derivative & \\
/SIGNAL_TYPES=LINK_MODEL_BASED+LINK_MO & \\
DEL_BASED+LINK_MODEL_BASED+LINK_MODE & \\
L_BASED & \\
/SIGNAL_FOLDER=ORIGINAL+ORIGINAL+ORIGIN & \\
AL+ORIGINAL \\
/SIGNAL_NAMES=LHeel_Wrt_Pelvis+LToe_Wr_Pelvi & \\
s+RHeel_Wrt_Pelvis+RToe_Wrt_Pelvis & \\
/RESULT_TYPES=DERIVED & \\
/RESULT_FOLDERS=EVENTS & \\
/RESULT_NAME=_Vel & \\
/APPLY_AS_SUFFIX_TO_SIGNAL_NAME=TRUE & \\
; & \\
Event_Threshold & \\
/RESULT_EVENT_NAME=RHS & \\
/SIGNAL_TYPES=DERIVED & \\
/SIGNAL_FOLDER=EVENTS & \\
/SIGNAL_NAMES=RHeel_Wrt_Pelvis_Vel \\
/SIGNAL_COMPONENTS=Y & \\
\hline
\end{tabular}




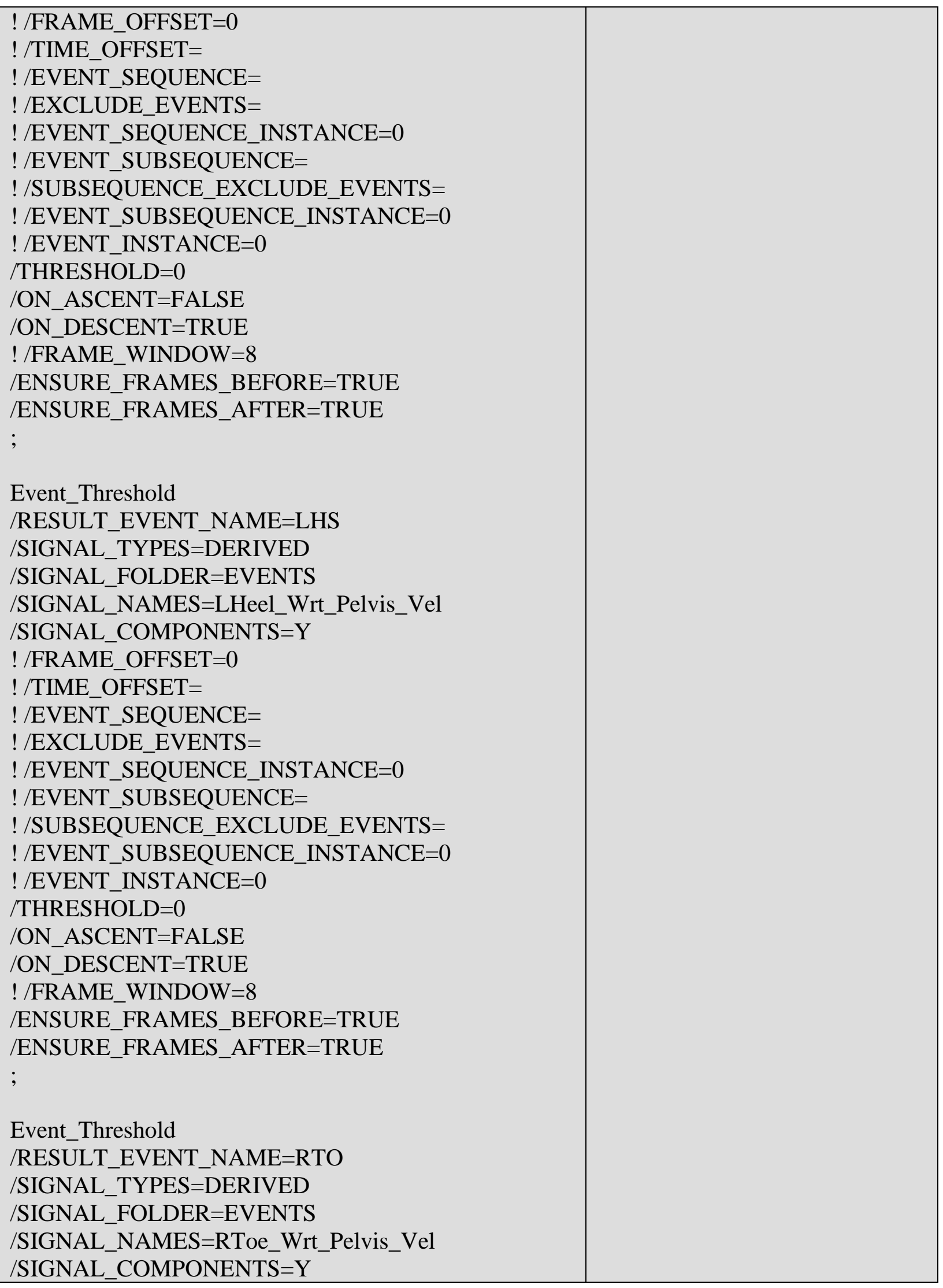




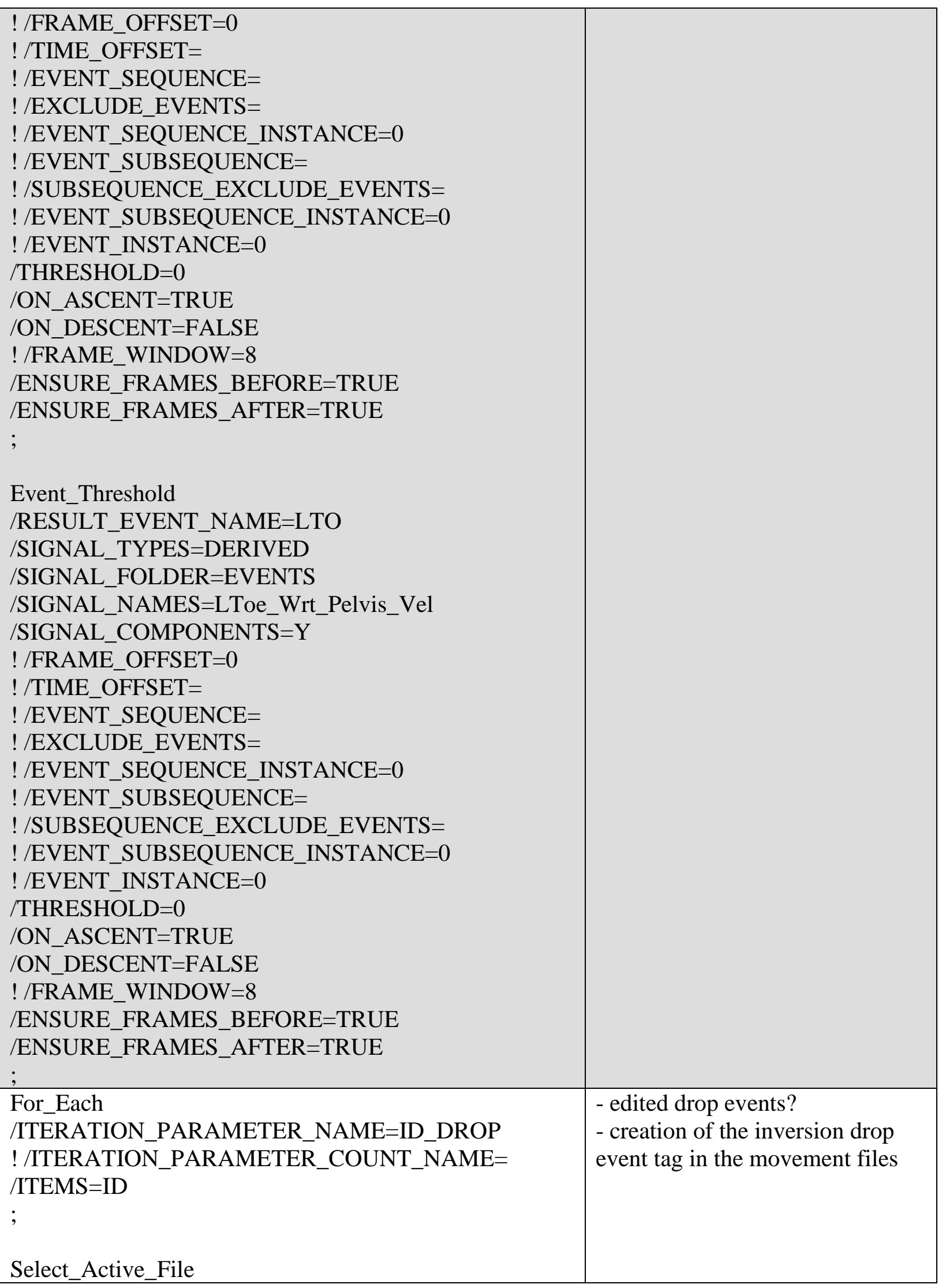




\begin{tabular}{|l|l|}
\hline /FILE_NAME=ID & \\
!/QUERY= & \\
$;$ & \\
Moving_RMS & \\
/SIGNAL_TYPES=ANALOG & \\
!/SIGNAL_FOLDER=ORIGINAL & \\
/SIGNAL_NAMES=ID Switch & \\
!/RESULT_TYPES= & \\
!/RESULT_FOLDERS=PROCESSED & \\
!/RESULT_NAME= & \\
/APPLY_AS_SUFFIX_TO_SIGNAL_NAME=FALSE & \\
/NUM_WINDOW_FRAMES=25 & \\
$;$ \\
Moving_RMS & \\
/SIGNAL_TYPES=ANALOG+ANALOG+ANALOG+A & \\
NALOG+ANALOG+ANALOG+ANALOG & \\
/SIGNAL_FOLDER=PROCESSED+PROCESSED+PRO & \\
CESSED+PROCESSED+PROCESSED+PROCESSED+ & \\
PROCESSED & \\
/SIGNAL_NAMES=Contralateral Gluteus & \\
Medius+Contralateral Oblique+Ipsilateral Gluteus & \\
Medius+Ipsilateral Oblique+Peroneus & \\
Longus+Soleus+Tibialis Anterior & \\
!/RESULT_TYPES= \\
!/RESULT_FOLDERS=PROCESSED \\
!/RESULT_NAME= \\
/APPLY_AS_SUFFIX_TO_SIGNAL_NAME=FALSE \\
/NUM_WINDOW_FRAMES=25 \\
; \\
Event_Explicit & \\
/EVENT_NAME=Rest1 \\
/FRAME=1 \\
!/TIME= \\
; \\
Event_Explicit \\
/EVENT_NAME=Rest2 \\
/FRAME=50 \\
!/TIME= \\
; \\
Metric_Maximum \\
!/RESULT_METRIC_FOLDER=PROCESSED & \\
\hline
\end{tabular}




\begin{tabular}{l}
\hline /RESULT_METRIC_NAME=_MAX \\
/APPLY_AS_SUFFIX_TO_SIGNAL_NAME=TRUE \\
/SIGNAL_TYPES=ANALOG \\
/SIGNAL_FOLDER=PROCESSED \\
/SIGNAL_NAMES=ID Switch \\
/COMPONENT_SEQUENCE=ALL \\
/EVENT_SEQUENCE=Rest1+Rest2 \\
/EXCLUDE_EVENTS= \\
/SEQUENCE_PERCENT_START $=$ \\
/SEQUENCE_PERCENT_END= \\
/GENERATE_MEAN_AND_STDDEV=FALSE \\
!/APPEND_TO_EXISTING_VALUES=FALSE \\
; \\
Metric_StdDev \\
!/RESULT_METRIC_FOLDER=PROCESSED \\
/RESULT_METRIC_NAME=_SD \\
/APPLY_AS_SUFFIX_TO_SIGNAL_NAME=TRUE \\
/SIGNAL_TYPES=ANALOG \\
/SIGNAL_FOLDER=PROCESSED \\
/SIGNAL_NAMES=ID Switch \\
/COMPONENT_SEQUENCE=ALL \\
/EVENT_SEQUENCE=Rest1+Rest2 \\
/EXCLUDE_EVENTS= \\
/SEQUENCE_PERCENT_START= \\
/SEQUENCE_PERCENT_END= \\
/GENERATE_MEAN_AND_STDDEV=FALSE \\
!/APPEND_TO_EXISTING_VALUES=FALSE \\
; \\
Event_Threshold \\
/RESULT_EVENT_NAME=ID_Drop \\
/SIGNAL_TYPES=ANALOG \\
/SIGNAL_FOLDER=PROCESSED \\
/SIGNAL_NAMES=ID Switch \\
/SIGNAL_COMPONENTS=ALL \\
!/FRAME_OFFSET=0 \\
!/TIME_OFFSET= \\
!/EVENT_SEQUENCE= \\
!/EXCLUDE_EVENTS= \\
!/EVENT_SEQUENCE_INSTANCE=0 \\
!/EVENT_SUBSEQUENCE= \\
!/SUBSEQUENCE_EXCLUDE_EVENTS= \\
!/EVENT_SUBSEQUENCE_INSTANCE=0 \\
!/EVENT_INSTANCE=0 \\
\end{tabular}




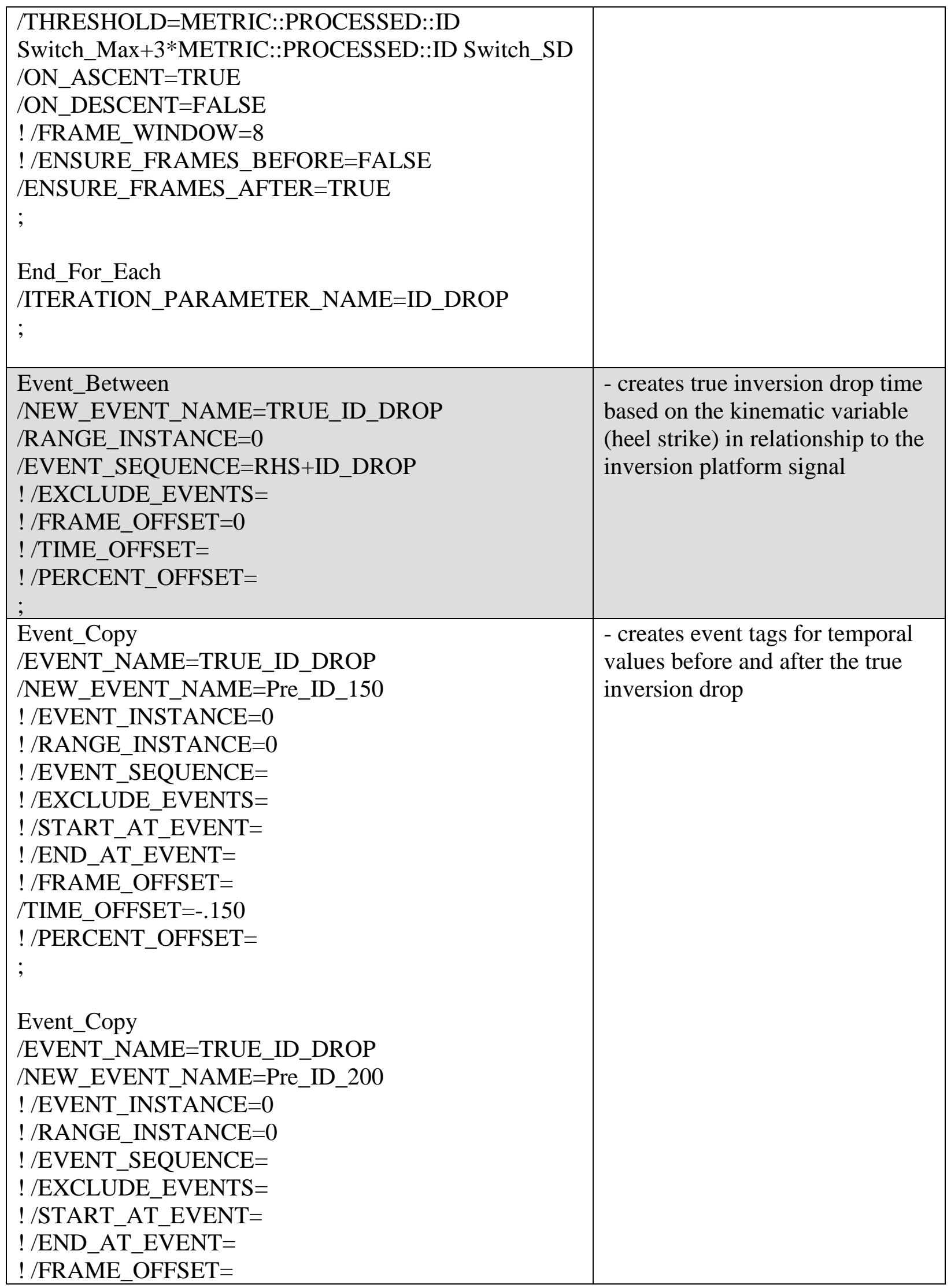




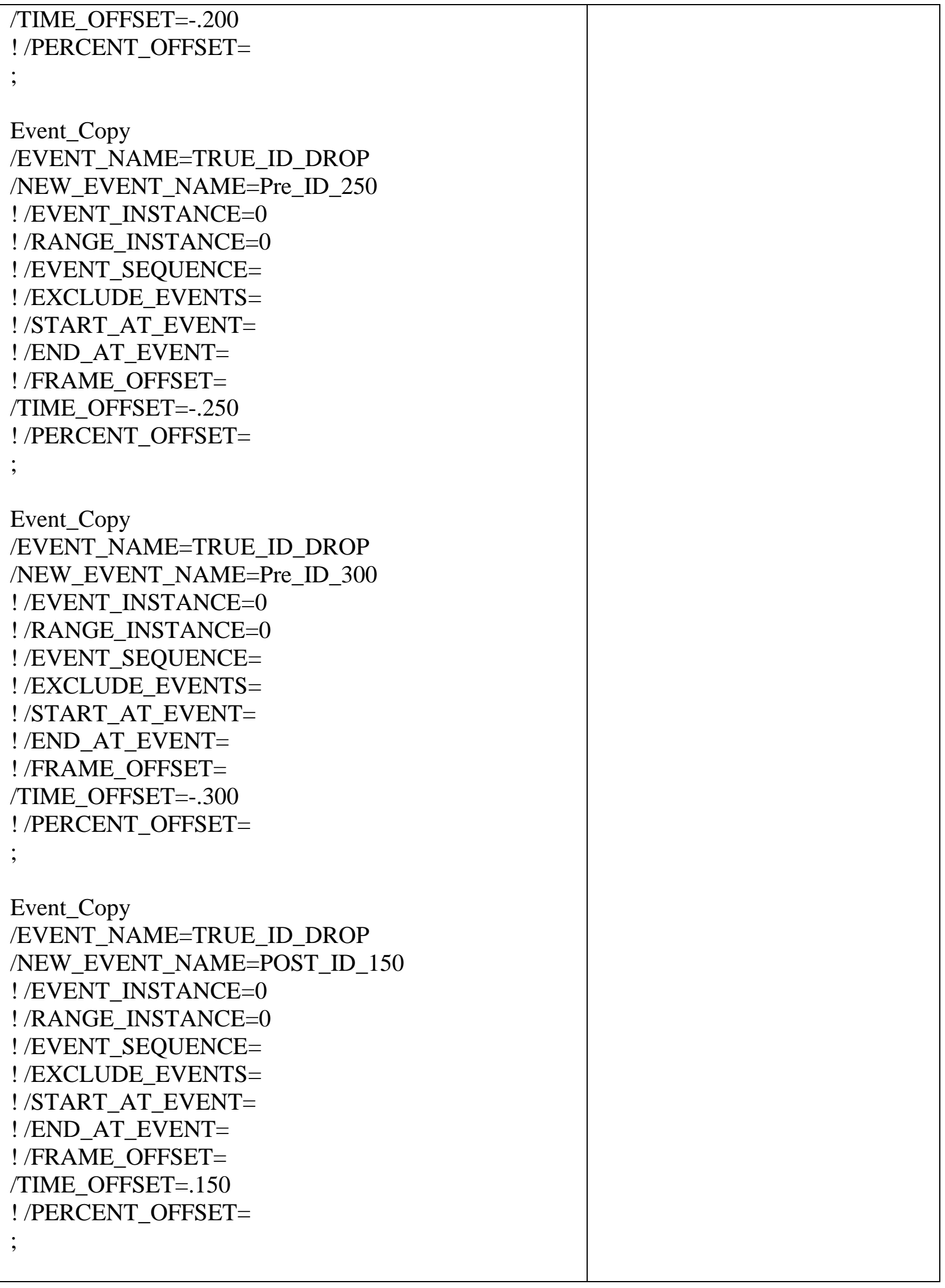




\begin{tabular}{|c|c|}
\hline 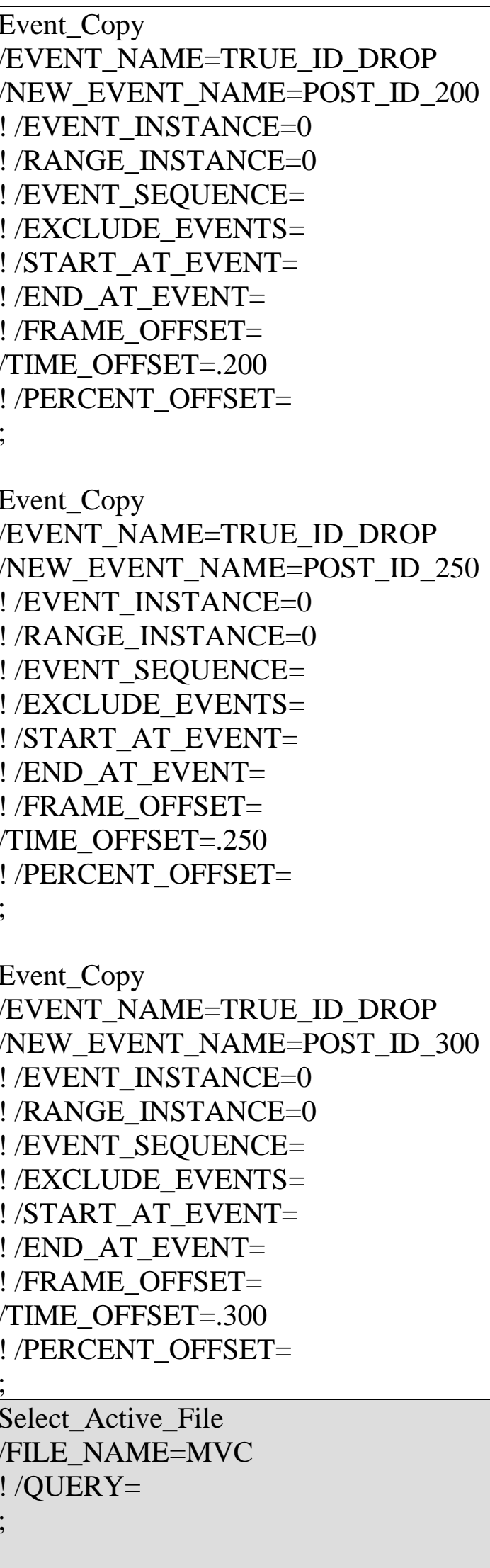 & $\begin{array}{l}\text { - finds the peak of each burst of } \\
\text { muscle reactivity for all MVC } \\
\text { files } \\
\text { - calculates means of each MVC } \\
\text { trial }\end{array}$ \\
\hline
\end{tabular}




\begin{tabular}{|c|c|}
\hline $\begin{array}{l}\text { Moving_RMS } \\
\text { /SIGNAL_TYPES=ANALOG } \\
\text { /SIGNAL_FOLDER=PROCESSED } \\
\text { ! /SIGNAL_NAMES= } \\
\text { ! /RESULT_TYPES= } \\
\text { ! /RESULT_FOLDERS=PROCESSED } \\
\text { /RESULT_NAME=_RMS } \\
\text { /APPLY_AS_SUFFIX_TO_SIGNAL_NAME=TRUE } \\
\text { /NUM_WINDOW_FRAMES=25 } \\
; \\
\text { For_Each } \\
\text { /ITERATION_PARAMETER_NAME=MVC_Frames } \\
\text { !/ITERATION_PARAMETER_COUNT_NAME= } \\
\text { /ITEMS=MVC } \\
; \\
\text { Select_Active_File } \\
\text { /FILE_NAME=MVC } \\
\text { ! /QUERY= } \\
\text {; } \\
\text { Metric_Maximum } \\
\text { ! /RESULT_METRIC_FOLDER=PROCESSED } \\
\text { /RESULT_METRIC_NAME=Total_Frames } \\
\text { ! /APPLY_AS_SUFFIX_TO_SIGNAL_NAME=FALSE } \\
\text { /SIGNAL_TYPES=FRAME_NUMBERS } \\
\text { ! /SIGNAL_FOLDER=ORIGINAL } \\
\text { /SIGNAL_NAMES=FRAMES } \\
\text { /COMPONENT_SEQUENCE=ALL } \\
\text { /EVENT_SEQUENCE= } \\
\text { /EXCLUDE_EVENTS= } \\
\text { /SEQUENCE_PERCENT_START= } \\
\text { /SEQUENCE_PERCENT_END= } \\
\text { /GENERATE_MEAN_AND_STDDEV=FALSE } \\
\text { ! /APPEND_TO_EXISTING_VALUES=FALSE } \\
\text { ! /CREATE_GLOBAL_MAXIMUM=FALSE } \\
\text {; } \\
\text { Event_Explicit } \\
\text { /EVENT_NAME=Beginning } \\
\text { /FRAME=1 } \\
\text { ! /TIME= } \\
; \\
\text { Event_Explicit }\end{array}$ & $\begin{array}{l}\text {-signal names varied based on } \\
\text { subject number }\end{array}$ \\
\hline
\end{tabular}




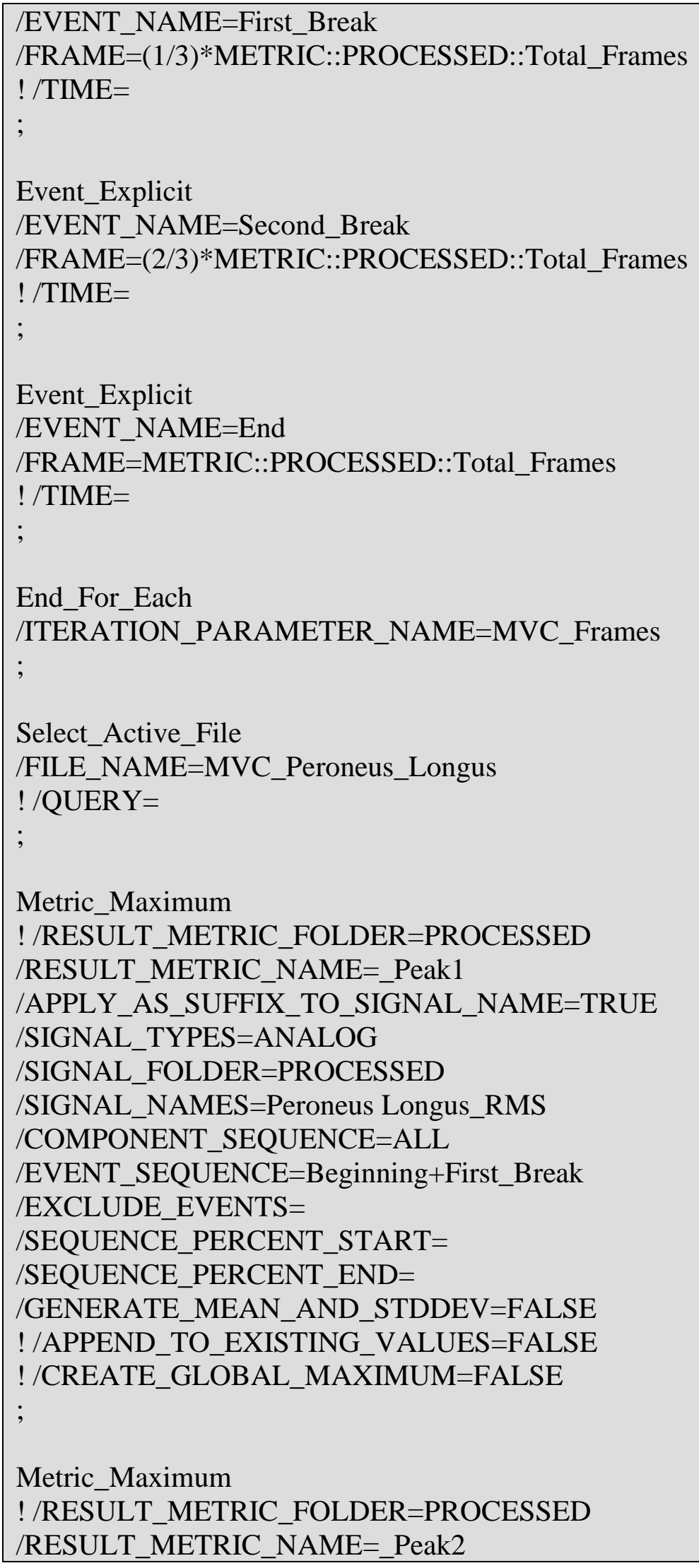




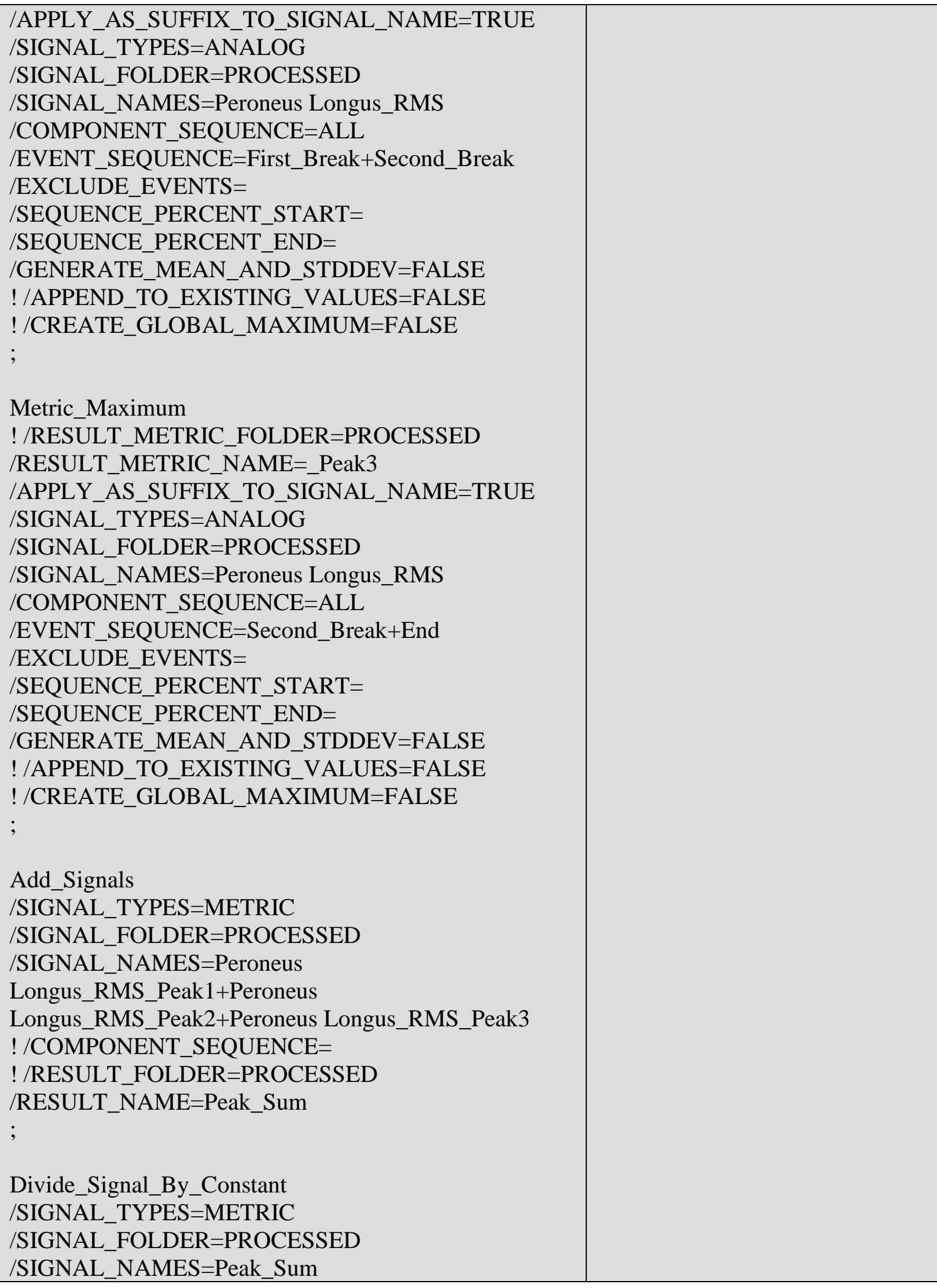




\begin{tabular}{|l|l|}
\hline$!$ /SIGNAL_COMPONENTS= & \\
!/RESULT_TYPES= \\
!/RESULT_FOLDERS=PROCESSED \\
/RESULT_NAME=_MVC \\
/APPLY_AS_SUFFIX_TO_SIGNAL_NAME=TRUE \\
/CONSTANT=3 \\
$;$ \\
Select_Active_File \\
/FILE_NAME=MVC_Cont_Oblique \\
!/QUERY= \\
; \\
Metric_Maximum \\
!/RESULT_METRIC_FOLDER=PROCESSED \\
/RESULT_METRIC_NAME=_Peak1 \\
/APPLY_AS_SUFFIX_TO_SIGNAL_NAME=TRUE \\
/SIGNAL_TYPES=ANALOG \\
/SIGNAL_FOLDER=PROCESSED \\
/SIGNAL_NAMES=Contralateral Oblique_RMS \\
/COMPONENT_SEQUENCE=ALL \\
/EVENT_SEQUENCE=Beginning+First_Break \\
/EXCLUDE_EVENTS= \\
/SEQUENCE_PERCENT_START = \\
/SEQUENCE_PERCENT_END= \\
/GENERATE_MEAN_AND_STDDEV=FALSE \\
!/APPEND_TO_EXISTING_VALUES=FALSE \\
!/CREATE_GLOBAL_MAXIMUM=FALSE \\
; \\
Metric_Maximum \\
!/RESULT_METRIC_FOLDER=PROCESSED \\
/RESULT_METRIC_NAME=_Peak2 \\
/APPLY_AS_SUFFIX_TO_SIGNAL_NAME=TRUE \\
/SIGNAL_TYPES=ANALOG \\
/SIGNAL_FOLDER=PROCESSED \\
/SIGNAL_NAMES=COntralateral Oblique_RMS \\
/COMPONENT_SEQUENCE=ALL \\
/EVENT_SEQUENCE=First_Break+Second_Break \\
/EXCLUDE_EVENTS= \\
/SEQUENCE_PERCENT_START= \\
/SEQUENCE_PERCENT_END= \\
/GENERATE_MEAN_AND_STDDEV=FALSE \\
!/APPEND_TO_EXISTING_VALUES=FALSE \\
!/CREATE_GLOBAL_MAXIMUM=FALSE \\
; \\
\hline
\end{tabular}




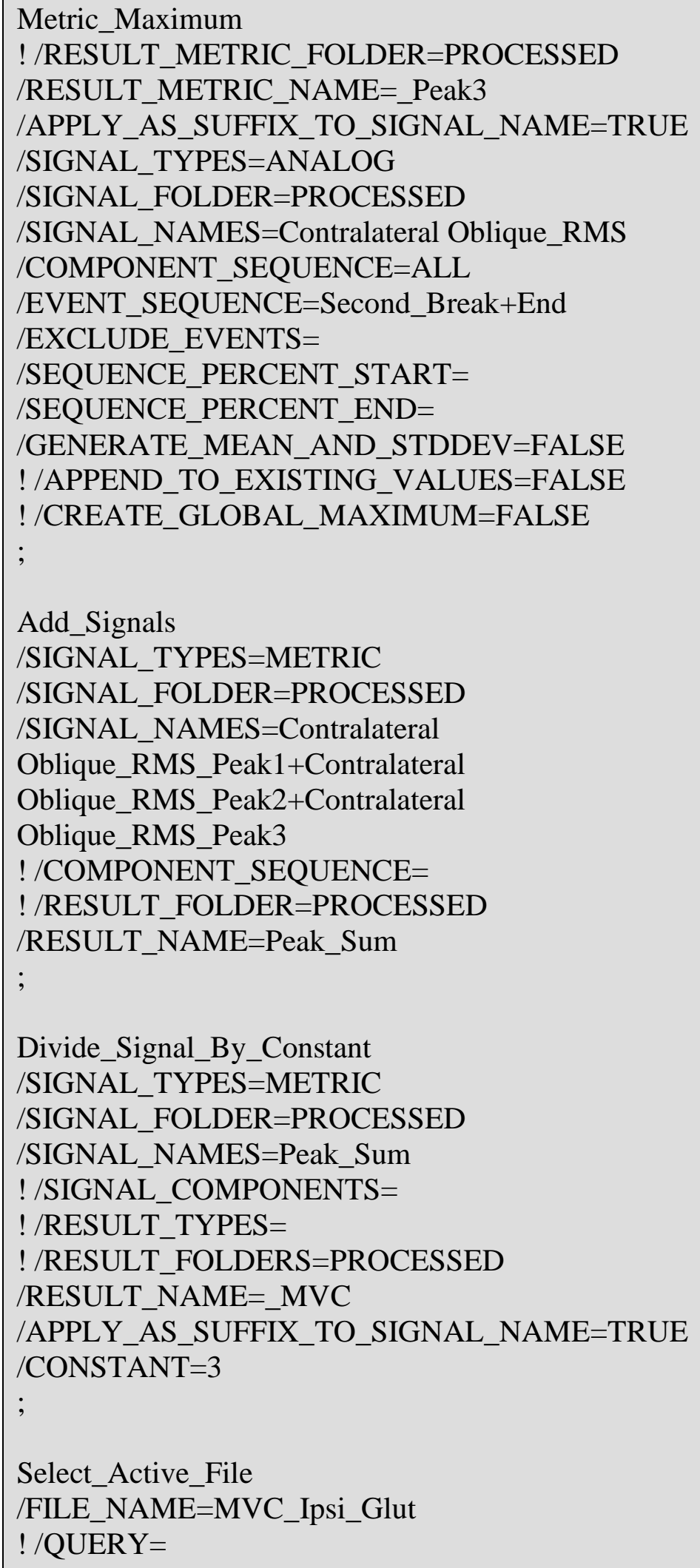




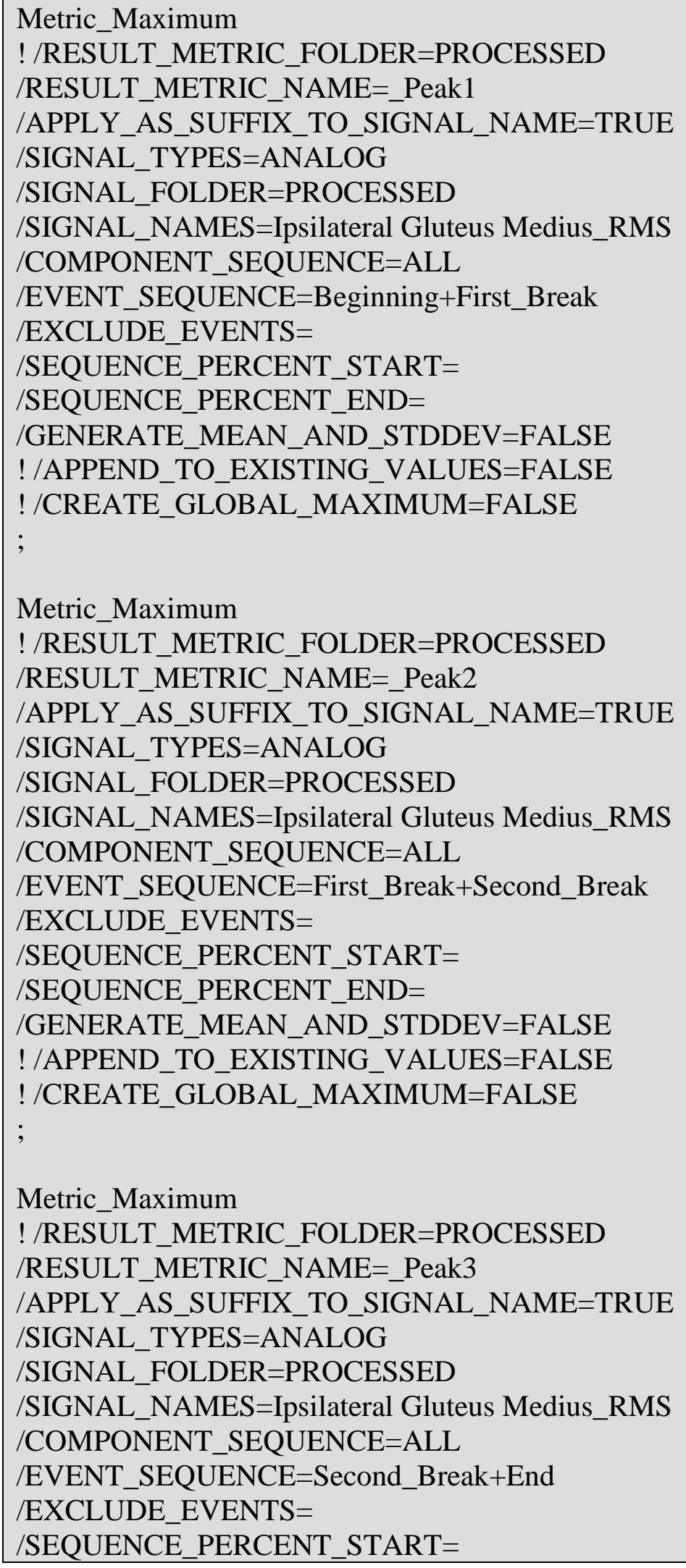




\begin{tabular}{|l|l|}
\hline /SEQUENCE_PERCENT_END= & \\
/GENERATE_MEAN_AND_STDDEV=FALSE & \\
!/APPEND_TO_EXISTING_VALUES=FALSE & \\
!/CREATE_GLOBAL_MAXIMUM=FALSE & \\
$;$ & \\
Add_Signals & \\
/SIGNAL_TYPES=METRIC & \\
/SIGNAL_FOLDER=PROCESSED & \\
/SIGNAL_NAMES=Ipsilateral Gluteus & \\
Medius_RMS_Peak1+Ipsilateral Gluteus & \\
Medius_RMS_Peak2+IPsilateral Gluteus & \\
Medius_RMS_Peak3 & \\
!/COMPONENT_SEQUENCE= & \\
!/RESULT_FOLDER=PROCESSED & \\
/RESULT_NAME=Peak_Sum & \\
; & \\
Divide_Signal_By_Constant & \\
/SIGNAL_TYPES=METRIC & \\
/SIGNAL_FOLDER=PROCESSED & \\
/SIGNAL_NAMES=Peak_Sum & \\
!/SIGNAL_COMPONENTS= & \\
!/RESULT_TYPES= \\
!/RESULT_FOLDERS=PROCESSED \\
/RESULT_NAME=_MVC \\
/APPLY_AS_SUFFIX_TO_SIGNAL_NAME=TRUE \\
/CONSTANT=3 \\
; \\
Select_Active_File \\
/FILE_NAME=MVC_Soleus \\
!/QUERY= \\
; \\
Metric_Maximum & \\
!/RESULT_METRIC_FOLDER=PROCESSED & \\
/RESULT_METRIC_NAME=_Peak1 & \\
/APPLY_AS_SUFFIX_TO_SIGNAL_NAME=TRUE & \\
/SIGNAL_TYPES=ANALOG \\
/SIGNAL_FOLDER=PROCESSED \\
/SIGNAL_NAMES=Soleus_RMS \\
/COMPONENT_SEQUENCE=ALL \\
/EVENT_SEQUENCE=Beginning+First_Break \\
/EXCLUDE_EVENTS= \\
/SEQUENCE_PERCENT_START= & \\
\hline
\end{tabular}




\begin{tabular}{|l|l|}
\hline /SEQUENCE_PERCENT_END= & \\
/GENERATE_MEAN_AND_STDDEV=FALSE & \\
!/APPEND_TO_EXISTING_VALUES=FALSE \\
!/CREATE_GLOBAL_MAXIMUM=FALSE \\
$;$ \\
Metric_Maximum \\
!/RESULT_METRIC_FOLDER=PROCESSED \\
/RESULT_METRIC_NAME=_Peak2 \\
/APPLY_AS_SUFFIX_TO_SIGNAL_NAME=TRUE & \\
/SIGNAL_TYPES=ANALOG & \\
/SIGNAL_FOLDER=PROCESSED & \\
/SIGNAL_NAMES=Soleus_RMS \\
/COMPONENT_SEQUENCE=ALL \\
/EVENT_SEQUENCE=First_Break+Second_Break \\
/EXCLUDE_EVENTS= \\
/SEQUENCE_PERCENT_START= \\
/SEQUENCE_PERCENT_END= \\
/GENERATE_MEAN_AND_STDDEV=FALSE \\
!/APPEND_TO_EXISTING_VALUES=FALSE \\
!/CREATE_GLOBAL_MAXIMUM=FALSE \\
; \\
Metric_Maximum \\
!/RESULT_METRIC_FOLDER=PROCESSED \\
/RESULT_METRIC_NAME=_Peak3 \\
/APPLY_AS_SUFFIX_TO_SIGNAL_NAME=TRUE \\
/SIGNAL_TYPES=ANALOG \\
/SIGNAL_FOLDER=PROCESSED \\
/SIGNAL_NAMES=SOleus_RMS \\
/COMPONENT_SEQUENCE=ALL \\
/EVENT_SEQUENCE=Second_Break+End \\
/EXCLUDE_EVENTS= \\
/SEQUENCE_PERCENT_START $=$ \\
/SEQUENCE_PERCENT_END= \\
/GENERATE_MEAN_AND_STDDEV=FALSE \\
!/APPEND_TO_EXISTING_VALUES=FALSE \\
!/CREATE_GLOBAL_MAXIMUM=FALSE \\
; \\
Add_SSignals \\
/SIGNAL_TYPES=METRIC \\
/SIGNAL_FOLDER=PROCESSED \\
/SIGNAL_NAMES=SOleus_RMS_Peak1+Soleus_RMS_ \\
Peak2+Soleus_RMS_Peak3 \\
!/COMPONENT_SEQUENCE= \\
\hline
\end{tabular}




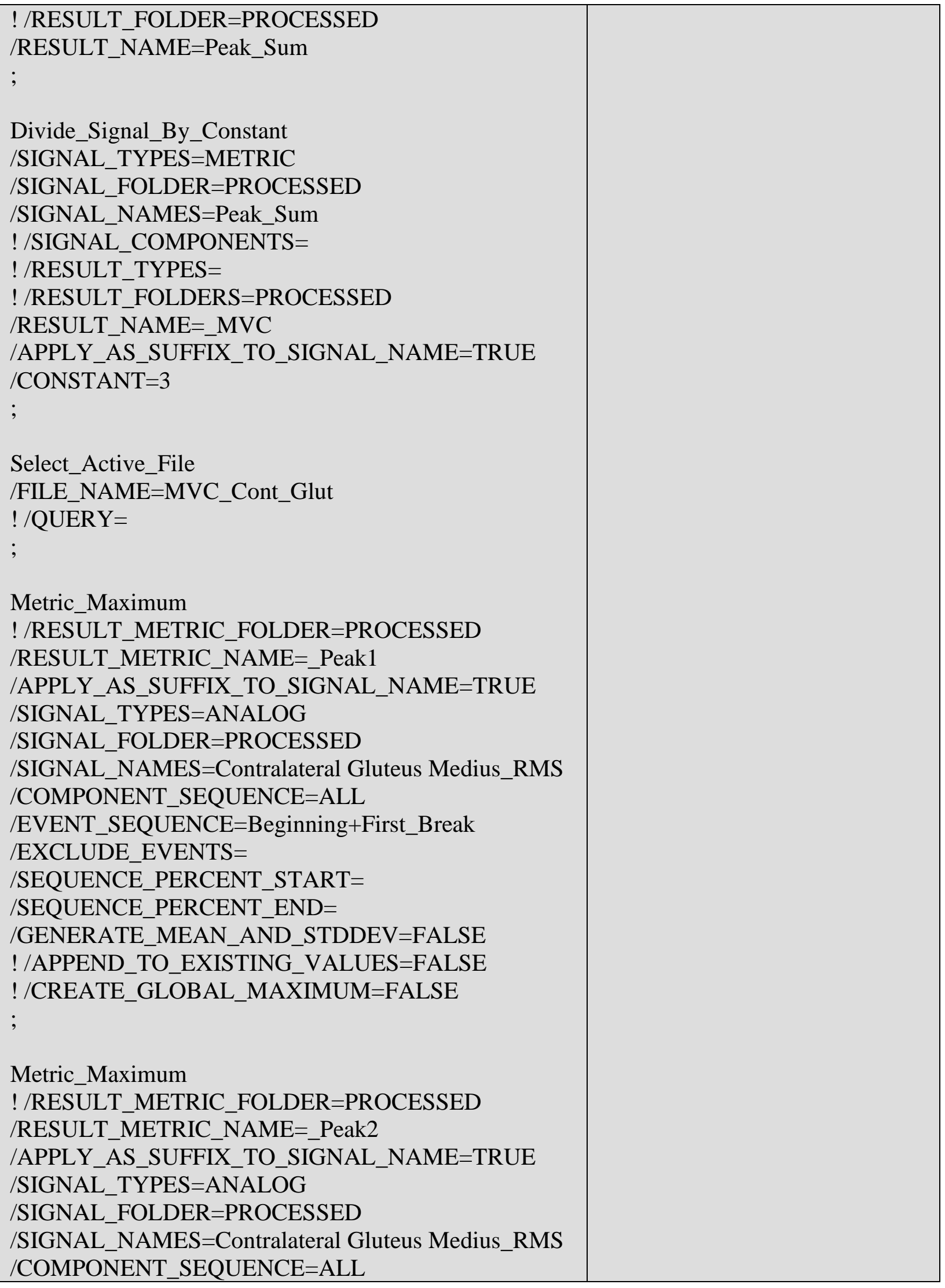




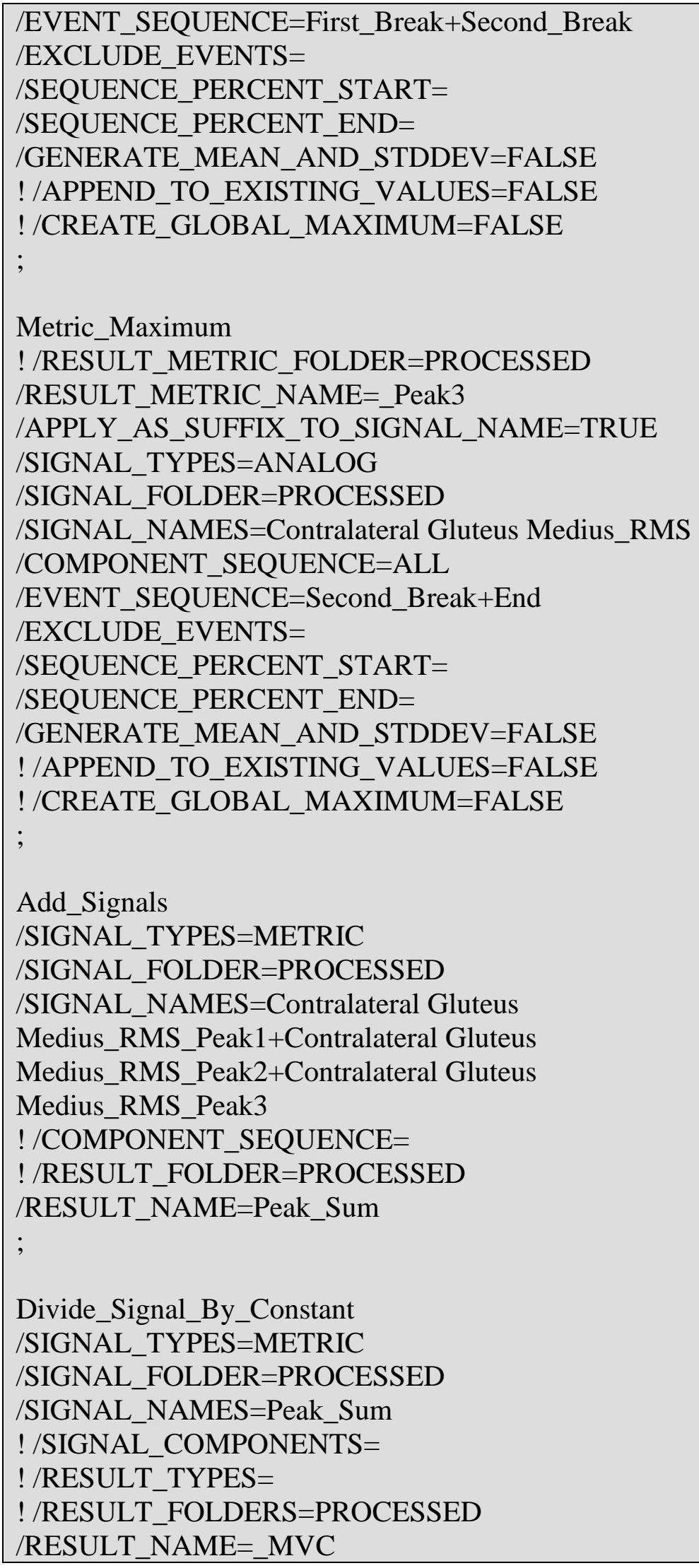




\begin{tabular}{|l|l|}
\hline /APPLY_AS_SUFFIX_TO_SIGNAL_NAME=TRUE & \\
/CONSTANT=3 & \\
$;$ \\
Select_Active_File \\
/FILE_NAME=MVC_Ipsi_Oblique \\
!/QUERY= \\
$;$ \\
Metric_Maximum & \\
!/RESULT_METRIC_FOLDER=PROCESSED & \\
/RESULT_METRIC_NAME=_Peak1 \\
/APPLY_AS_SUFFIX_TO_SIGNAL_NAME=TRUE \\
/SIGNAL_TYPES=ANALOG \\
/SIGNAL_FOLDER=PROCESSED \\
/SIGNAL_NAMES=Ipsilateral Oblique_RMS \\
/COMPONENT_SEQUENCE=ALL \\
/EVENT_SEQUENCE=Beginning+First_Break \\
/EXCLUDE_EVENTS= \\
/SEQUENCE_PERCENT_START $=$ \\
/SEQUENCE_PERCENT_END= \\
/GENERATE_MEAN_AND_STDDEV=FALSE \\
!/APPEND_TO_EXISTING_VALUES=FALSE \\
!/CREATE_GLOBAL_MAXIMUM=FALSE \\
; \\
Metric_Maximum \\
!/RESULT_METRIC_FOLDER=PROCESSED \\
/RESULT_METRIC_NAME=_Peak2 \\
/APPLY_AS_SUFFIX_TO_SIGNAL_NAME=TRUE \\
/SIGNAL_TYPES=ANALOG \\
/SIGNAL_FOLDER=PROCESSED \\
/SIGNAL_NAMES=Ipsilateral Oblique_RMS \\
/COMPONENT_SEQUENCE=ALL \\
/EVENT_SEQUENCE=First_Break+Second_Break \\
/EXCLUDE_EVENTS= \\
/SEQUENCE_PERCENT_START= \\
/SEQUENCE_PERCENT_END= \\
/GENERATE_MEAN_AND_STDDEV=FALSE \\
!/APPEND_TO_EXISTING_VALUES=FALSE \\
!/CREATE_GLOBAL_MAXIMUM=FALSE \\
; \\
Metric_Maximum \\
!/RESULT_METRIC_FOLDER=PROCESSED \\
/RESULT_METRIC_NAME=_Peak3 \\
\hline
\end{tabular}




\begin{tabular}{l|l|l}
\hline /APPLY_AS_SUFFIX_TO_SIGNAL_NAME=TRUE & \\
/SIGNAL_TYPES=ANALOG & \\
/SIGNAL_FOLDER=PROCESSED & \\
/SIGNAL_NAMES=Ipsilateral Oblique_RMS & \\
/COMPONENT_SEQUENCE=ALL & \\
/EVENT_SEQUENCE=Second_Break+End & \\
/EXCLUDE_EVENTS= & \\
/SEQUENCE_PERCENT_START= & \\
/SEQUENCE_PERCENT_END= & \\
/GENERATE_MEAN_AND_STDDEV=FALSE & \\
!/APPEND_TO_EXISTING_VALUES=FALSE & \\
!/CREATE_GLOBAL_MAXIMUM=FALSE & \\
; \\
Add_Signals & \\
/SIGNAL_TYPES=METRIC & \\
/SIGNAL_FOLDER=PROCESSED & \\
/SIGNAL_NAMES=Ipsilateral & \\
Oblique_RMS_Peak1+Ipsilateral & \\
Oblique_RMS_Peak2+Ipsilateral Oblique_RMS_Peak3 & \\
!/COMPONENT_SEQUENCE= \\
!/RESULT_FOLDER=PROCESSED \\
/RESULT_NAME=Peak_SUm \\
; \\
Divide_Signal_By_Constant & \\
/SIGNAL_TYPES=METRIC \\
/SIGNAL_FOLDER=PROCESSED \\
/SIGNAL_NAMES=Peak_Sum \\
!/SIGNAL_COMPONENTS= \\
!/RESULT_TYPES= \\
!/RESULT_FOLDERS=PROCESSED \\
/RESULT_NAME=_MVC \\
/APPLY_AS_SUFFIX_TO_SIGNAL_NAME=TRUE \\
/CONSTANT=3 \\
; \\
Select_Active_File & \\
/FILE_NAME=MVC_Tib_Anterior & \\
!/QUERY= \\
; \\
Metric_Maximum \\
!/RESULT_METRIC_FOLDER=PROCESSED \\
/RESULT_METRIC_NAME=_Peak1 \\
/APPLY_AS_SUFFIX_TO_SIGNAL_NAME=TRUE & \\
\hline
\end{tabular}




\begin{tabular}{l|l|}
\hline /SIGNAL_TYPES=ANALOG & \\
/SIGNAL_FOLDER=PROCESSED \\
/SIGNAL_NAMES=Tibialis Anterior_RMS \\
/COMPONENT_SEQUENCE=ALL \\
/EVENT_SEQUENCE=Beginning+First_Break \\
/EXCLUDE_EVENTS= \\
/SEQUENCE_PERCENT_START= \\
/SEQUENCE_PERCENT_END= \\
/GENERATE_MEAN_AND_STDDEV=FALSE \\
!/APPEND_TO_EXISTING_VALUES=FALSE \\
!/CREATE_GLOBAL_MAXIMUM=FALSE \\
; \\
Metric_Maximum \\
!/RESULT_METRIC_FOLDER=PROCESSED \\
/RESULT_METRIC_NAME=_Peak2 \\
/APPLY_AS_SUFFIX_TO_SIGNAL_NAME=TRUE \\
/SIGNAL_TYPES=ANALOG \\
/SIGNAL_FOLDER=PROCESSED \\
/SIGNAL_NAMES=Tibialis Anterior_RMS \\
/COMPONENT_SEQUENCE=ALL \\
/EVENT_SEQUENCE=First_Break+Second_Break \\
/EXCLUDE_EVENTS= \\
/SEQUENCE_PERCENT_START= \\
/SEQUENCE_PERCENT_END= \\
/GENERATE_MEAN_AND_STDDEV=FALSE \\
!/APPEND_TO_EXISTING_VALUES=FALSE \\
!/CREATE_GLOBAL_MAXIMUM=FALSE \\
; \\
Metric_Maximum \\
!/RESULT_METRIC_FOLDER=PROCESSED \\
/RESULT_METRIC_NAME=_Peak3 \\
/APPLY_AS_SUFFIX_TO_SIGNAL_NAME=TRUE \\
/SIGNAL_TYPES=ANALOG \\
/SIGNAL_FOLDER=PROCESSED \\
/SIGNAL_NAMES=Tibialis Anterior_RMS \\
/COMPONENT_SEQUENCE=ALL \\
/EVENT_SEQUENCE=Second_Break+End \\
/EXCLUDE_EVENTS= \\
/SEQUENCE_PERCENT_START= \\
/SEQUENCE_PERCENT_END= \\
/GENERATE_MEAN_AND_STDDEV=FALSE \\
!/APPEND_TO_EXISTING_VALUES=FALSE \\
!/CREATE_GLOBAL_MAXIMUM=FALSE \\
; \\
\hline
\end{tabular}


Add_Signals

/SIGNAL_TYPES=METRIC

/SIGNAL_FOLDER=PROCESSED

/SIGNAL_NAMES=Tibialis

Anterior_RMS_Peak1+Tibialis

Anterior_RMS_Peak2+Tibialis Anterior_RMS_Peak3

! /COMPONENT_SEQUENCE $=$

! /RESULT_FOLDER=PROCESSED

/RESULT_NAME=Peak_Sum

;

Divide_Signal_By_Constant

/SIGNAL_TYPES=METRIC

/SIGNAL_FOLDER=PROCESSED

/SIGNAL_NAMES=Peak_Sum

! /SIGNAL_COMPONENTS=

! /RESULT_TYPES=

! /RESULT_FOLDERS=PROCESSED

/RESULT_NAME=_MVC

/APPLY_AS_SUFFIX_TO_SIGNAL_NAME=TRUE $/ \mathrm{CONSTANT}=3$

;

For_Each

/ITERATION_PARAMETER_NAME=Movement_Files !/ITERATION_PARAMETER_COUNT_NAME= $/$ ITEMS=MOVEMENT

;

For_Each

! /ITERATION_PARAMETER_COUNT_NAME=

/ITEMS=MOVEMENT

;

Select_Active_File

/FILE_NAME=::Movement_Files

! /QUERY=

;

Compute_Model_Based_Data

/RESULT_NAME=L Ankle Angle

/FUNCTION=JOINT_ANGLE

$/$ SEGMENT $=$ LFT

/REFERENCE_SEGMENT $=$ LSK

/RESOLUTION_COORDINATE_SYSTEM=

- kinematics of the lower

extremity segments/joints

calculated 


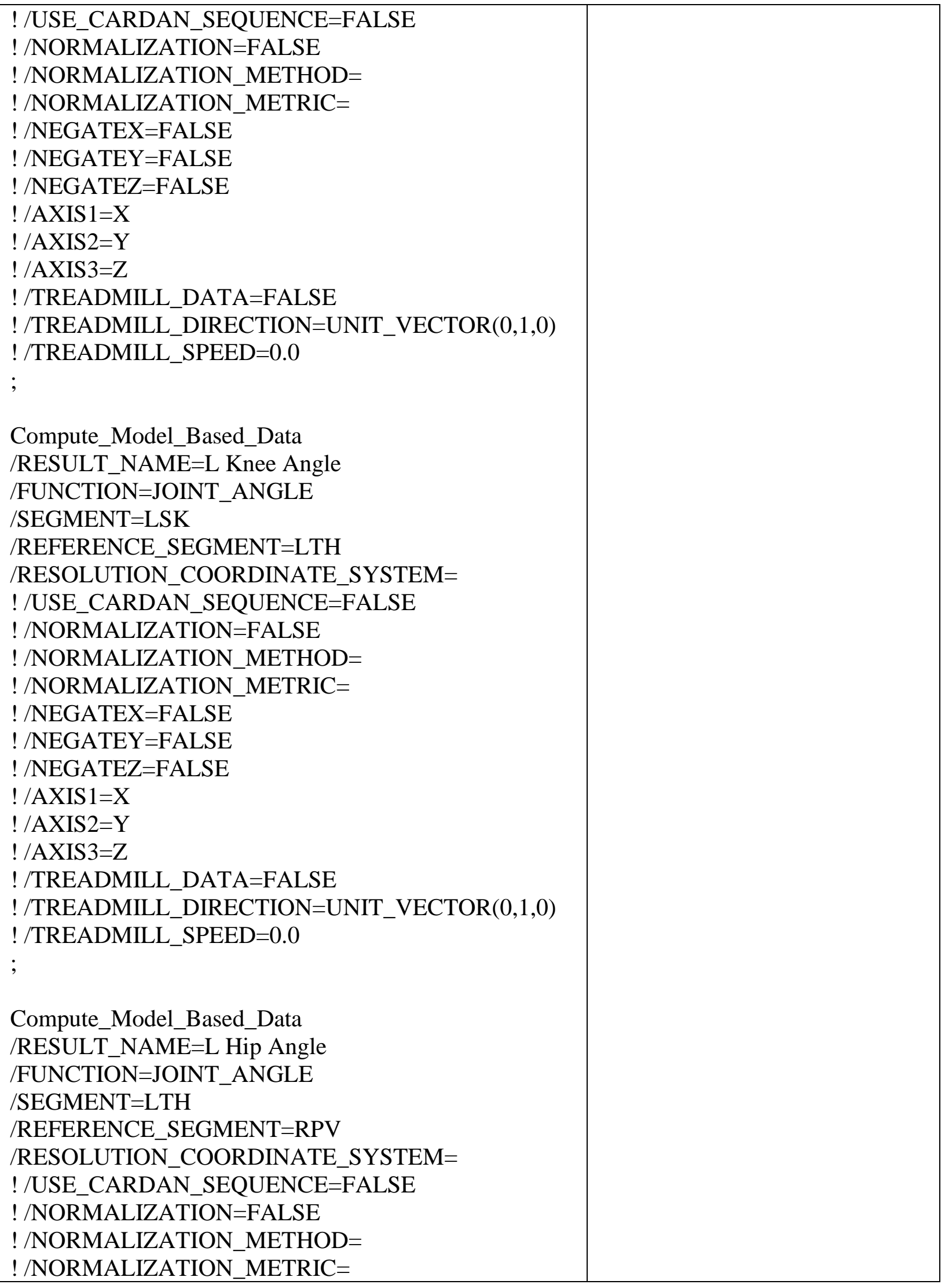




\begin{tabular}{|c|c|}
\hline $\begin{array}{l}\text {; } \\
\text { Compute_Model_Based_Data } \\
\text { /RESULT_NAME=R Ankle Angle } \\
\text { /FUNCTION=JOINT_ANGLE } \\
\text { /SEGMENT=RFT } \\
\text { /REFERENCE_SEGMENT=RSK } \\
\text { /RESOLUTION_COORDINATE_SYSTEM= } \\
\text { ! /USE_CARDAN_SEQUENCE=FALSE } \\
\text { ! /NORMALIZATION=FALSE } \\
\text { ! /NORMALIZATION_METHOD= } \\
\text { ! /NORMALIZATION_METRIC= } \\
\text { ! /NEGATEX=FALSE } \\
\text { ! /NEGATEY=FALSE } \\
\text { ! /NEGATEZ=FALSE } \\
\text { ! /AXIS1=X } \\
\text { ! /AXIS2=Y } \\
\text { ! /AXIS3=Z } \\
\text { ! /TREADMILL_DATA=FALSE } \\
\text { ! /TREADMILL_DIRECTION=UNIT_VECTOR }(0,1,0) \\
\text { ! /TREADMILL_SPEED=0.0 } \\
\text {; } \\
\text { Compute_Model_Based_Data } \\
\text { /RESULT_NAME=R Knee Angle } \\
\text { /SEGMENT=RSK _ANGLE } \\
\text { /REFERENCE_SEGMENT=RTH } \\
\text { /RESOLUTION_COORDINATE_SYSTEM= } \\
\text { ! /USE_CARDAN_SEQUENCE=FALSE } \\
\text { ! /NORMALIZATION=FALSE } \\
\text { ! /NORMALIZATION_METHOD= } \\
\text { ! /NORMALIZATION_METRIC= } \\
\text { ! /NEGATEX=FALSE } \\
\text { ! /NEGATEY=FALSE } \\
\text { ! /NEGATEZ=FALSE } \\
\text { ! /AXIS1=X }\end{array}$ & \\
\hline
\end{tabular}




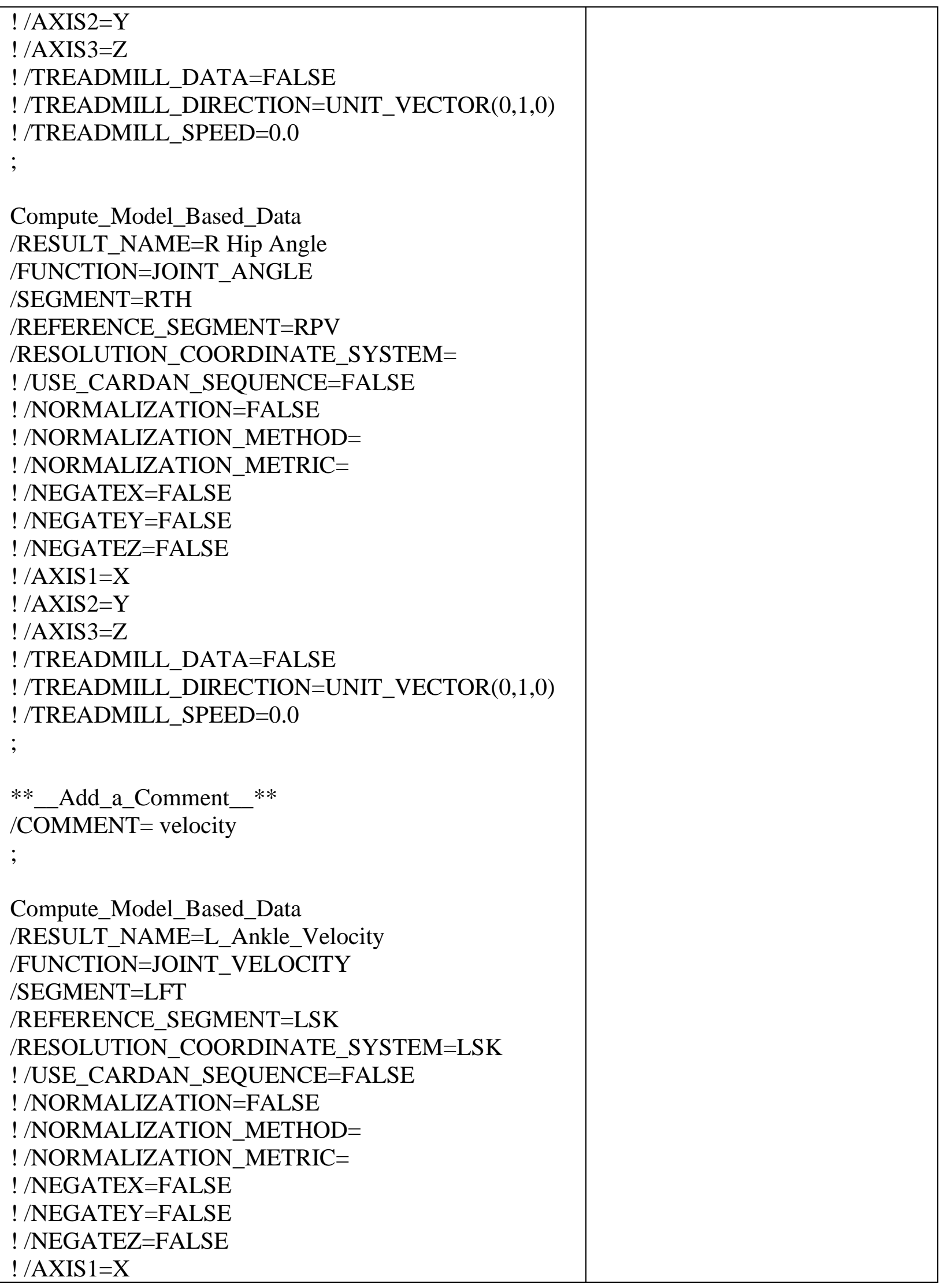




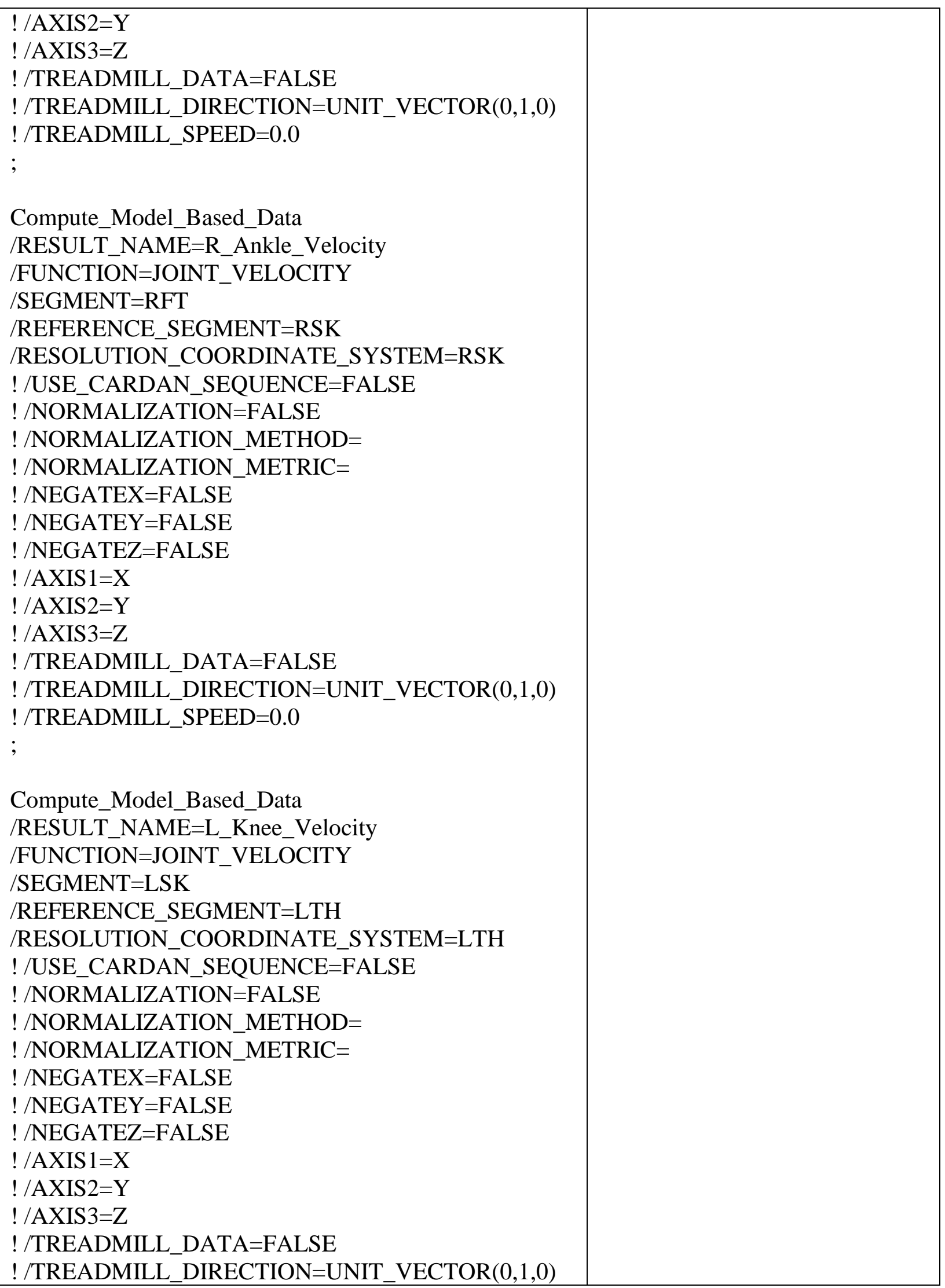




\begin{tabular}{|l|l|}
\hline !/TREADMILL_SPEED=0.0 & \\
$;$ & \\
Compute_Model_Based_Data & \\
/RESULT_NAME=R_Knee_Velocity & \\
/FUNCTION=JOINT_VELOCITY & \\
/SEGMENT=RSK & \\
/REFERENCE_SEGMENT=RTH & \\
/RESOLUTION_COORDINATE_SYSTEM=RTH & \\
!/USE_CARDAN_SEQUENCE=FALSE & \\
!/NORMALIZATION=FALSE & \\
!/NORMALIZATION_METHOD= \\
!/NORMALIZATION_METRIC= \\
!/NEGATEX=FALSE \\
!/NEGATEY=FALSE \\
!/NEGATEZ=FALSE \\
!/AXIS1=X \\
!/AXIS2=Y \\
!/AXIS3=Z \\
!/TREADMILL_DATA=FALSE \\
!/TREADMILL_DIRECTION=UNIT_VECTOR $(0,1,0)$ \\
!/TREADMILL_SPEED=0.0 \\
; \\
Compute_Model_Based_Data \\
/RESULT_NAME=L_Hip_Velocity \\
/FUNCTION=JOINT_VELOCITY \\
/SEGMENT=LTH \\
/REFERENCE_SEGMENT=RPV \\
/RESOLUTION_COORDINATE_SYSTEM=RPV \\
!/USE_CARDAN_SEQUENCE=FALSE \\
!/NORMALIZATION=FALSE \\
!/NORMALIZATION_METHOD= \\
!/NORMALIZATION_METRIC= \\
!/NEGATEX=FALSE \\
!/NEGATEY=FALSE \\
!/NEGATEZ=FALSE \\
!/AXIS1=X \\
!/AXIS2=Y \\
!/AXIS3=Z \\
!/TREADMILL_DATA=FALSE \\
!/TREADMILL_DIRECTION=UNIT_VECTOR $(0,1,0)$ \\
!/TREADMILL_SPEED=0.0 \\
$;$ \\
Compute_Model_Based_Data & \\
\hline
\end{tabular}




\begin{tabular}{|l|l|}
\hline /RESULT_NAME=R_Hip_Velocity & \\
/FUNCTION=JOINT_VELOCITY & \\
/SEGMENT=RTH & \\
/REFERENCE_SEGMENT=RPV & \\
/RESOLUTION_COORDINATE_SYSTEM=RPV & \\
!/USE_CARDAN_SEQUENCE=FALSE & \\
!/NORMALIZATION=FALSE & \\
!/NORMALIZATION_METHOD $=$ & \\
!/NORMALIZATION_METRIC $=$ & \\
!/NEGATEX=FALSE & \\
!/NEGATEY=FALSE & \\
!/NEGATEZ=FALSE & \\
!/AXIS1=X & \\
!/AXIS2=Y & \\
!/AXIS3=Z & \\
!/TREADMILL_DATA=FALSE & \\
!/TREADMILL_DIRECTION=UNIT_VECTOR $(0,1,0)$ & \\
!/TREADMILL_SPEED=0.0 & \\
; & \\
**_Add_a_Comment_** & \\
/COMMENT=Accel & \\
; & \\
Compute_Model_Based_Data & \\
/RESULT_NAME=L_Hip_Accel & \\
/FUNCTION=JOINT_ACCELERATION & \\
/SEGMENT=LTH & \\
/REFERENCE_SEGMENT=RPV & \\
/RESOLUTION_COORDINATE_SYSTEM=RPV & \\
!/USE_CARDAN_SEQUENCE=FALSE \\
!/NORMALIZATION=FALSE \\
!/NORMALIZATION_METHOD $=$ \\
!/NORMALIZATION_METRIC= \\
!/NEGATEX=FALSE \\
!/NEGATEY=FALSE \\
!/NEGATEZ=FALSE & \\
!/AXIS1=X & \\
!/AXIS2=Y \\
!/AXIS3=Z \\
!/TREADMILL_DATA=FALSE \\
!/TREADMILL_DIRECTION=UNIT_VECTOR $(0,1,0)$ \\
!/TREADMILL_SPEED=0.0 \\
; \\
\hline
\end{tabular}




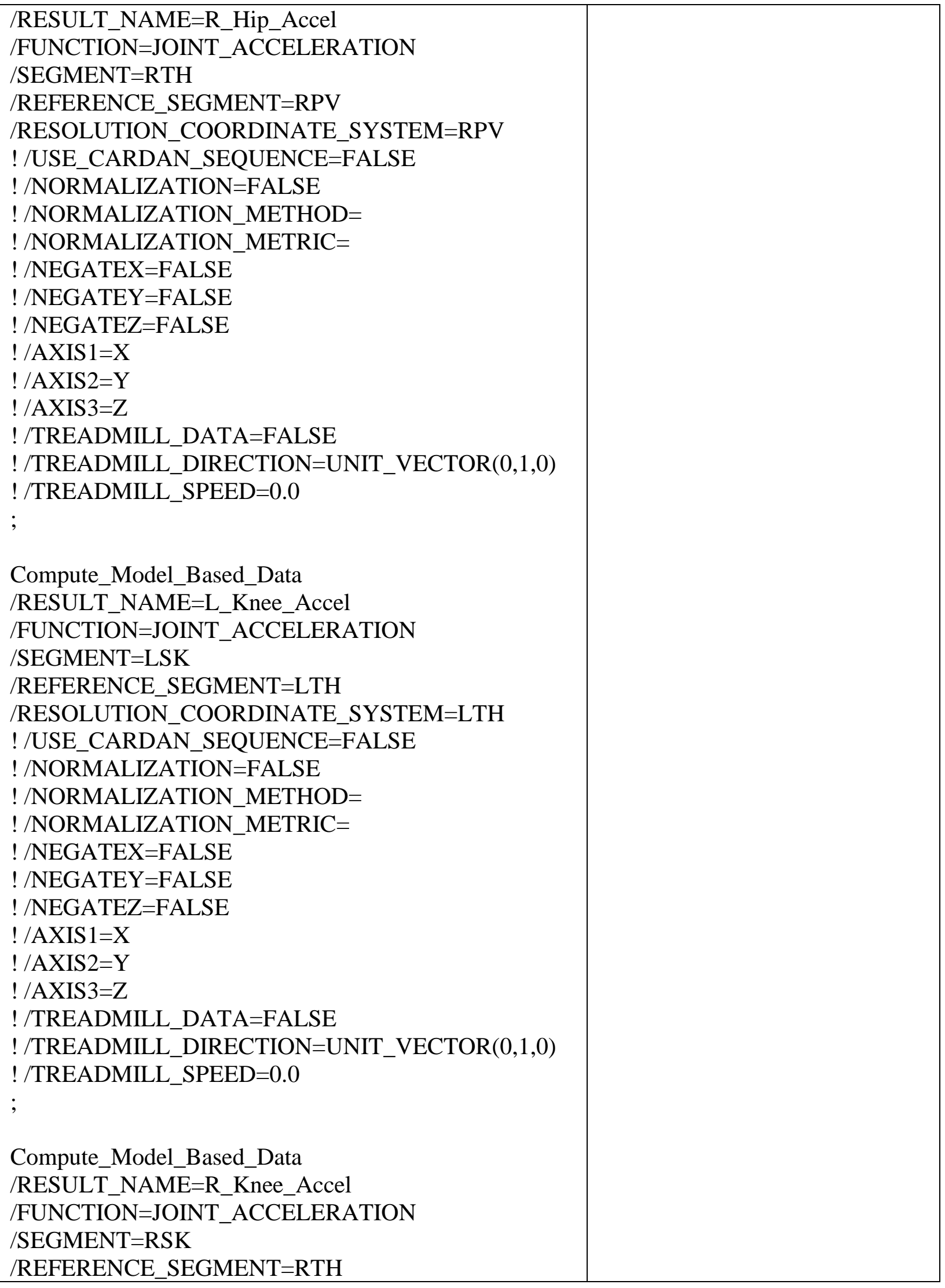




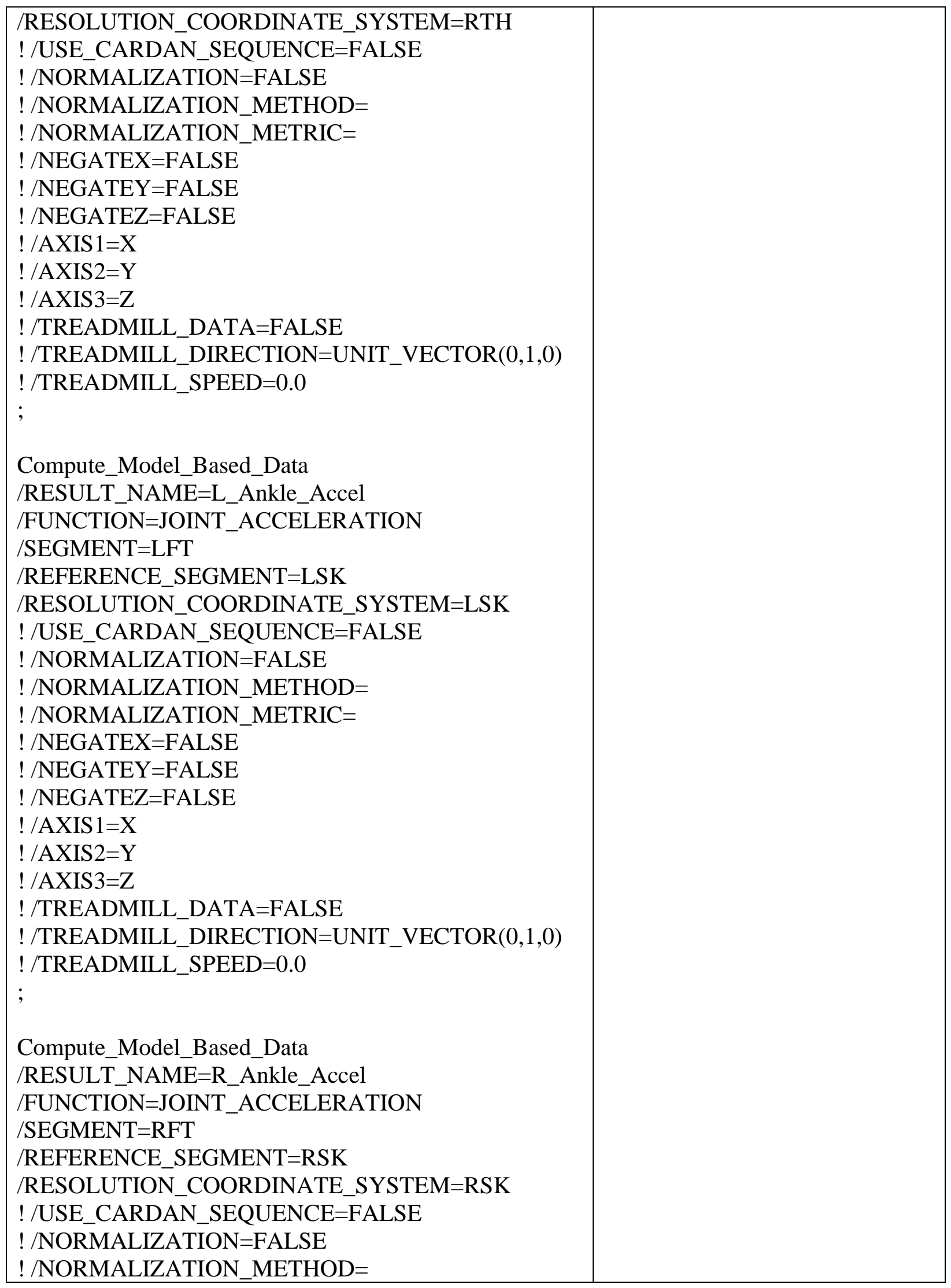




\begin{tabular}{|l|l|}
\hline !/NORMALIZATION_METRIC= & \\
!/NEGATEX=FALSE & \\
!/NEGATEY=FALSE & \\
!/NEGATEZ=FALSE & \\
!/AXIS1=X & \\
!/AXIS2=Y & \\
!/AXIS3=Z & \\
!/TREADMILL_DATA=FALSE & \\
!/TREADMILL_DIRECTION=UNIT_VECTOR(0,1,0) & \\
!/TREADMILL_SPEED=0.0 & \\
; & \\
End_For_Each & \\
/ITERATION_PARAMETER_NAME=Movement_Files & \\
; & \\
\hline Metric_Mean & \\
!/RESULT_METRIC_FOLDER=PROCESSED & - mean and SD the EMG signal \\
/RESULT_METRIC_NAME=_MEAN & - mean and SD taken from 150ms \\
/APPLY_AS_SUFFIX_TO_SIGNAL_NAME=TRUE & pre-drop to the true drop event \\
/SIGNAL_TYPES=ANALOG+ANALOG+ANALOG+A & -signal names varied based on \\
NALOG+ANALOG+ANALOG+ANALOG & subject number \\
/SIGNAL_FOLDER=PROCESSED+PROCESSED+PRO & \\
CESSED+PROCESSED+PROCESSED+PROCESSED+ & \\
PROCESSED & \\
/SIGNAL_NAMES=COntralateral Gluteus & \\
Medius+Contralateral Oblique+Ipsilateral Gluteus & \\
Medius+Ipsilateral Oblique+Peroneus & \\
Longus+Soleus+Tibialis Anterior & \\
/COMPONENT_SEQUENCE=ALL & \\
/EVENT_SEQUENCE=Pre_ID_150+TRUE_ID_DROP & \\
/EXCLUDE_EVENTS= & \\
/SEQUENCE_PERCENT_START= \\
/SEQUENCE_PERCENT_END= \\
/GENERATE_MEAN_AND_STDDEV=FALSE & \\
!/APPEND_TO_EXISTING_VALUES=FALSE & \\
; & \\
Metric_StdDev & \\
!/RESULT_METRIC_FOLDER=PROCESSED & \\
/RESULT_METRIC_NAME=_SD \\
/APPLY_AS_SUFFIX_TO_SIGNAL_NAME=TRUE & \\
/SIGNAL_TYPES=ANALOG+ANALOG+ANALOG+A & \\
NALOG+ANALOG+ANALOG+ANALOG \\
/SIGNAL_FOLDER=PROCESSED+PROCESSED+PRO & \\
CESSSE+PROCESSED+PROCESSED+PROCESSED+ & \\
PROCESSED & \\
\hline
\end{tabular}




\begin{tabular}{|l|l|}
\hline /SIGNAL_NAMES=Contralateral Gluteus & \\
Medius+Contralateral Oblique+Ipsilateral Gluteus & \\
Medius+Ipsilateral Oblique+Peroneus & \\
Longus+Soleus+Tibialis Anterior & \\
/COMPONENT_SEQUENCE=ALL & \\
/EVENT_SEQUENCE=Pre_ID_150+TRUE_ID_DROP & \\
/EXCLUDE_EVENTS= & \\
/SEQUENCE_PERCENT_START= & \\
/SEQUENCE_PERCENT_END= & \\
/GENERATE_MEAN_AND_STDDEV=FALSE & \\
!/APPEND_TO_EXISTING_VALUES=FALSE & ; creates event tag for when the \\
; & \\
\hline Event_Threshold & inversion drop and 200ms post- \\
/RESULT_EVENT_NAME=REACTION_ONSET_Contr & drop events increases 2 SD above \\
aGM & the mean \\
/SIGNAL_TYPES=ANALOG & - marks when the signal reaches \\
/SIGNAL_FOLDER=PROCESSED & the threshold \\
/SIGNAL_NAMES=Contralateral Gluteus Medius & - shows where the muscle first \\
/SIGNAL_COMPONENTS=ALL & reacts to the inversion drop \\
!/FRAME_OFFSET=0 & \\
!/TIME_OFFSET= & \\
/EVENT_SEQUENCE=TRUE_ID_DROP+POST_ID_20 & - signal names varied based on \\
0 & subject number \\
!/EXCLUDE_EVENTS= & \\
/EVENT_SEQUENCE_INSTANCE=1 & \\
!/EVENT_SUBSEQUENCE= & \\
!/SUBSEQUENCE_EXCLUDE_EVENTS= & \\
/EVENT_SUBSEQUENCE_INSTANCE=1 & \\
!/EVENT_INSTANCE=0 & \\
/THRESHOLD=METRIC::PROCESSED::Contralateral & \\
Gluteus Medius_MEAN+2 * & \\
METRIC::PROCESSED::Contralateral Gluteus & \\
Medius_SD & \\
/ON_ASCENT=TRUE & \\
/ON_DESCENT=FALSE & \\
!/FRAME_WINDOW=8 & \\
!/ENSURE_FRAMES_BEFORE=FALSE & \\
!/ENSURE_FRAMES_AFTER=FALSE & \\
; & \\
Event_Threshold & \\
/RESULT_EVENT_NAME=REACTION_ONSET_Contr & \\
aOblique & \\
/SIGNAL_TYPES=ANALOG & \\
/SIGNAL_FOLDER=PROCESSED \\
/SIGNAL_NAMES=Contralateral Oblique
\end{tabular}




\begin{tabular}{|c|c|}
\hline $\begin{array}{l}\text { Event_Threshold } \\
\text { /RESULT_EVENT_NAME=REACTION_ONSET_IpsiG } \\
\text { M } \\
\text { /SIGNAL_TYPES=ANALOG } \\
\text { /SIGNAL_FOLDER=PROCESSED } \\
\text { /SIGNAL_NAMES=Ipsilateral Gluteus Medius } \\
\text { /SIGNAL_COMPONENTS=ALL } \\
\text { !/FRAME_OFFST=0 } \\
\text { !/TIME_OFFSET= } \\
\text { /EVENT_SEQUENCE=TRUE_ID_DROP+POST_ID_20 } \\
0 \\
\text { ! /EXCLUDE_EVENTS= } \\
\text { /EVENT_SEQUENCE_INSTANCE=1 } \\
\text { ! /EVENT_SUBSEQUENCE= } \\
\text { !/SUBSEQUENCE_EXCLUDE_EVENTS= } \\
\text { /EVENT_SUBSEQUENCE_INSTANCE=1 } \\
\text { !/EVENT_INSTANCE=0 } \\
\text { /THRESHOLD=METRIC::PROCESSED::Ispilateral } \\
\text { Gluteus Medius_MEAN+2 * } \\
\text { METRIC::PROCESSED::Ipsilateral Gluteus Medius_SD } \\
\text { /ON_ASCENT=TRUE } \\
\text { /ON_DESCENT=FALSE } \\
\text { !/FRAME_WINDOW=8 } \\
\text { !/ENSURE_FRAMES_BEFORE=FALSE } \\
\text { !/ENSURE_FRAMES AFTER=FALSE }\end{array}$ & \\
\hline
\end{tabular}




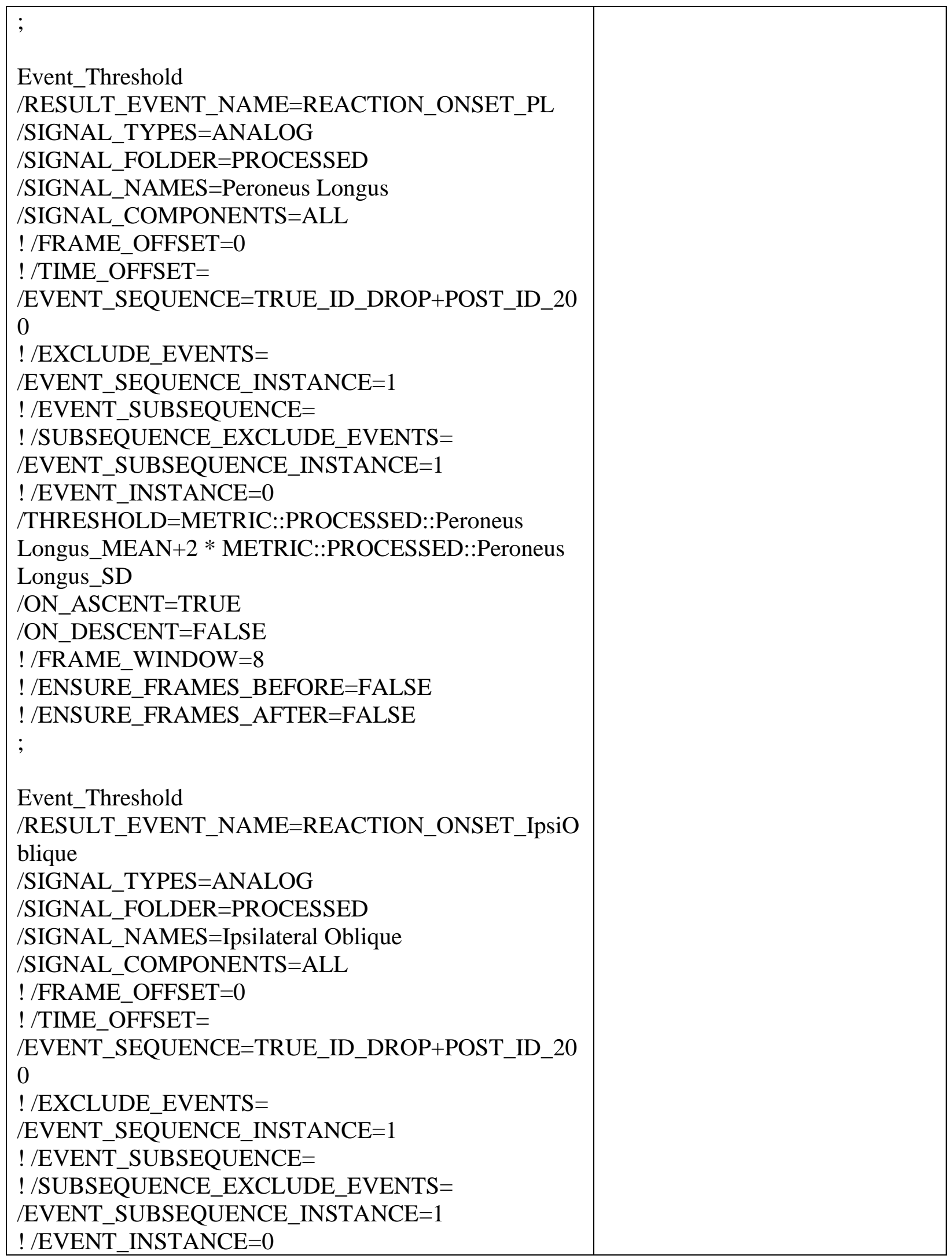




\begin{tabular}{|l|l|}
\hline /THRESHOLD=METRIC::PROCESSED::Ipsilateral & \\
Oblique_MEAN+2 $*$ METRIC::PROCESSED::Ipsilateral & \\
Oblique_SD & \\
/ON_ASCENT=TRUE & \\
/ON_DESCENT=FALSE \\
!/FRAME_WINDOW=8 \\
!/ENSURE_FRAMES_BEFORE=FALSE \\
!/ENSURE_FRAMES_AFTER=FALSE \\
; \\
Event_Threshold \\
/RESULT_EVENT_NAME=REACTION_ONSET_Soleu \\
S \\
/SIGNAL_TYPES=ANALOG \\
/SIGNAL_FOLDER=PROCESSED \\
/SIGNAL_NAMES=Soleus \\
/SIGNAL_COMPONENTS=ALL \\
!/FRAME_OFFSET=0 \\
!/TIME_OFFSET $=$ \\
/EVENT_SEQUENCE=TRUE_ID_DROP+POST_ID_20 \\
0 \\
!/EXCLUDE_EVENTS= \\
/EVENT_SEQUENCE_INSTANCE=1 \\
!/EVENT_SUBSEQUENCE= \\
!/SUBSEQUENCE_EXCLUDE_EVENTS= \\
/EVENT_SUBSEQUENCE_INSTANCE=1 \\
!/EVENT_INSTANCE=0 \\
/THRESHOLD=METRIC::PROCESSED::SOleus_MEA \\
N+2 * METRIC::PROCESSED::Soleus_SD \\
/ON_ASCENT=TRUE \\
/ON_DESCENT=FALSE \\
!/FRAME_WINDOW=8 \\
!/ENSURE_FRAMES_BEFORE=FALSE \\
!/ENSURE_FRAMES_AFTER=FALSE \\
; \\
Event_Threshold \\
/RESULT_EVENT_NAME=REACTION_ONSET_TibA \\
nt \\
/SIGNAL_TYPES=ANALOG \\
/SIGNAL_FOLDER=PROCESSED \\
/SIGNAL_NAMES=Tibialis Anterior \\
/SIGNAL_COMPONENTS=ALL \\
!/FRAME_OFFSET=0 \\
!/TIME_OFFSET = \\
\end{tabular}




\begin{tabular}{|c|c|}
\hline $\begin{array}{l}\text { /EVENT_SEQUENCE=TRUE_ID_DROP+POST_ID_20 } \\
0 \\
\text { ! /EXCLUDE_EVENTS= } \\
\text { /EVENT_SEQUENCE_INSTANCE=1 } \\
\text { ! /EVENT_SUBSEQUENCE= } \\
\text { ! /SUBSEQUENCE_EXCLUDE_EVENTS= } \\
\text { /EVENT_SUBSEQUENCE_INSTANCE=1 } \\
\text { ! /EVENT_INSTANCE=0 } \\
\text { /THRESHOLD=METRIC::PROCESSED::Tibialis } \\
\text { Anterior_MEAN+2 * METRIC::PROCESSED::Tibialis } \\
\text { Anterior_SD } \\
\text { /ON_ASCENT=TRUE } \\
\text { /ON_DESCENT=FALSE } \\
\text { ! /FRAME_WINDOW=8 } \\
\text { ! /ENSURE_FRAMES_BEFORE=FALSE } \\
\text { ! /ENSURE_FRAMES_AFTER=FALSE } \\
\text {; Metric_Time_Between_Events } \\
\text { /RESULT_METRIC_NAME=Rxn_Time_ContraGM } \\
\text { ! /RESULT_METRIC_FOLDER=PROCESSED } \\
\text { /EVENT_SEQUENCE=TRUE_ID_DROP+REACTION_ } \\
\text { ONSET_ContraGM } \\
\text { /EXCLUDE_EVENTS= } \\
\text { /GENERATE_MEAN_AND_STDDEV=FALSE } \\
\text { ! /APPEND_TO_EXISTING_VALUES=FALSE } \\
\text {; } \\
\text { Metric_Time_Between_Events } \\
\text { /RESULT_METRIC_NAME=Rxn_Time_ContraOblique } \\
\text { ! /RESULT_METRIC_FOLDER=PROCESSED } \\
\text { /EVENT_SEQUENCE=TRUE_ID_DROP+REACTION_ } \\
\text { ONSET_ContraOblique } \\
\text { /EXCLUDE_EVENTS= } \\
\text { /GENERATE_MEAN_AND_STDDEV=FALSE } \\
\text { ! /APPEND_TO_EXISTING_VALUES=FALSE } \\
\text {; } \\
\text { Metric_Time_Between_Events } \\
\text { /RESULT_METRIC_NAME=Rxn_Time_IpsiGM } \\
\text { ! /RESULT_METRIC_FOLDER=PROCESSED } \\
\text { /EVENT_SEQUENCE=TRUE_ID_DROP+REACTION__ } \\
\text { ONSET_IpsiGM } \\
\text { /EXCLUDE_EVENTS= } \\
\text { /GENERATE_MEAN_AND_STDDEV=FALSE } \\
\text { ! /APPEND_TO_EXISTING_VALUES=FALSE } \\
\text { / }\end{array}$ & $\begin{array}{l}\text { - calculates the reaction time of } \\
\text { the muscle based off the reaction } \\
\text { time event created } \\
\text { - calculates the time between the } \\
\text { reaction onset event and the true } \\
\text { drop event } \\
\text {-signal names varied based on } \\
\text { subject number }\end{array}$ \\
\hline
\end{tabular}




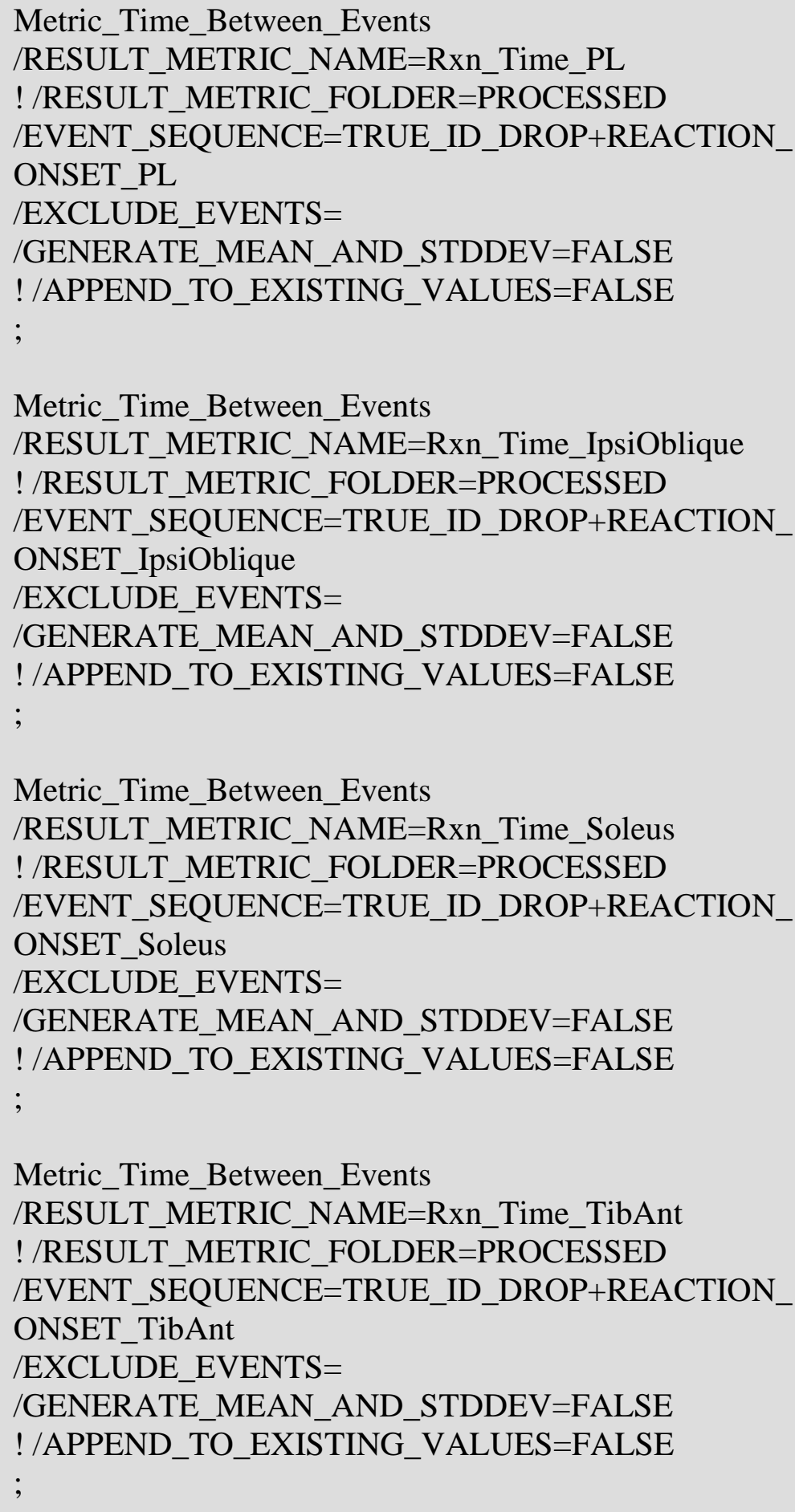




\begin{tabular}{|l|l|}
\hline PIPELINE & USE \\
\hline Metric_Frames_Between_Events & -calculates the number of frames between \\
/RESULT_METRIC_FOLDER=PROCESSED & the last RHS event and ID_Drop event \\
/RESULT_METRIC_NAME=RHS to ID_Signal & \\
/EVENT_SEQUENCE=RHS+ID_Drop & \\
/EXCLUDE_EVENTS= & \\
/GENERATE_MEAN_AND_STDDEV=FALSE & \\
$!$ \\
/APPEND_TO_EXISTING_VALUES=FALSE & \\
$;$ & \\
\hline
\end{tabular}

